
Aus der Abteilung Neurogenetik

(Leiter: Prof. K.-A. Nave, Ph.D.)

des Max-Planck-Instituts für experimentelle Medizin

in Göttingen

\title{
Tierexperimentelle Behandlungsversuche der Charcot-Marie-Tooth-Erkrankung 1A
}

\author{
INAUGURAL - DISSERTATION \\ zur Erlangung des Doktorgrades \\ der Medizinischen Fakultät \\ der Georg-August-Universität zu Göttingen \\ vorgelegt von \\ Bernhard G. Weiß \\ aus \\ Düsseldorf
}

Göttingen 2014 
Dekan:

I. Berichterstatter:

II. Berichterstatter/in:

Tag der mündlichen Prüfung: $\quad$ 03.03.2014
Prof. Dr. rer. nat. H. K. Kroemer

Prof. Dr. med. M. W. Sereda PD Dr. med. M. Henneke 


\section{Abkürzungsverzeichnis}

\begin{tabular}{|c|c|}
\hline ASS & Acetylsalicylsäure \\
\hline BSA & Körperoberfläche (body surface area) \\
\hline $\mathrm{CD}$ & Unterscheidungsgruppen (cluster of differentiation) \\
\hline CMAP & Muskelsummenaktionspotential (compound muscle action potential) \\
\hline CMT & Charcot-Marie-Tooth-Erkrankung (Charcot-Marie-Tooth disease) \\
\hline CMT1 & Charcot-Marie-Tooth-Erkrankung Typ 1 \\
\hline CMT1A & Charcot-Marie-Tooth-Erkrankung Subtyp 1A (PMP22-Duplikation) \\
\hline CMT2 & Charcot-Marie-Tooth-Erkrankung Typ 2 \\
\hline CMTNS & $\begin{array}{l}\text { Charcot-Marie-Tooth-Neuropathiescore (Charcot-Marie-Tooth Neuropathy } \\
\text { Score) }\end{array}$ \\
\hline CMT-Ratte & PMP22 überexprimierende transgene Ratten \\
\hline CMTrNS & Charcot-Marie-Tooth-Erkrankungs (Ratten) Neuropathiescore \\
\hline $\mathrm{COX}$ & Cyclooxygenase \\
\hline $\mathrm{C}_{\mathrm{T}}-\mathrm{Wert}$ & cycle threshold-Wert \\
\hline $\mathrm{ddH}_{2} \mathrm{O}$ & doppelt destilliertes Wasser \\
\hline ED1 & Monoklonaler Maus Anti-Ratte CD68 Antikörper \\
\hline EDTA & Ethylendiamintetraacetat \\
\hline ELISA & $\begin{array}{l}\text { Enzymgekoppelter Immunadsorptionstest (enzyme-linked immunosorbent } \\
\text { assay) }\end{array}$ \\
\hline EPO & Erythropoetin \\
\hline EPOR & Erythropoetin Rezeptor \\
\hline ER & Endoplasmatisches Retikulum \\
\hline f.c. & Endkonzentration (final concentration) \\
\hline Fwd & Vorwärtsprimer (forward primer) \\
\hline g-Ratio & Quotient aus innerem und äußerem Umfang der Myelinscheide \\
\hline HED & Humane Äquivalenzdosis \\
\hline $\mathrm{Hk}$ & Hämatokrit \\
\hline Igf1 & insulin-like growth factor 1 \\
\hline Igfbp5 & insulin-like growth factor binding protein 5 \\
\hline $\mathrm{kDa}$ & Kilodalton (= 1000 Dalton; atmoare Masseneinheit) \\
\hline $\mathrm{K} \& \mathrm{~S}$ & Gewebefixans nach Karlsson \& Schultz (1965) \\
\hline
\end{tabular}


KG Körpergewicht

Km-Faktor Quotient des durchschnittlichen Körpergewichts $[\mathrm{kg}]$ und der Körperober-

fläche $\left[\mathrm{m}^{2}\right]$ einer Spezies

LXR Leber X Rezeptor (liver X receptor)

MCP-1 monocyte chemoattractant protein-1

MN alpha-Motoneuron

mRNA Boten-RNA (messenger RNA)

n.s. nicht signifikant

NLG Nervenleitgeschwindigkeit

PA Progesteronantagonist

PFA Paraformaldehyd

PMP22 peripheres Myelinprotein $22 \mathrm{kDa}$

PR Progesteronrezeptor

PRE progesteronresponsible Elemente

RAG-1 recombination-activating-gene-1

RFE relative Fluorezenzeinheiten

RT Raumtemperatur

Rev Rückwärtsprimer (reverse primer)

spp. $\quad$ mehrere Spezies einer Gattung (species pluralis)

T0 T0901317

TBS Trispuffer (tris buffer saline)

TBS+M Trispuffer versetzt mit $2 \%$ Milchpulver 


\section{Inhaltsverzeichnis}

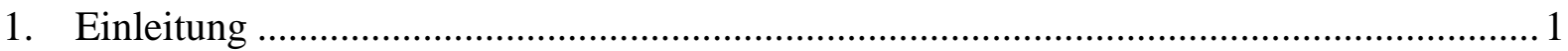

1.1. Charcot-Marie-Tooth-Erkrankung (CMT), eine hereditäre Neuropathie.................... 1

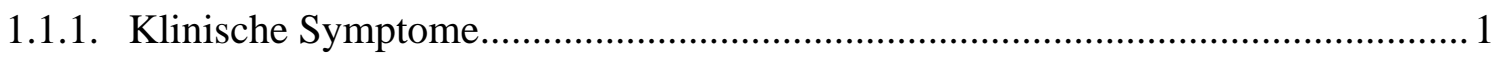

1.1.2. Elektrophysiologische und histologische Befunde........................................... 3

1.2. Charcot-Marie-Tooth-Erkrankung Subtyp 1A (CMT1A) ...................................... 4

1.2.1. Diskutierte Pathomechanismen ...................................................................... 5

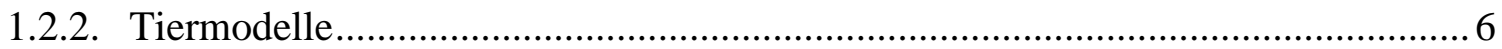

1.3. Stand der experimentellen Therapien der CMT1A …........................................... 7

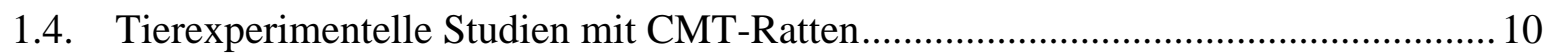

1.4.1. Der Progesteronrezeptor als pharmakologisches Ziel ...................................... 10

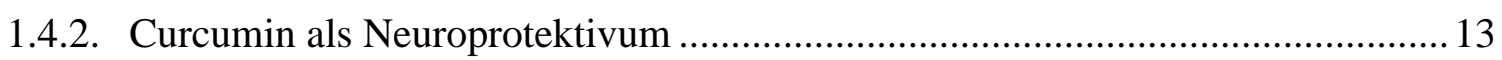

1.4.3. Acetylsalicylsäure als Inhibitor der Cyclooxygenase........................................ 15

1.4.4. Erythropoetin, ein hämatopoetisches Hormon ................................................ 17

1.4.5. T0901317, ein Agonist für den Leber X Rezeptor ............................................ 18

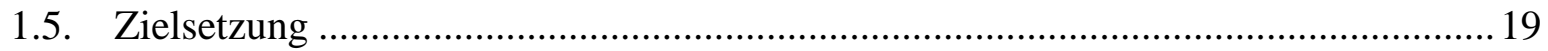

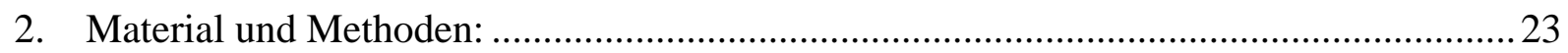

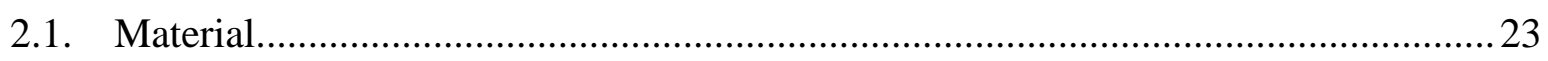

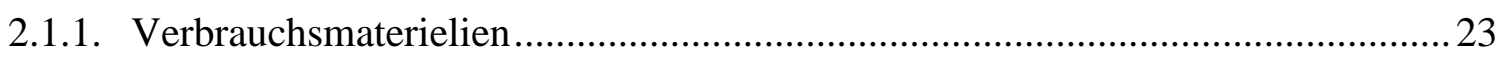

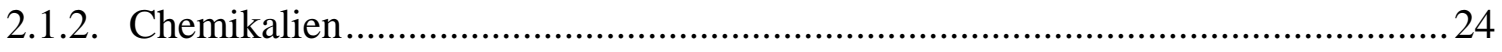

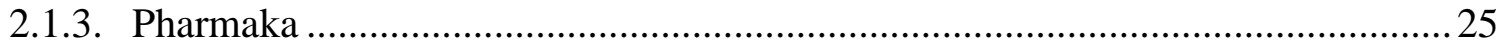

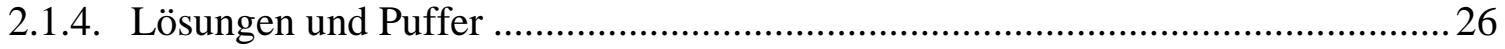

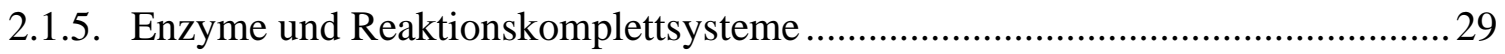

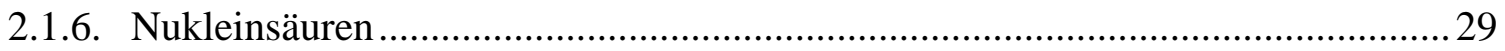

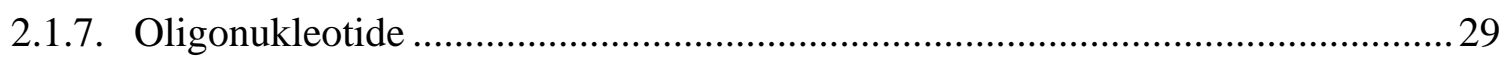

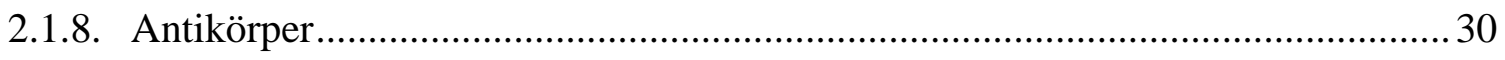

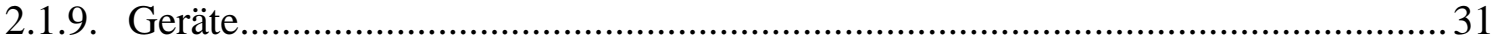

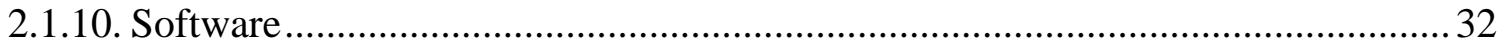

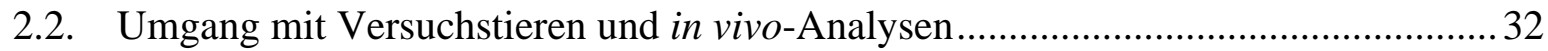

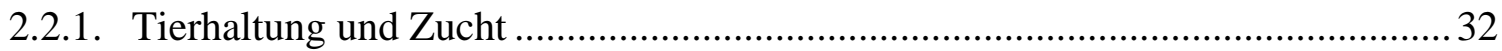

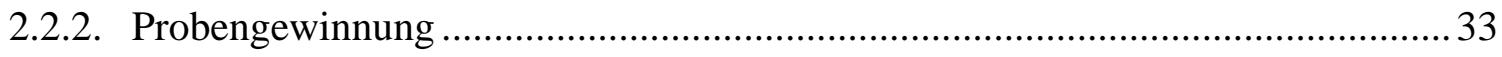

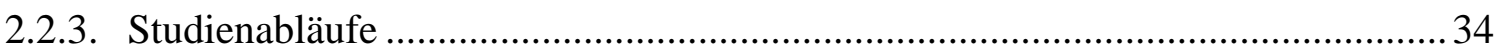




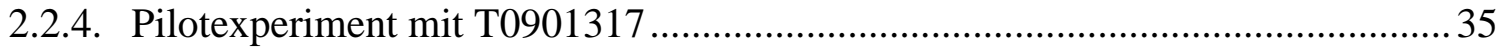

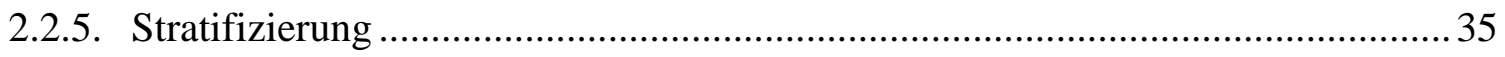

2.2.6. Lonaprisan-Therapiestudie nach dem „Proof-of-Principle Paradigm“ ................ 35

2.2.7. Therapiestudie mit Curcumin, Acetylsalicylsäure und Erythropoetin nach dem

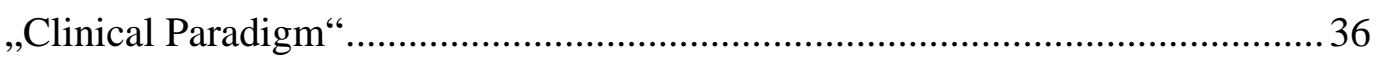

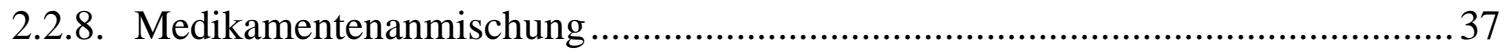

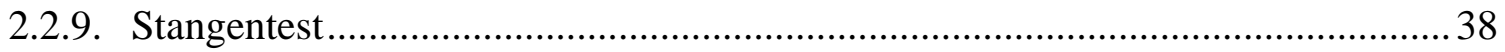

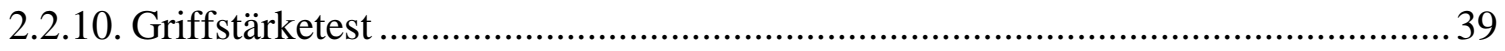

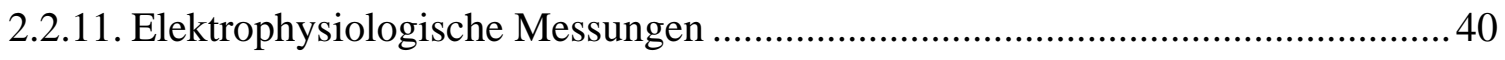

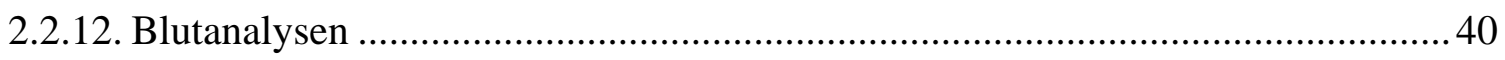

2.2.13. Berechnung der humanen Äquivalenzdosis unter Normalisierung auf die

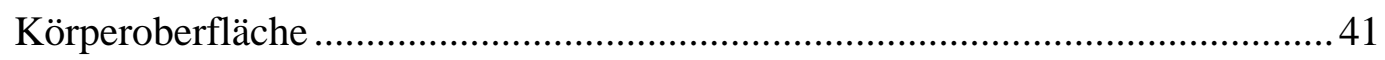

2.2.13.1. Berechnung der humanen Äquivalenzdosis der Lonaprisan-Therapie....... 42

2.2.13.2. Berechnung der Curcumin-Reindosis und humanen Äquivalenzdosis der

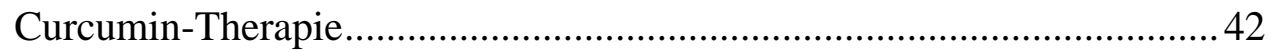

2.3. Histologische und histochemische Methoden .................................................. 44

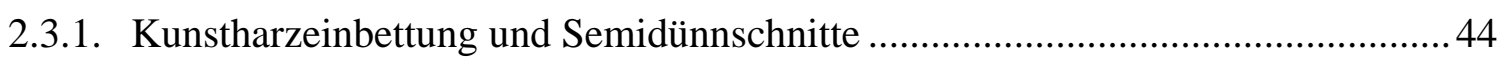

2.3.2. Färbung, Mikroskopie und Quantifizierungen myelinisierter und unphysiologisch unmyelinisierter Axone und der Myelindicke .................................................. 45

2.3.3. Erstellen von Gefrierschnitten, Färbung und Mikroskopie von alphaMotoneuronen in Rückenmarksquerschnitten 45

2.3.4. Paraffineinbettung und Immunhistologie von Nervenquerschnitten mit Quantifizierung der intraneuralen Makrophagen ..............................................46

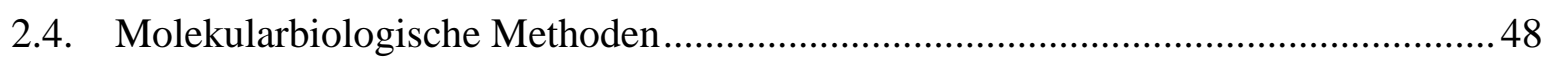

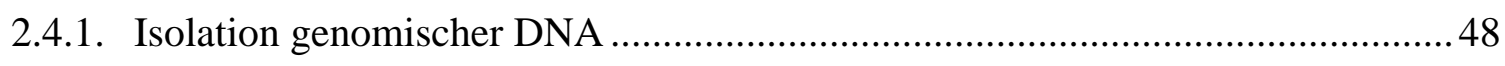

2.4.2. Isolation von RNA aus Ischiasnerven und Hautgewebe ................................... 49

2.4.3. Bestimmung von Qualität und Quantität der RNA …........................................50

2.4.4. cDNA-Synthese durch Reverse Transkription ...................................................51

2.4.5. Genotypisierung durch PCR und Gelelektrophorese .........................................51

2.4.6. Semiquantitative Real-Time-PCR ................................................................ 52

2.4.7. Etablierung biologischer Marker aus Hautgewebe..............................................54

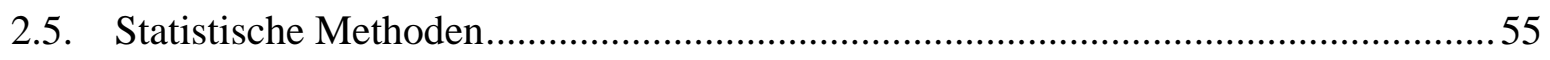

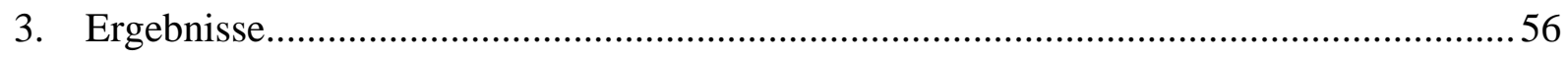

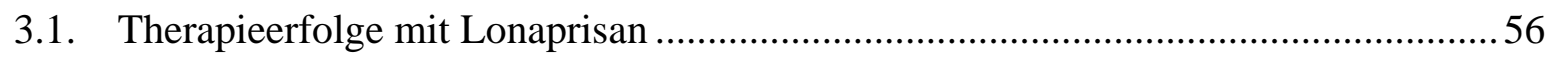


3.1.1. Längere Haltezeit und erhöhte Griffstärke .......................................................56

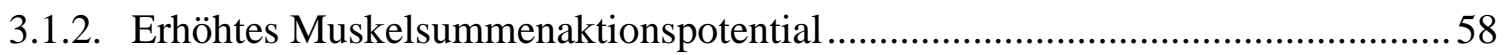

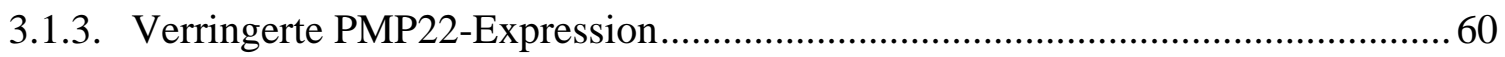

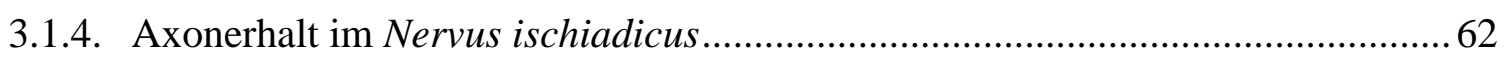

3.1.5. Verringerter alpha-Motoneuronverlust in Rückenmarksquerschnitten ................64

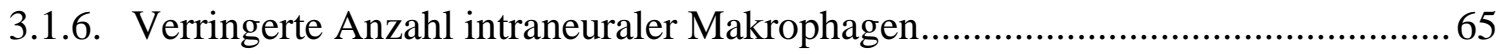

3.1.7. Igfbp5 als ein biologischer Marker aus Hautgewebe mit diagnostischer

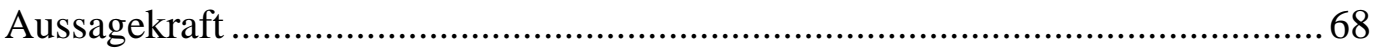

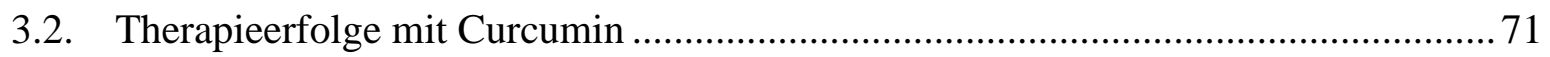

3.2.1. Relative Verbesserung des klinischen Phänotyps ............................................ 71

3.2.2. Erhöhte Muskelsummenaktionspotentiale und Nervenleitgeschwindigkeiten..... 73

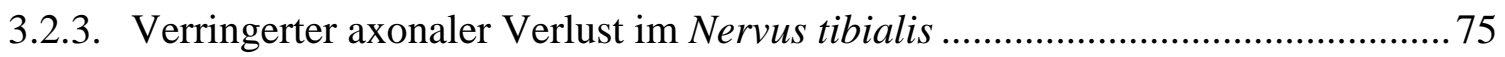

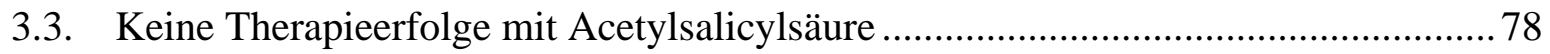

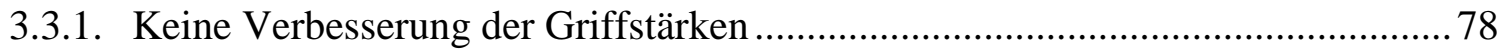

3.3.2. Unveränderte Nervenleitgeschwindigkeiten und Muskelsummen-

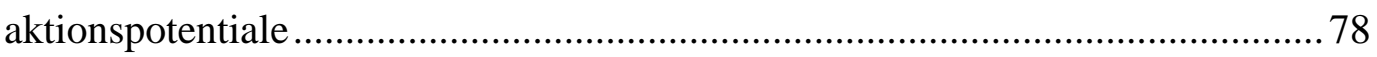

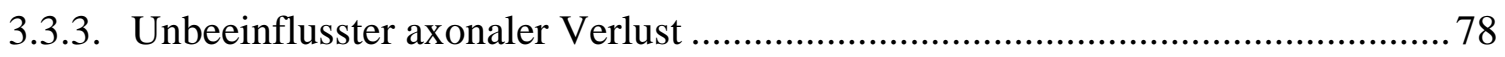

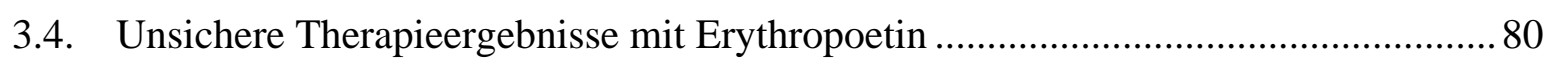

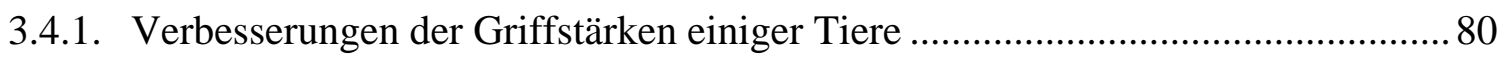

3.4.2. Erhöhter Hämatokrit und keine Antikörperbildung gegen endogenes

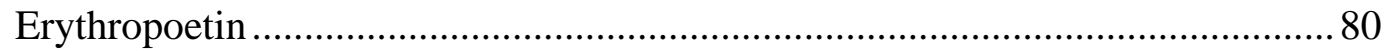

3.4.3. Fehlender Einfluss auf den axonalen Verlust .................................................. 81

3.5. Auswirkungen der T0901317-Behandlung auf die PMP22-Überexpression ..............83

3.5.1. Veränderte Expression von Abcal und Pmp22 in Ischiasnerven ........................ 83

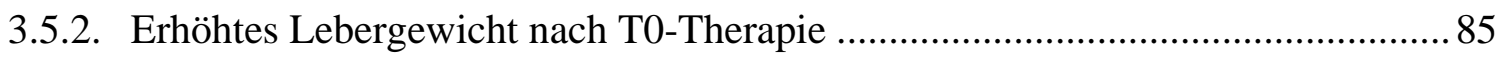

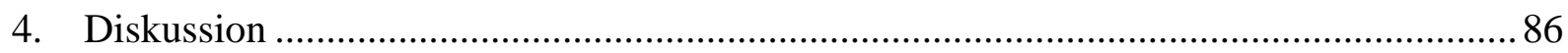

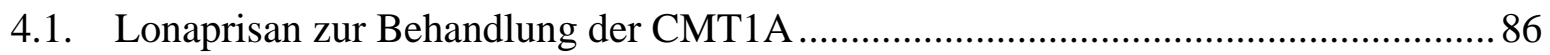

4.1.1. Verbesserter Phänotyp, Linderung der Axonpathologien und verringerter alphaMotoneuronverlust bei CMT-Ratten nach Lonaprisan-Behandlung ... 86

4.1.2. Mögliche Wirkmechanismen des Progesteronantagonisten auf Schwannzell- und neuronaler Ebene

4.1.3. Der diagnostische Biomarker Igfbp5 als Readout einer Lonaprisan-Studie und Möglichkeiten prognostischer Marker bei Therapien der CMT1A...................... 90

4.2. Curcumin zur Behandlung der CMT1A 
4.2.1. Auswirkungen des Curcumin enthaltenden Prüffutters auf die CMT-Ratte ........92

4.2.2. Mögliche Mechanismen der Curcuminwirkung bei der CMT1A ........................ 94

4.2.3. Der Weg zur Translation der Curcumin-Therapie in die Klinik ........................ 96

4.3. Ausbleibender Therapieerfolg mit Acetylsalicylsäure .............................................98

4.3.1. Vergleich der antiinflammatorischen Wirkungen von ASS und Curcumin ......... 98

4.4. Erythropoetin als Therapieoption der CMT1A nicht auszuschließen ....................... 99

4.5. LXR-Agonisten als vielversprechende Therapieoption der CMT1A...................... 100

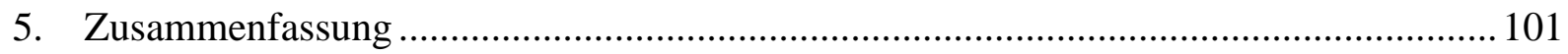

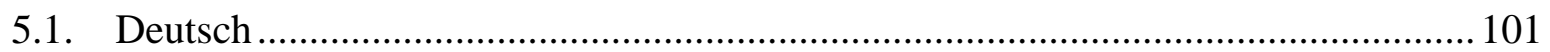

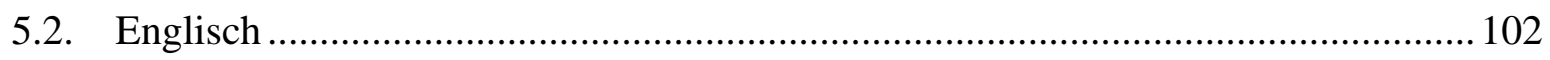

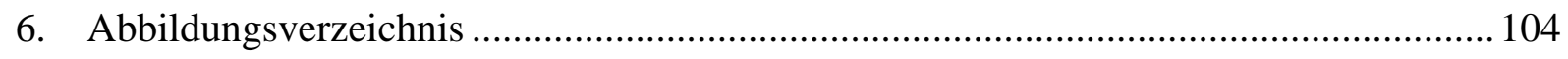

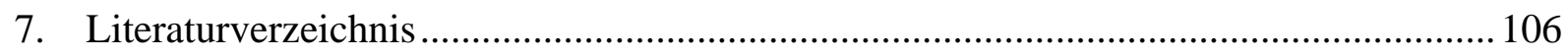

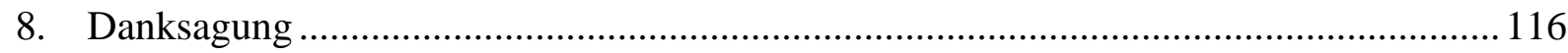

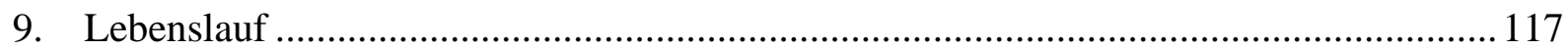




\section{Einleitung}

\subsection{Charcot-Marie-Tooth-Erkrankung (CMT), eine hereditäre Neuropathie}

Die Charcot-Marie-Tooth-Erkrankung (CMT), auch bekannt als hereditäre motorisch sensible Neuropathie, ist eine heterogene Gruppe von hereditären Neuropathien des peripheren Nervensystems. Sowohl motorische als auch sensible Nervenfasern sind betroffen. Charakteristisch ist das klinische Bild einer langsam progredienten, symmetrischen, distal betonten Muskelatrophie, mit Beginn im jungen Erwachsenenalter. Ursprünglich wurde aufgrund von klinischen, elektrophysiologischen und histologischen Merkmalen eine demyelinisierende Form (CMT1) mit primärem Schwannzelldefekt von einer axonalen Form (CMT2) unterschieden (Dyck et al. 1993). Durch besseres Verständnis der krankheitsverursachenden Mutationen und ihrer molekularbiologischen Charakterisierung wurde diese Einteilung weiterentwickelt.

Eine Vielzahl an Mutationen, die zum klinischen Bild der CMT führen, ist identifiziert. Mutationen können in Myelingenen lokalisiert sein, wie dem peripheren Myelinprotein $22 \mathrm{kDa}$ (PMP22) oder dem Myelin Protein Zero und zur CMT1 führen. Auch Defekte in Genen für Transkriptionsfaktoren können diese Form der Erkrankung bedingen. Mutationen in axonalen Proteingenen führen zur axonalen Form CMT2. Eine aktualisierte Liste der Mutationen findet sich in der „Inherited Peripheral Neuropathies Mutation Database“ unter www.molgen.ua.ac.be/CMTMutations/.

\subsubsection{Klinische Symptome}

Klinisch ist die CMT charakterisiert als eine symmetrische, distal betonte Muskelschwäche besonders der unteren Extremitäten sowie schwächer ausgeprägt auch der oberen Extremitäten. Die Symptome sind dabei langsam progredient. Die neurogene Muskelatrophie, welche initial die intrinsische Fußmuskulatur betrifft, resultiert in charakteristischen Fußdeformitäten (Hohlfuß, Krallenzehen; Abbildung 1 B, C) bis hin zu Beeinträchtigungen des Gehens mit dem klinischen Bild des Steppergangs (Dyck et al. 1993). Sensible Defizite sind weniger stark 
ausgeprägt und werden von Patienten häufig nicht bemerkt, sind aber stets ein nachweisbares Merkmal, insbesondere zeigen sich die Muskeleigenreflexe reduziert auslösbar (Dyck et al. 1993). Das erste Auftreten von Symptomen variiert zwischen dem 10. und dem 40. Lebensjahr (Dyck et al. 1993). Auch der Grad der Ausprägung bei molekulargenetisch positiv getesteten Patienten variiert von völligem Ausbleiben klinischer Symptome bis hin zur Rollstuhlpflichtigkeit. (Birouk et al. 1997). Die Ursache für diese variable Expressivität ist ungeklärt, diskutiert werden nichtgenetische (epigenetische) Faktoren.
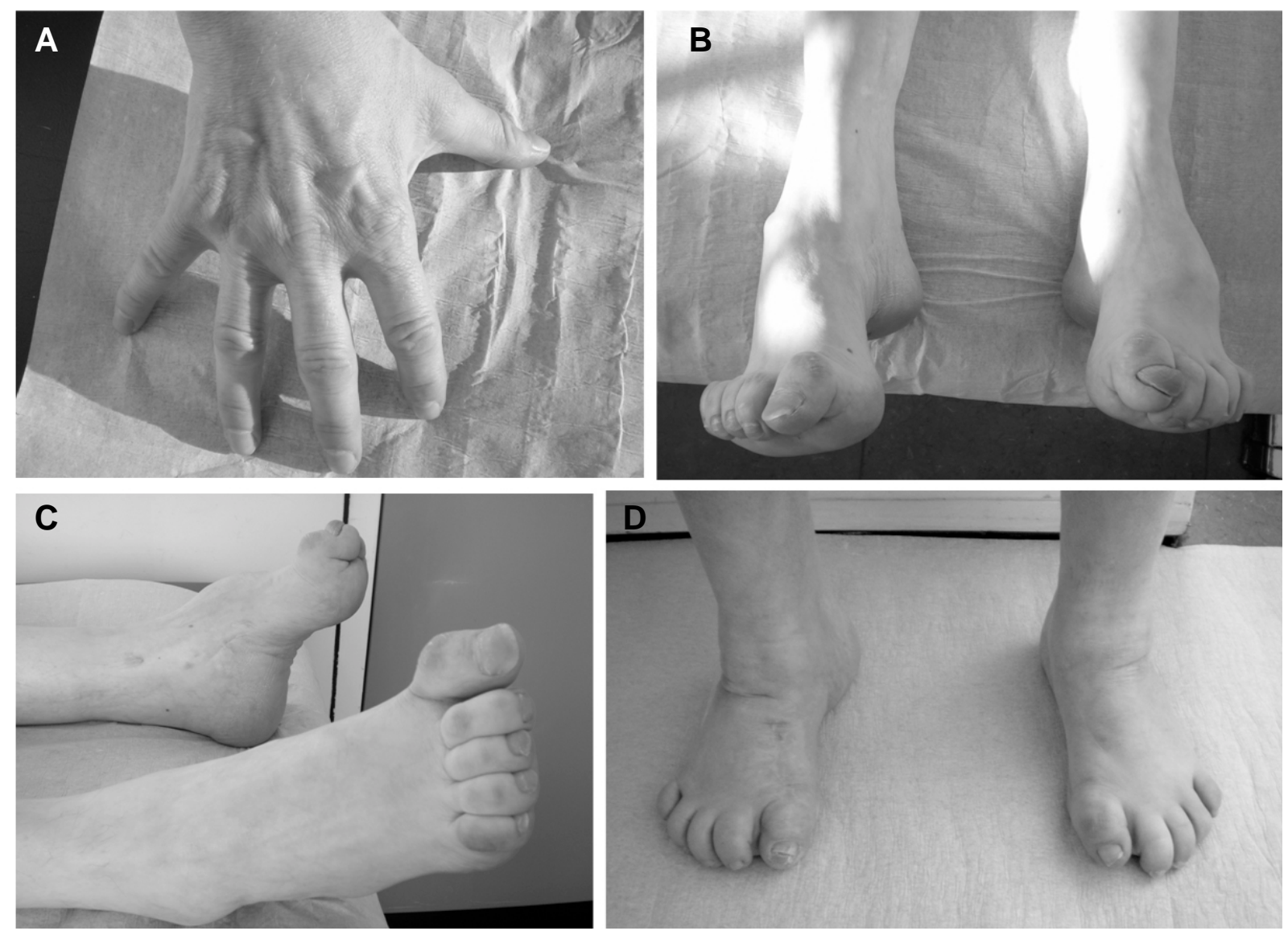

\section{Abbildung 1: CMT1A-Patienten der Göttinger CMT-Ambulanz}

Charakteristische Deformitäten entstehen durch die distal betonte neurogene Muskelatrophie. Am Handrücken eines CMTPatienten imponiert die interossäre Muskelatrophie des Metacarpus, besonders betont zwischen Pollex und Index (A). An der unteren Extremität führt die Atrophie der intrinsischen Fußmuskeln zu Hohlfuß und Krallenzehen. Durch ungleichmäßige Schwächung der Flexoren und Extensoren des oberen Sprunggelenks kommt es durch Überwiegen der Peroneusgruppenatrophie zur Entstehung eines Spitzfußes (B, C). Nur durch operative Achillessehnenverlängerung kann wieder ein normaler Stand erreicht werden (D). Die Bilder wurden freundlicherweise von Frau Tuuli Schnitzer, Universitätsmedizin Göttingen, zur Verfügung gestellt. 


\subsubsection{Elektrophysiologische und histologische Befunde}

Die Unterscheidung zwischen axonaler Form (primärer axonaler Verlust - CMT2) und demyelinisierender Form der CMT (primärer Myelindefekt, mit konsekutiver Demyelinisierung und sekundärem axonalen Verlust - CMT1) hat ihren Ursprung in elektrophysiologischen Untersuchungen von Patienten mit dem klinischen Bild der CMT (Dyck und Lambert 1968). Durch Demyelinisierung kommt es zu einer Verringerung der Nervenleitgeschwindigkeit (NLG). Diese bleibt bei der rein axonalen Form meist unverändert. Hierbei steht die Verringerung des Muskelsummenaktionspotentials (CMAP) im Vordergrund. Durch den sekundären axonalen Verlust ist eine Verringerung des CMAP jedoch auch bei Patienten mit CMT1 nachzuweisen. Zur Unterscheidung der beiden Formen bedient man sich somit der NLG. Als signifikant reduzierte NLG wird eine Geschwindigkeit von $<38 \mathrm{~m} / \mathrm{s}$ angenommen, es wird von einer primär demyelinisierenden Form der CMT ausgegangen. Die molekularbiologische Diagnostik sollte sich im Folgenden auf entsprechende Mutationen konzentrieren. NLGs >38 m/s sprechen für eine primär axonale Form (Harding und Thomas 1980).

Bei Patienten, die unter der primär demyelinisierenden Form der CMT leiden, ist die NLG stets reduziert. Das Ausmaß der Reduktion korreliert jedoch nicht mit dem klinischen Phänotyp (Killian et al. 1996). Direkt mit dem Phänotyp hingegen korreliert die Verringerung der Muskelsummenaktionspotentiale (Krajewski et al. 2000). Dennoch kann bereits vor dem Auftreten erster klinischer Symptome die Nervenleitgeschwindigkeit reduziert sein. Somit ist mittels dieser neurophysiologischen Untersuchung auch neben der Molekulargenetik eine frühe Diagnosestellung möglich (Birouk et al. 1997).

Auf histologischer Ebene zeigt sich in peripheren Nerven das Bild der segmentalen Demyelinisierung, von der besonders großkalibrige Axone betroffen sind. Auch lassen sich Zwiebelschalenformationen nachweisen als ein Zeichen von parallel ablaufender De- und Remyelinisierung, wobei nicht eine, sondern mehrere Schwannzellen das Axon mit einer Schicht Myelin umrunden (Gabreels-Festen und Wetering 1999; Guenard et al. 1996). Der sekundäre axonale Verlust mit konsekutiver Muskelatrophie führt zu dem klinischen Bild der CMT. Auch hier sind besonders die großkalibrigen Axone betroffen (Lewis et al. 2003). 


\subsection{Charcot-Marie-Tooth-Erkrankung Subtyp 1A (CMT1A)}

Mit einer Prävalenz von 1-4 je 10000 (bzw. 1 : 2500) ist die CMT die häufigste hereditäre Neuropathie (Mostacciuolo et al. 1991; Schenone et al. 2011; Skre 1974). Oft bedingt die Erkrankung eine Veränderung des für das periphere Myelinprotein 22 kDa (PMP22) kodierenden Gens. Punktmutationen, Duplikationen oder Deletionen resultieren in unterschiedlichen Neuropathien. Eine Duplikation führt zur demyelinisierenden Charcot-Marie-ToothErkrankung Subtyp 1A (CMT1A) (Lupski et al. 1991; Raeymaekers et al. 1991). Die verschiedenen Ebenen der Krankheitsentstehung sind in Abbildung 2 dargestellt.

$\mathrm{Zu}$ 60-70\% liegt der CMT eine DNA-Duplikation von ca. 1,5 Millionen Basenpaaren auf Chromosom 17p11.2-12 zugrunde (Ionasescu 1995). Die Weitergabe dieser Duplikation folgt einem autosomal dominanten Erbgang. Doch ist ein unvollständiges Crossing Over während der Spermatogenese die häufigste Ursache dieser Duplikation. Die betroffene Region ist flankiert durch eine sehr homologe Wiederholungssequenz, welche das ungleiche Crossing Over begünstigt (Palau et al. 1993). Dieser Mutations-Hot-Spot wird als Ursache für die hohe Prävalenz der genomischen Duplikation angesehen. Die Duplikationsregion enthält das Gen für das PMP22, welches als das krankheitsbedingende Gen identifiziert wurde (Matsunami et al. 1992; Patel et al. 1992; Timmerman et al. 1992; Valentijn et al. 1992). PMP22 ist ein hydrophobes Protein mit vier Transmembrandomänen. Es ist lokalisiert im kompakten Myelin und macht 3-5 \% der Proteinmasse des peripheren Myelins aus (Suter und Scherer 2003). Im adulten Nervensystem wird PMP22 von Myelin-bildenden Schwannzellen exprimiert. Auch gibt es eine transiente Expression in embryonalen Motoneuronen und außerhalb des Nervensystems (Baechner et al. 1995). Als ein $18 \mathrm{kDa}$ Vorläuferpolypeptid wird PMP22 synthetisiert, welches posttranslational durch N-gekoppelte Glykosylierung zu einem 22 kDa Protein modifiziert wird (Pareek et al. 1993). Seine biologische Funktion ist nicht vollends geklärt (Suter und Scherer 2003). Einige Hypothesen werden im Zusammenhang mit pathomechanistischen Überlegungen diskutiert. 


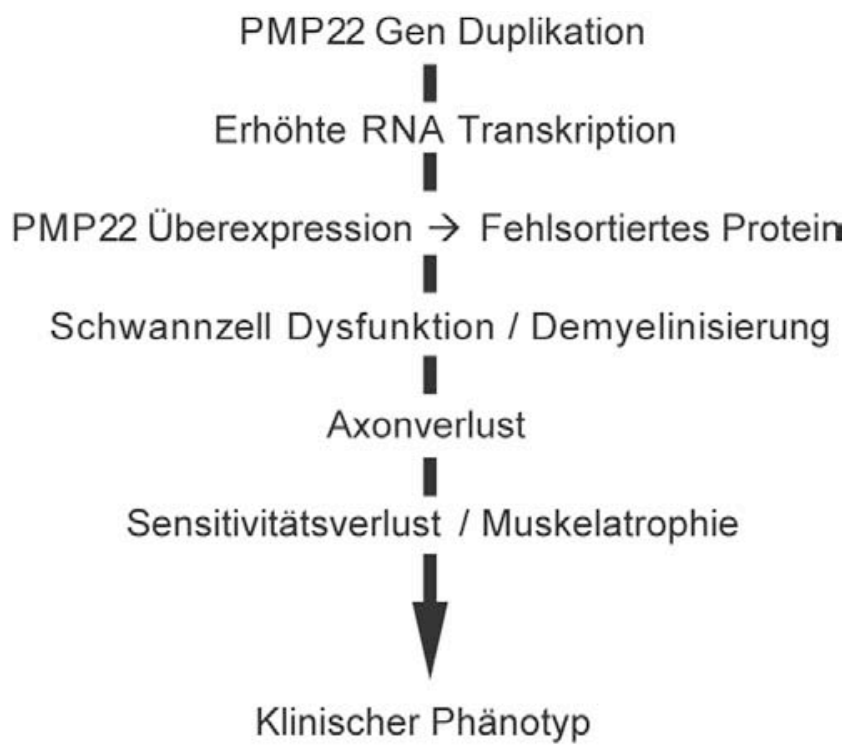

Abbildung 2: Ebenen der CMT1A-Erkrankung

Eine Duplikation der für PMP22-Protein codierenden Genregion liegt der CMT1A zugrunde. Die dadurch bedingte PMP22Überexpression in Schwannzellen führt zu Demyelinisierung und Axonverlust. Es resultieren Sensibilitätsdefizite und distal betonte Muskelatrophie, der klinische Phänotyp (Meyer zu Hörste und Nave 2006).

\subsubsection{Diskutierte Pathomechanismen}

Durch das ungleiche Crossing Over kommt es zu einer veränderten Anzahl an Kopien des PMP22-Gens. Die somit veränderte PMP22-Genexpression hat eine Neuropathie zur Folge. Dabei korreliert die Anzahl der PMP22-Kopien mit dem Phänotyp. Ein Verlust der Funktion eines PMP22-Allels führt zu einer um die Hälfte verringerten Gendosis und hat die hereditäre Neuropathie mit Neigung zu Druckparesen zur Folge (Stogbauer et al. 2000). Unter einem schwereren Krankheitsverlauf leiden Patienten mit einer 1,5-fachen Gendosis. Diese liegt bei heterozygoter Duplikation des für das PMP22-Protein kodierenden Genabschnittes vor. Die daraus resultierende Erkrankung ist die CMT1A. Homozygotie der PMP22-Duplikation (2fache Gendosis) führt zu dem am schwersten ausgeprägten Krankheitsverlauf (Lupski et al. 1991). In Nervenbiopsien der CMT1A-Patienten lassen sich erhöhte Mengen an PMP22mRNA und Protein nachweisen (Vallat et al. 1996; Yoshikawa et al. 1994).

Aufgrund der Korrelation von Erkrankungsausmaß mit der Menge an Gen spricht man von einer Gendosiserkrankung. Erst die erhöhte Genexpression macht das physiologische Gen zu einem Krankheitsgen (Lupski et al. 1992). Verschiedene Hypothesen versuchen dieses Phänomen zu erklären: 
Eine Interaktion zwischen PMP22 und dem im Myelin am häufigsten vorkommenden Myelin Protein Zero wird angenommen (D'Urso et al. 1999; Hasse et al. 2004). Dies steht im Einklang mit der Beobachtung, dass beide Proteine räumlich und zeitlich co-exprimiert werden (Hagedorn et al. 1999; Notterpek et al. 1999). Die Veränderung der Proteinmenge der beiden Interaktionspartner könnte zu einer Destabilisierung der Myelinmembranen führen.

Des Weiteren scheint es zu Proteinanhäufungen in verschiedenen intrazellulären Membrankompartimenten, wie beispielsweise den späten Endosomen, zu kommen. Auch der Membrantransport zeigte sich in Zellkulturexperimenten verändert (Chies et al. 2003).

Eine weitere Studie diskutiert die Beteiligung des Cholesterolstoffwechsels am Krankheitsgeschehen von PMP22-Gendosiserkrankungen. Es konnte eine Reduktion der Expression von Schlüsselenzymen des Cholesterolstoffwechsels gezeigt werden (Giambonini-Brugnoli et al. 2005). Das weist auf eine gestörte Lipidanordnung in den Myelinmembranen demyelinisierender Erkrankungen hin.

Außerdem wird eine intrazelluläre Akkumulation von ubiquitinierten PMP22Proteinenaggregaten angenommen (Fortun et al. 2006; Notterpek et al. 1999). Neben der Überladung der Proteasomen kommt es begleitend zu einer Reduktion ihrer Aktivität, was Auswirkungen auf den Erhalt der Homöostase in Schwannzellen nahelegt (Bence et al. 2001; Fortun et al. 2006). Vermehrte autophagische Prozesse wurden in Schwanzellen von Pmp22überexprimierenden Nagetieren beobachtet. Diskutiert wurde eine Erhöhung der Autophagie als kompensatorischer Mechanismus auf die Beeinträchtigung der Proteasomen (Fortun et al. 2006). Möglicherweise könnten hier zukünftige Therapien ansetzten (Fortun et al. 2007).

\subsubsection{Tiermodelle}

Verschiedene PMP22-transgene Mausmodelle (Huxley et al. 1998; Magyar et al. 1996; Robertson et al. 2002) und ein Rattenmodell (CMT-Ratte) (Sereda et al. 1996) wurden entwickelt. Dabei wirkt sich die Anzahl der zusätzlichen Kopien des PMP22-Gens direkt auf das Ausmaß der Erkrankung aus. Eine milde Überexpression führt zu einem der CMT1Aähnlichen, demyelinisierenden Phänotyp, während es bei höherer Genexpression zu einem fast vollständigen Fehlen von Myelin kommt (Magyar et al. 1996). Die CMT-Ratte eignet sich besonders zur Untersuchung von Pathomechanismen und experimentellen Therapien. Vergleichbar mit CMT1A-Patienten zeigt die CMT-Ratte eine milde (ca. 1,6-fach) Überexpression von Pmp22, woraus der demyelinisierenden Phänotyp mit charakteristischen Zwie- 
belschalenformationen, sekundärem axonalen Verlust und konsekutiver Muskalatrophie und -schwäche resultiert. Auch sind verringerte Nervenleitgeschwindigkeiten und Muskelsummenaktionspotentiale messbar (Sereda et al. 1996; Sereda et al. 2003).

\subsection{Stand der experimentellen Therapien der CMT1A}

Bisher bestehen keine kausalen oder die Erkrankrankung modifizierenden Therapieoptionen. Supportive Maßnahmen beinhalten Physiotherapie sowie orthopädietechnische und chirurgische Behandlung zur Aufrechterhaltung von Funktionen, besonders der unteren Extremitäten. Analgesierende Medikation dient als symptomatischer Ansatz, um neuropathischen und mechanischen Schmerz zu lindern (Shy 2006).

Anhand pathomechanistischer Überlegungen wurden Ideen präklinischer Therapiestrategien entwickelt:

Die Verringerung der PMP22-Überexpression stellt eine Möglichkeit dar in die Pathogenese der CMT1A aktiv einzugreifen. Erste tierexperimentelle Therapien mit dem Progesteronantagonisten Onapriston waren erfolgreich (Meyer zu Hörste et al. 2007; Sereda et al. 2003). Aufgrund gravierender unerwünschter Nebenwirkungen ist eine weitere klinische Erprobung von Onapriston jedoch ausgeschlossen (Robertson et al. 1999).

Alternativ könnten experimentelle Therapien an den durch die PMP22-Überexpression entstandenen Proteinaggregaten ansetzten, welche die Proteasomen beeinträchtigen und Schwannzell-toxisch wirken (Fortun et al. 2006; Saifi et al. 2003).

In Nerven von Nagetiermodellen der CMT1A konnte ein Defizit an trophischen Faktoren (z.B. ciliary neurotrophic factor) festgestellt werden. Ein Ersetzten dieser Faktoren könnte die Erkrankung ebenfalls beeinflussen (Vigo et al. 2005).

Eine inflammatorische Beteiligung an der Pathogenese der CMT1A konnte bisher nicht ausgeschlossen werden. Insbesondere bei Kindern wurden in elektronenmikroskopischen Aufnahmen endoneurale Makrophagen dargestellt, die einen aktiven Demyelinisierungsprozess herbeiführen (Gabreels-Festen et al. 1992; Vital et al. 1992). Entscheidend aber für die Überlegungen, dass in der humanen CMT1A auch Immunzellen eine Rolle spielen könnten, ist das Ansprechen auf antiinflammatorische Therapie bei einer Untergruppe von Patienten (Bird und Sladky 1991; Dyck et al. 1982; Vital et al. 2003). Dabei ist aber herauszustellen, dass die für eine derartige Therapie sensiblen Patienten zwar positiv auf die CMT1A diagno- 
stiziert wurden, ihre Erkrankung aber uncharakteristische Merkmale aufwies. So wurde eine schnelle Progression bei zuvor asymptomatischen Patienten berichtet sowie eine proximal betonte und auch asymmetrische Muskelschwäche (Ginsberg et al. 2004; Vital et al. 2003). All das, wie auch die histopathologischen Merkmale inflammatorischer Infiltrate und Ödeme, könnten auch für eine die CMT-Erkrankung überlagernde chronisch inflammatorische demyelinisierende Polyradikuloneuropathie sprechen. Ob die Entwicklung dieser Erkrankung aber durch das Vorhandensein einer CMT begünstigt wurde (als Autoimmunantwort auf eine konstant ablaufende Myelindestruktion mit permanenter Abgabe immunogener Myelinbruchstïcke) und ob die aufgrund der chronischen Neuropathie ohnehin vermehrt anwesenden aktiven Immunzellen wie Makrophagen eine Autoimmunantwort erleichtern, wird diskutiert (Martini und Toyka 2004).

Auch in peripheren Nerven Pmp22-überexprimierender Mäuse (C61-Mauslinie) wurden vermehrt CD8 ${ }^{+}$-Lymphozyten und F4/80 ${ }^{+}$-Makrophagen nachgewiesen (Kobsar et al. 2005). Eine kritische Beteiligung der T-Lymphozyten am Erkrankungsgeschehen der CMT1A wurde in diesem Tiermodell hingegen ausgeschlossen. Zum einen überragt die Anzahl der Makrophagen in peripheren Nerven die der T-Lymphozyten um ein vielfaches (Kobsar et al. 2005). Zum anderen hatte ein Fehlen funktionstüchtiger T- und B-Zellen (Kreuzverpaarung mit RAG-1-, recombination-activating-gene-1-defizienten Mäusen) oder eine übermäßige Aktivierung der Lymphozyten (Inaktivierung des lymphozytären Koinhibitors programmed death1) keine Veränderung des Phänotyps oder der Axonopathie zur Folge (Kohl et al. 2010b). Makrophagen hingegen scheinen von entscheidender Bedeutung zu sein. In elektronenmikroskopischen Aufnahmen konnte eine Penetration der Basallamina durch Makrophagen dargestellt werden, welche scheinbar aktiv Myelin phagozytieren. Es wurde hypothetisiert, dass die Überexpression von Pmp22 in Schwannzellen intrazellulären Stress bedingt, welcher die Expression von Chemokinen wie dem monocyte chemoattractant protein-1 (MCP-1) zur Folge hat. MCP-1 wurde dabei als kritischer Faktor der Aktivierung endoneuraler Makrophagen diskutiert (Kobsar et al. 2005). In darauffolgenden Experimenten konnte durch eine Kreuzverpaarung Pmp22-überexprimierender Mäuse mit MCP-1-Mutanten eine verringerte Anzahl gewebsständiger Makrophagen erzielt werden. Folge war eine Verbesserung des Phänotyps und der Axonpathologie (Kohl et al. 2010a). Die Modulation des Immunsystems ist folglich ein weiterer Ansatz für experimentelle Therapien. 
Einige präklinisch gewonnene Ansätze zu neuartigen Therapien wurden bereits in ersten klinischen Studien überprüft:

Ascorbinsäure erwies sich in Schwannzell-Spinalganglien-Zellkulturen essentiell für die Myelinisierung, wobei sie zur Bildung der Basallamina von Bedeutung ist (Eldridge et al. 1987). In einer ersten präklinischen Studie konnten Passage et al. zeigen, dass in einem Mausmodell für die CMT1A die Therapie mit Ascorbinsäure den Phänotyp verbessert sowie zu einer Verlängerung der Lebenszeit führt. Auch eine Verringerung der PMP22-Überexpression wurde gezeigt (Passage et al. 2004). Ascorbinsäure ist günstig, leicht zu applizieren und bereits hochdosiert in klinischen Studien verwendet, sodass schnell klinische Studien initiiert werden konnten.

Erste klinische Studien überprüften eine hochdosierte Ascorbinsäure-Therapie bei CMT1APatienten zwischen 18 und 70 Jahren (Micallef et al. 2009; Pareyson et al. 2011), jungen Erwachsenen unter 25 Jahren (Verhamme et al. 2009) und Kindern (Burns et al. 2009). Eine Verbesserung des Phänotyps wurde erhofft, der Charcot-Marie-Tooth Neuropathy Score (CMTNS) diente als klinischer Verlaufsparameter. Alle Studien endeten erfolglos.

Coenzym Q10 ist ein Elektronenakzeptor der mitochondrialen Atmungskette mit antioxidativen Eigenschaften. In einer ersten Studie wurden drei klinisch diagnostizierte CMTPatienten niedrig dosiert mit Coenzym Q10 therapiert. Ein verbesserter Krankheitszustand wurde berichtet (Folkers und Simonsen 1995). Eine größere Studie wurde kürzlich eröffnet, in der 46 CMT-Patienten über 60 Tage mit Coenzym Q10 therapiert werden (NCT00541164 auf http://www.clinicaltrials.gov). Diese Studie ist jedoch nicht spezifisch für Patienten des CMTSubtyps 1A. Auch fokussiert sie nicht ausschließlich CMT-Formen, die mitochondriale Dysfunktion als auslösenden Faktor teilen. Alleinige klinische Diagnostik ist zum Einschluss erforderlich.

Neurotrophin-3 (NT-3) ist wichtig für das Überleben von Schwannzellen und axonaler Regeneration. Studien zeigten, dass in der CMT1A ein Mangel an NT-3 vorliegt. In einem Pilotexperiment, Placebo-kontrolliert und doppelt geblindet, wurden 4 CMT1A-Patienten für 24 Wochen mit rekombinanten methionylierten humanen NT-3 (r-metHuNT-3) behandelt. Es ergab sich eine signifikante Verbesserung der sensiblen Defizite und des „Neuropathy Impairment Score“. Motorische Einschränkungen blieben jedoch unverändert. Im Vergleich von vorher und nachher gewonnenen Nervus suralis-Biopsien zeigte sich, verglichen mit der Pla- 
cebogruppe, eine erhöhte Dichte myelinisierter Nervenfasern. NT-3 wurde gut vertragen (Sahenk et al. 2005).

\subsection{Tierexperimentelle Studien mit CMT-Ratten}

Im Zuge dieser Arbeit wurden mithilfe der CMT-Ratte andere Therapieansätze auf ihre Wirksamkeit überprüft. Behandelt wurde mit dem auf Schwannzellebene agierendem Progesteronantagonisten (PA) Lonaprisan mit dem Ziel, die PMP22-Überexpression zu verringern. Die diskutierten neuroprotektiven Eigenschaften des Hormons Erythropoetin sowie des Gewürzextraktes Curcumin wurden auf ihre Wirksamkeit zur Linderung der CMT1A hin überprüft. Eine etwaige inflammatorische Komponente im Krankheitsgeschehen der CMT1A sollte in einer letzen Studie mit der antiinflammatorisch wirksamen Substanz Acetylsalicylsäure überprüft werden. In einem Pilotexperiment wurde die Möglichkeit zur Verringerung der PMP22Überexpression durch die Behandlung mit dem LXR-Agonisten T0901317 überprüft.

\subsubsection{Der Progesteronrezeptor als pharmakologisches Ziel}

Der Progesteronrezeptor (PR) ist ein Liganden-aktivierter Transkriptionsfaktor, der als Monomer gebunden an das Hitzeschockprotein 90 im Zytosol lokalisiert ist. Progesteron bindet an die zytosolischen Rezeptormonomere, was eine Dimerisierung und Translokation in den Zellkern zur Folge hat. (Beato 1989; Edwards et al. 1995; McKenna und O'Malley 2002). Dort bindet der Progesteron-Rezeptor-Komplex an spezifische ProgesteronresponsiblenElemente (PRE) der DNA, und reguliert, abhängig von Coaktivatoren und Corepressoren, die Genexpression (McKenna und O'Malley 2002; Wu et al. 2005).

In Zellkulturen wurde eine progesteronabhängige Expressionssteigerung der Myelingene MPZ und PMP22 gezeigt (Desarnaud et al. 1998; Melcangi et al. 1999). Auf Grundlage dessen folgten Überlegungen, die durch PMP22-Überexpression bedingte CMT1A-Erkrankung durch Progesteronantagonisten (PA) zu lindern.

Drei Arten von PA werden unterschieden. Typ I-Antiprogestine wie Onapriston verhindern die Bindung des Rezeptors an die DNA. Sie wirken als reine Antagonisten und verhindern somit die Progesteron-abhängige Genexpression. Typ II-Rezeptorantagonisten (Mifepriston) 
führen zu einer Erhöhung der Bindungsaffinität des Rezeptors an die DNA, ohne jedoch die Rezeptorwirkung zu entfalten. Eine Konfomationsänderung der Rezeptorstruktur als Ursache für diese Wirkung wird angenommen. Partialagonistisches Potential entfalten diese Antagonisten jedoch durch cAMP-abhängige Proteinkinase A-Stimulation (Afhuppe et al. 2010; Edwards et al. 1995). Eine letzte Art der PA wurde entwickelt und als Typ III definiert: Der Antagonist Lonaprisan (ZK230211) induziert ebenfalls die Rezeptorbindung an die PRE, ohne aber unter Proteinkinase A-Aktivierung partialagonistische Wirkung zu entfalten (Afhuppe et al. 2010; Fuhrmann et al. 2000). Antagonisten des Typs I oder III sind aufgrund ihrer rein antagonistischen Wirkung zur Therapie der CMT1A besonders geeignet.

Durch die Therapie von CMT-Ratten mit dem rein antagonistischen Typ I-PA Onapriston wurde eine Verringerung der PMP22-Überexpression erreicht. Im Gegenzug hatte die Gabe von Progesteron eine Erhöhung der Expression zur Folge. Das Potential der Progesteronantagonisten zur Therapie der CMT1A-Erkrankung wurde somit gezeigt, im Gegenzug ließ sich auch die Erkenntnis ableiten, dass Progesteron-Therapie, wie beispielsweise zur oralen Kontrazeption, den Verlauf der Erkrankung negativ beeinflussen könnte und somit vermieden werden sollte (Grandis und Shy 2005; Sereda et al. 2003; Shy 2004).

Zwei experimentelle Therapiestudien demonstrierten die positive Wirkung von Onapriston auf den Verlauf der CMT1A-Erkrankung. In einem ersten Ansatz wurden junge Ratten für 7 Wochen therapiert. Eine Verbesserung der Muskelstärke sowie eine Verringerung des axonalen Verlustes wurden erzielt (Sereda et al. 2003). Näher der klinischen Situation, in der Dignosestellung und darauffolgender Therapiebeginn erst bei auftreten von Symptomen erfolgt, wurden in einem zweiten Ansatz ältere CMT-Ratten ab dem Alter von 5 Wochen behandelt. Vergleichbar mit Patienten zum Zeitpunkt der Erstdiagnose sind in diesem Alter bei CMTRatten klinische Symptome wie die Verringerung der Muskelstärke erkennbar. Die somit bereits vorangeschrittene Erkrankung wurde dennoch durch die Therapie mit Onapriston gelindert. Auch wurde gezeigt, dass die Behandlung mit Onapriston zwar den axonalen Verlust verringert, jedoch keinen Einfluss auf den Grad der Demyelinisierung hat. Es wurde somit eine axosupportive Funktion von Schwannzellen, unabhängig von ihren Aufgaben zur Myelinisierung geschlussfolgert. Durch die Behandlung mit Onapriston wurde diese wichtige Funktion der Schwannzellen aufrechterhalten und die Erkrankungsprogression gelindert (Meyer zu Hörste et al. 2007).

Onapriston wurde ursprünglich für die Behandlung von Hormonrezeptor-exprimierenden Neoplasien wie Brustkrebs oder Meningeome entwickelt (Jang und Benet 1997; Neef et al. 
1984). Bis zu klinischen Studien der Phase II wurde Onapriston geprüft. Aufgrund von Leberenzymerhöhungen musste jedoch von weiterer Erprobung abgesehen werden (Robertson et al. 1999). 


\subsubsection{Curcumin als Neuroprotektivum}

Die getrocknete Bodenwurzel der Pflanze Curcuma longa Linn., tumerik auf Englisch, haldi auf Hindi und ukon auf Japanisch, wurde in der japanischen Medizin bereits seit dem zweiten Jahrtausend vor Christus verwandt (Brouk 1975). Bekannt ist das aus ihr gewonnene hellgelbe Pulver Curcumin besonders als Gewürz und ist Bestandteil sowie farbgebende Substanz der Gewürzmischung Curry.

In den vergangenen zwei Dekaden erweckte die Erforschung der biologischen Eigenschaften des Curcumins sowie auch die potentielle Verwendung in der westlichen Medizin zunehmend Aufmerksamkeit. Curcumin wurde als ein neuroprotektiver Wirkstoff diskutiert und entzündungshemmende, antioxidative, anti-proteinanhäufende Eigenschaften wurden beschrieben (Cole et al. 2007).

Der aus den Curcuma spp. Wurzeln gewonnene Gewürzextrakt enthält Tumerin (ein wasserlösliches Peptid), ätherische Öle (wie Tumerone, Atlantone, und Zingiberene) sowie die Curcuminoide (u.a. Curcumin/Diferuloylmethan) (Tayyem et al. 2006).

Chemisch gesehen handelt es sich bei dem reinen Curcumin um die Substanz Diferuloylmethan [1,7-bis-(4-hydroxy-3-methoxyphenyl)-1,6-heptadiene-3,5-dione], einem Polyphenol mit geringem Molekulargewicht. Kommerziell erhältliches Curcumin enthält des Weiteren etwa $17 \%$ Demethoxycurcumin und $3 \%$ Bisdemethoxycurcumin (Abbildung 3). Curcumin (Diferuloylmethan) wurde als die biologisch aktivste Form beschrieben (Sandur et al. 2007). Der Anteil an Curcumin in den gewonnenen Gewürzextrakten liegt bei 1-6 \% (Goel et al. 2008).<smiles>COc1cc(/C=C/C(=O)/C=C(O)/C=C/c2ccc(Cl)c(OC)c2)ccc1O</smiles><smiles>COc1cc(/C=C/C(O)=C/C(=O)/C=C/c2ccc(O)cc2)ccc1O</smiles><smiles>COC(=O)OCC(C)(C)C</smiles>

Abbildung 3: Strukturformeln der Curcuminoide Die drei Curcuminoide Diferuloylmethan, Demethoxycurcumin, Bisdemethoxycurcumin sind in kommerziell erhältlichem Curcumin enthalten. Diferuloylmethan wurde als die biologisch aktivste Form beschrieben (modifiziert nach Sandur et al. 2007, S. 1766). 
In kürzlich veröffentlichten Arbeiten wurde der positive Einfluss von Curcumin (Diferuloylmethan) auf Formen der CMT1 beschrieben, bei denen Missense-Mutationen von PMP22 oder $M P Z$ die Erkrankung bedingen. Bei diesen Subtypen kommt es zu einem Aufstau von missgefaltetem, mutierten Protein im Endoplasmatischen Retikulum (ER). Die intrazelluläre Proteinakkumulation führt im Folgenden zur Apoptose. Mit Zellkulturen wurde gezeigt, dass durch die Behandlung mit Curcumin mutiertes Protein vom ER freigelassen und die damit assoziierte Apoptoserate der Schwannzellen reduziert wurde (Khajavi et al. 2005; Khajavi et al. 2007). Daraufhin wurden neugeborene Trembler-J-Mäuse mit Curcumin therapiert. Bei diesem Mausmodell liegt eine Pmp22-Missens-Mutation vor, assoziiert mit einer schweren Form der humanen CMT1. Unter Curcumin-Therapie zeigte sich eine merkliche Verbesserung des Phänotyps (Khajavi et al. 2007). Mithilfe des gleichen Tiermodells konnte in pharmakokinetischen Analysen in peripheren Nerven die Substanz Curcumin nachgewiesen werden. Obwohl die detektierten Level sehr niedrig waren, schien es offensichtlich auszureichen, Einfluss auf die Erkrankung zu nehmen (Khajavi et al. 2007). Ein Therapieerfolg bei älteren Tieren wurde jedoch nicht erzielt, eine zu geringe Dosis, oder eine zu weit vorangeschrittene Erkrankung könnten hierfür eine Erklärung liefern. 


\subsubsection{Acetylsalicylsäure als Inhibitor der Cyclooxygenase}

Acetylsalicylsäure (ASS) als ein Inhibitor der Cyclooxygenase (COX) wirkt analgetisch, antipyretisch und antiphlogistisch. Zusätzlich verhindert ASS durch die Irreversibilität der Cyclooxygenaseinihibition in Thromboyzten deren Aggregation. Aufgrund der antiphlogistischen Eigenschaften wurde im Zuge dieser Arbeit eine experimentelle Therapiestudie der CMT1A mit ASS unternommen.

Die Wirkung von ASS beruht auf einer Hemmung der Cyclooxygenase, einem Enzym, welches die Reaktion der Arachidonsäure zu den zyklischen Endoperoxiden vermittelt (Vane 1971). Aus den zyklischen Endoperoxiden entstehen im weiteren Verlauf Eikosanoide, stark wirksame Gewebshormone mit mannigfachem Wirkungsspektrum. Eikosanoide, wie die Prostaglandine, das Prostazyclin und das Thromboxan entstehen katalysiert durch die COX. Die Entstehung der Leukotriene, einem letzten Eikosanoid als ein Derivat der Arachidonsäure, wird katalysiert durch die Lipoxygenase und daher nicht durch ASS gehemmt (Smith et al. 2000).

Zwei Isoformen der Cyclooxygenasen werden unterschieden, COX-1 und COX-2. Während COX-1 in vielen Zellen konstitutiv exprimiert wird und an eine Reihe physiologischer Prozesse beteiligt ist entfaltet die COX-2-Isoform insbesondere unter pathologischen Bedingungen ihre Wirksamkeit. Sie ist mit entzündlichen Prozessen assoziiert und wird von Entzündungsfaktoren (z.B. Cytokine) in einwandernden Leukozyten und Makrophagen induziert. Anschließend katalysiert sie die Synthese der Prostaglandine, wie dem Prostaglandin $\mathrm{E}_{2}$ oder $\mathrm{I}_{2}$, die den Grad der Inflammation intensivieren (Meade et al. 1993; Vane et al. 1998).

Tiermodelle der CMT1A deuten an, dass inflammatorische Reaktionen die Demyelinisierung beeinflussen. Auch wurde in Nervenbiopsien einiger Patienten mit besonders rapider Erkrankungsprogression eine Immunzelleninfiltration nachgewiesen. Ein Ansprechen dieser Patienten auf Immuntherapie wurde beschrieben (Dyck et al. 1982; Ginsberg et al. 2004; Kobsar et al. 2005). Demzufolge wurde diskutiert, in Nervenbiopsien die CD ${ }^{+}-T-Z e l l e n$ und Makrophagen zu quantifizieren sowie deren Aktivitätsstatus zu charakterisieren um anschließend eine immunmodulatorische Therapie zu erwägen. Dem gegenüber stände der Ansatz dauerhaft mit einer milden antiinflammatorischen Therapie zu behandeln um eine etwaige, durch Immunzellen verursachte Progression der Erkrankung einzudämmen. Durch ASS-Behandlung könnte auch in den einwandernden Immunzellen die beschriebene Synthese der Prostaglandi- 
ne und somit die Intensivierung einer inflammatorischen Komponente reduziert werden. Möglicherweise ist es gerade dieser leicht intensivierte Grad, der die chronische Progredienz der CMT1A bedingt. 


\subsubsection{Erythropoetin, ein hämatopoetisches Hormon}

Erythropoetin (EPO) ist ein Glycoprotein-Hormon mit hämatopoetischer Wirkung. Es wird in der Niere gebildet und auf hypoxischen Reiz hin ausgeschüttet. Im Knochenmark stimuliert es die Erythropoese (Jelkmann 2008). Neben diesen Wirkungen als Wachstumsfaktor konnten auch neuroprotektive Eigenschaften sowohl auf Ebene des ZNS als auch des PNS demonstriert werden.

EPO und sein Rezeptor (EPOR) werden in peripherem Nevengewebe konstitutiv exprimiert. Als Antwort auf eine axonale Schädigung schütten periaxonale Schwannzellen vermehrt EPO aus, welches dann EPOR-vermittelt eine axonale Degeneration verhindert (Keswani et al. 2004b). In Modellen für periphere Neuropathien (z.B. HIV assoziierte sensorische Polyneuropathie, diabetische Polaneuropathie) zeigte sich in vitro als auch in vivo ein günstigerer Verlauf durch eine EPO-Rezeptor vermittelte Therapie mit rekombinanten EPO (Keswani et al. 2004a; Schmidt et al. 2008). Auch bei einer Kohorte prädialytischer Patienten mit ausgeprägter Polyneuropathie konnte durch eine fünfmonatige EPO-Therapie eine signifikante Verbesserung motorischer Nervenleitgeschwindigkeiten des Nervus medianus, peroneus und tibialis erzielt werden (Hassan et al. 2003). Eine EPO-vermittelte Remyelinisierung durch direkte Wirkung an neuronalen EPOR wurde diskutiert. 


\subsubsection{T0901317, ein Agonist für den Leber X Rezeptor}

T0901317 (T0) ist ein synthetischer Agonist für die Leber X Rezeptoren (liver X receptor, LXR) (Schultz et al. 2000). LXRs sind als ligandenaktivierte, nukleäre Transkriptionsfaktoren an der Regulation des Lipidstoffwechsels beteiligt (Cao et al. 2004; Edwards et al. 2002). Auch im Nervensystem scheinen LXRs von Bedeutung zu sein. In Gehirnen von LXR Knockout Mäusen wurden Lipidablagerungen nebst neurodegenerativen Merkmalen (Neronenverlust, Astrozytenproliferation, Disorganisation der Myelinscheiden) gefunden (Wang et al. 2002). Im Gegenzug dazu zeigte in Schlaganfallmodellen die Agonisierung der Rezeptoren durch T0901317 neuroprotektive Wirkung und eine Verringerung proinflammatorischer Gene (Morales et al. 2008; Sironi et al. 2008). Auch in Tiermodellen für neurodegenerative Erkrankungen wie dem Morbus Alzheimer und der Niemann-Pick Typ C Erkrankung wurde mittels LXR-Aktivierung durch T0 eine Verbesserung krankheitsspezifischer Charakteristika erzielt (Koldamova et al. 2005; Langmade et al. 2006). 


\subsection{Zielsetzung}

In dieser Arbeit wurden die Wirkungen der oben beschriebenen Substanzen Lonaprisan, Curcumin, Acetylsalicylsäure, Erythropoetin und T0901317 auf die CMT1A-Erkrankung untersucht.

Der neue Progesteronantagonist Lonaprisan, der als Typ III-Antagonist keine partialagonistische Wirkung entfaltet, versprach weniger unerwünschte Nebenwirkungen als Onapriston (Fuhrmann et al. 2000) und wurde bereits in klinischen Studien der Phase II getestet.

In dieser Arbeit sollte die Möglichkeit der Linderung der CMT1A-Erkrankung durch diesen neuen PA überprüft werden. Es sollte untermauert werden, dass nicht Onapriston allein, sondern die Substanzklasse der PA in der Lage ist, die CMT1A zu lindern. Die Annahme, dass die PMP22-Überexpression das krankheitsauslösende Moment darstellt, sollte somit bestätigt werden. Des Weiteren war es Ziel, neue Erkenntnisse über die Funktion des Progesteronrezeptors im peripheren Nervensystem zu erlangen, insbesondere warum eine sich primär auf Schwannzell-Ebene abspielende Wirkung (Senkung der PMP22-Überexpression) einen axoprotektiven Effekt zur Folge hat. In diesem Zusammenhang sollte eine etwaige neuronale Wirkung von Lonaprisan überprüft werden. Um sich neuen Fragestellungen bezüglich der CMT1A-Pathogenese sowie der Pharmakodynamik des PA zu nähern, wurde nach erfolgreicher Therapie eine Vielzahl biologischer Materialien für weitere Analysen gesammelt. Über all dem stand der translationale Gedanke, die in dem Tiermodell gewonnenen Erkenntnisse auf Patienten zu übertragen. Es sollte der Weg bereitet werden, in einer ersten klinischen Studie die bisher nicht kausal behandelbare CMT1A mit dem sicheren Progesteronrezeptorantagonisten Lonaprisan zu therapieren.

Ein letzter Schwerpunkt dieser Studie lag bei der Etablierung biologischer Marker aus Hautbiopsien. Überprüft wurden differentiell regulierte Gene, die in einer DNA-MikroarrayAnalyse stark und schwach betroffener CMT-Ratten identifiziert wurden (Fledrich et al. 2012). Im Zuge dieser Arbeit sollte die Übertragbarkeit und das Ansprechen dieser Biomarker auf die Therapiesituation getestet werden. Die Bedeutung von Biomarkern ergibt sich unter anderem aus dem bisher minderen Erfolg klinischer Studien mit CMT1A-Patienten. Problematisch sind die auf ein oder zwei Jahre begrenzten kurzen Zeiträume klinischer Studien. Da es sich jedoch um eine Erkrankung mit chronischem Verlauf handelt, lassen sich signifikante Veränderungen des Phänotyps oft erst nach vielen Jahren darstellen. Dieser Zeitraum könnte 
jedoch zu kurz sein, um Änderungen in dem als Verlaufsparameter verwendeten CharcotMarie-Tooth Neuropathy Score (CMTNS) zu erzielen. Denn obwohl der CMTNS auf eine Vielzahl an Faktoren ausgerichtet ist (periphere Sensibilität, Feinmotorik, Gangbild, Kraftgrade der Extremitäten, elektrophysiologische Untersuchungsparameter (Shy et al. 2005) und somit ein umfangreiches Abbild der klinischen Situation eines CMT1A-Patienten liefert, fallen Behandlungserfolge eben aufgrund dieser Komplexität erst sehr spät ins Gewicht. Es wird diskutiert, ob die vielversprechenden klinischen Studien mit Ascorbinsäure durch die Trägheit des CMTNS gescheitert sind. Etablierte Biomarker, deren Expression eng mit dem klinischen Phänotyp korreliert, könnten eine zu messende Variable schaffen, die keine so große Trägheit aufweist wie der CMTNS. Ein etablierter Biomarker könnte diesbezüglich die Brücke über einen Zeitraum schaffen, in dem sich Behandlungserfolge einstellen, der aber für signifikante Änderungen des CMTNS zu kurz ist. Es galt somit, die Voraussetzungen zu schaffen, Therapieerfolge bzw. ein Ansprechen mithilfe dieser Biomarker zu monitoren. Im Idealfall sollte es im Vorhinein möglich sein, mittels Biomarker die Responder einer Therapie von NonRespondern zu unterscheiden. Somit könnte verhindert werden, dass sich Patienten auf eine nebenwirkungsreiche Therapie einlassen, ohne daraus Nutzen zu ziehen.

In einer Therapiestudie mit dem Gewürzextrakt Curcumin sollte durch eine neuroprotektiv wirkende Substanz ein Therapieerfolg erzielt werden, dessen Wirkmechanismus nicht die Herunterregulation der PMP22-Expression ist. Eine Alternative zur Therapie mit dem endokrin wirksamen Progesteronantagonisten wurde erhofft. Es gibt viele Ansätze einen potentiellen Wirkmechanismus von Curcumin zu beschreiben. In dem Tiermodell eines anderen Subtyps der CMT konnten Khajavi et al. 2007 zeigen, dass innerhalb der Schwannzelle mutiertes und kumuliertes Pmp22-Protein vom Endoplasmatischen Retikulum freigelassen und die damit assoziierte Apoptoserate der Schwannzellen reduziert wurde. Unklar blieb, ob auch bei der CMT1A-Erkrankung eine pathologische Proteinakkumulationen oder andere Pathomechanismen auf Schwannzellebene das Ziel der Curcumin-Therapie sein könnten. Auch wäre es möglich, dass Curcumin seinen Ansatz jenseits der spezifischen Pathomechanismen hat. Zum Beispiel könnte es in dem von Nave et al. 2007 beschriebenen final common pathway der CMT-Erkrankungen eingreifen und darüber einen axonalen Verlust verringern. Unter diesen Umständen ließe sich eine erfolgreiche Therapie mit Curcumin auf eine große Bandbreite peripherer Neuropathien übertragen. 
Immunzellen in Nervenbiopsien wurden sowohl im Tiermodell als auch in CMT1A-Patienten nachgewiesen (Gabreels-Festen et al. 1992; Kobsar et al. 2005; Vital et al. 1992). Inwieweit sie aktiv in das Krankheitsgeschehen der CMT1A eingreifen, ist nicht endgültig geklärt. Es ist möglich, dass gerade der geringe Grad an Inflammation den bei Menschen langsam progredienten Erkrankungsverlauf bedingt. Immunzellen wie Makrophagen könnten durch die ständige Präsenz immunogener Myelinbruchstücke in ihrer Aktivität gesteigert sein. Das stände im Gegensatz zu der beschriebenen raschen Erkrankungsprogredienz und Besserung unter Kortikosteroid-Therapie von CMT1A-Patienten, bei denen eine überlagerte chronisch inflammatorische demyelinisierende Polyradikuloneuropathie vermutet wurde. Im Regelfall jedoch könnte eine langfristige entzündungsmodulierende Therapie zu einem abgemilderten Erkrankungsverlauf führen. Es sollte daher in einer Therapiestudie nach dem „Clinical Paradigm“", mit einer langen Therapiedauer und Beginn bei bereits entwickelter Symptomatik, die Wirksamkeit einer antiinflammatorischen Therapie mit der Acetylsalicylsäure überprüft werden.

Eine neuroprotektive Wirkung des Erythropoetin konnte in vitro und in vivo demonstriert werden. Dabei scheinen sowohl die für demyelinisierende Neuropathien charakteristische axonale Degeneration als auch ein direkter neuronaler Zelluntergang durch EPO beeinflussbar (Keswani et al. 2004a). Auch bei der CMT könnte Erythropoetin eine potentielle Therapieoption darstellen. Dabei wäre Ziel nicht die Senkung der PMP22-Überexpression oder ein spezifischer Pathomechanismus anderer CMT-Formen. Vielmehr scheint EPO eine davon unabhängige direkt neuroprotektive Wirkung zu entfalten. Auch hier könnte der final common pathway der CMT-Neuropathien Ziel der Erythropoetin-Wirkung sein (Nave et al. 2007). In einer experimentellen Therapiestudie mit rekombinanten Erythropoetin sollte dessen Wirkung auf die CMT1A-Erkrankung untersucht werden.

In unpublizierten Vorexperimenten haben Massaad et al. in Schwannzellkulturen durch die Gabe von T0901317 eine signifikante Reduktion der PMP22-mRNA festgestellt. Auch hat sich in Mikroarray-Analysen von Ischiasgewebe stark betroffener CMT-Ratten (Fledrich et al. 2012) eine reduzierte Expression von ABCA1 gezeigt (Targetgen von T0), ein durch den Leber X Rezeptor-reguliertes Gen (Repa et al. 2000).

Im Rahmen eines Pilotexperiments sollte die Hypothese untersucht werden, ob der LXRAgonist T0901317 in der Lage ist, in Analogie zum Progesteronantagonisten, die toxische 
Überexpression von PMP22 in CMT-Ratten zu senken. Zusätzlich wurde die DosisWirkungs-Beziehung untersucht. 


\section{Material und Methoden:}

\subsection{Material}

Alle nicht näher bezeichneten, laborüblichen Chemikalien und Verbrauchsmaterialien wurden von den Herstellern Roche, Falcon, Eppendorf, Merck und Sigma bezogen.

\subsubsection{Verbrauchsmaterielien}

$\mathrm{CO}_{2}$-Gas

Deckgläschen

Einmalhandschuhe

Eppendorfgefäße

Falconröhrchen Rundboden $6 \mathrm{ml}$

Falconröhrchen, Größe: 15 ml, 50 ml

Injektionskanülen

Injektionskanülen, Größe: 17 G, 20 G, 23 G

Kosmetiktücher

Mikro-Hämatokritkapillare

Objektträger

PCR-Mikrotiterplatten

PCR-Plattenfolie „Air Pore Sheet”

Pipettenspitzen

Rattenstandarddiät ssniff R/Z V1325-0

Serum-Monovette, Größe: 2,6 ml
Messer-Griesheim, Krefeld

Gerhard Menzel Glasbearbeitungswerk, Braunschweig

Hartmann, Heidenheim

Eppendorf, Hamburg

Becton \& Dickinson, Le Pont De Claix, Frankreich

Becton \& Dickinson, Le Pont De Claix, Frankreich

Becton \& Dickinson, Le Pont De Claix, Frankreich

Becton \& Dickinson, Le Pont De Claix, Frankreich

Wepa professional, Arnsberg

Brand, Wertheim

Menzel-Gläser, Braunschweig

ABgene, Surrey, UK

ABgene, Surrey, UK

Molecular Bioproducts, San Diego, CA, USA

ssniff Spezialdiäten $\mathrm{GmbH}$, Soest

Sarstedt, Nümbrecht 
Spritzen „NormInjekt“, Größe: $1 \mathrm{ml}$

Stickstoff, flüssig

SuperFrost ${ }^{\circledR}$ Plus Objektträger

Transferpipetten

Trockeneis

Weichholzgranulateinstreu „Bedding S8/15“
Henke Saas Wolf, Tuttlingen

Messer-Griesheim, Krefeld

Gerhard Menzel Glasbearbeitungswerk, Braunschweig

Bio-Rad, Hercules, CA, USA

Messer-Griesheim, Krefeld

ssniff Spezialdiäten $\mathrm{GmbH}$, Soest

\subsubsection{Chemikalien}

„Ficoll (Typ 400)“

1,4-Dithiotreitol (DTT)

2,4,6-tris-dimethylaminomethyl-Phenol

(DMP30)

2-Duodecenyl-succinicacidanhydrid (DDSA) Agarose

Ammoniumacetat

Azur-II-Farbstoff

Benzylbenzoat

Beta-Mercaptoethanol

Bromphenolblau

Chloroform

DAB Chromogen

Dinatriumhydrogenphosphat $\left(\mathrm{Na}_{2} \mathrm{HPO}_{4}\right)$

Dinatriumhydrogenphosphat-Diydrat

$\left(\mathrm{Na}_{2} \mathrm{HPO}_{4} * 2 \mathrm{H}_{2} \mathrm{O}\right)$

Essigsäure

Ethanol

Ethidiumbromid

Ethylendiamintetraacetat (EDTA)

Glutardialdehyd
Sigma-Aldrich, Schnelldorf

GibcoBRL, Karlsruhe

Serva, Heidelberg

Serva, Heidelberg

Bio-Rad, Hercules, CA, USA

Merck, Darmstadt

Merck, Darmstadt

Sigma, Hamburg

Merck, Darmstadt

International Biotechnology Inc.

Merck, Darmstadt

Dako Deutschland GmbH, Hamburg,

Deutschland

Merck, Darmstadt

Merck, Darmstadt

Merck, Darmstadt

Merck, Darmstadt

Sigma-Aldrich, Schnelldorf

Merck, Darmstadt

Merck, Darmstadt 
histologisches Einschlussmittel „Eukitt“

Instant-Magermilchpulver

Isopropanol

Kaliumchlorid ( $\mathrm{KCl})$

Methanol

Methylenblau

Natriumchlorid $(\mathrm{NaCl})$

Natriumdihydrogenphosphat-Monohydrat

$\left(\mathrm{NaH}_{2} \mathrm{PO}_{4} * \mathrm{H}_{2} \mathrm{O}\right)$

Natriumhydroxid $(\mathrm{NaOH})$

Osmiumtetroxid

Paraformaldehyd

Pellet Paint TM

Propylenoxid

Rinderserumalbumin (bovine serum albumin)

Salzsäure (HCl) Serva, Heidelberg

Shandon Cryomatrix ${ }^{\mathrm{TM}}$

Tris-HCl Base

Wasserstoffperoxid

Xylencyanol

Xylol
Kindler, Freiburg

Naturaflor frema Reform

Merck, Darmstadt

Merck, Darmstadt

Merck, Darmstadt

Merck, Darmstadt

Merck, Darmstadt

Merck, Darmstadt

Merck, Darmstadt

Serva, Heidelberg

Serva, Heidelberg

Merck, Darmstadt

Serva, Heidelberg

Sigma-Aldrich, Schnelldorf

Serva, Heidelberg

Thermo Scientific, Langenselbold

Sigma-Aldrich, Schnelldorf

Merck, Darmstadt

Merck, Darmstadt

Merck, Darmstadt

\subsubsection{Pharmaka}

Acetylsalicylsäure (Aspirin ${ }^{\circledR}$ i.v.)

Erythropoetin

Haldi (Turmeric) Powder

$\operatorname{Ketamin}\left(\right.$ Ketanest $\left.^{\circledR}\right)$

Lonaprisan (ZK230211)

Natriumchlorid Lösung 0,9\%
Bayer AG, Leverkusen

Johnson\&Johnson Pharmaceutical Research, Raritan, USA

TRS Wholesale Co. Ltd, Middlesex, Großbritannien

Parke-Davis, Berlin

Bayer-Schering Pharma AG, Berlin

Diaco, Naila 
Sesamöl

T0903017

Wasser für Injektionszwecke

Xylazin $\left(\right.$ Rompun $^{\circledR}$ )
Henry Lamotte Oils GMBH, Bremen

Cayman Chemical Company, Tallinn, Estland

Bayer AG, Leverkusen

Bayer, Leverkusen

\subsubsection{Lösungen und Puffer}

\section{Eprex Lösungsmittel}

Polysorbat 80

Glycin

$\mathrm{NaCl}$

Natriumdihydrogenphosphat $* \mathrm{H}_{2} \mathrm{O}$

Dinatriumhydrogenphosphat $* 2 \mathrm{H}_{2} \mathrm{O}$
$3,00 \mathrm{mg}$

$50,00 \mathrm{mg}$

$43,80 \mathrm{mg}$

$5,13 \mathrm{mg}$

$22,30 \mathrm{mg}$

$\rightarrow$ mit Wasser für Injektionszwecke auf 10,00 g auffüllen

\section{Färbelösung nach Nissl}

Kresylviolett

$0,5 \mathrm{~g}$

Acetatpuffer $\mathrm{pH}$ 3,8-4

Natriumacetat 2,72\%

Essigsäure 1,2 \%

Entfetterlösung

Chloroform

$$
100 \mathrm{ml}
$$

$100 \mathrm{ml}$

$400 \mathrm{ml}$

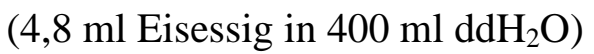

$348 \mathrm{ml}$

Äther

$48 \mathrm{ml}$

Alkohol

Fixanz für Licht- und Elektronenmikroskopie nach Karlsson und Schultz (Schultz und

\section{Karlsson 1965)}

Natriumdihydrogenphosphat $* \mathrm{H}_{2} \mathrm{O}$

$0,36 \mathrm{~g}$

Dinatriumhydrogenphosphat $* 2 \mathrm{H}_{2} \mathrm{O}$

$3,1 \mathrm{~g}$

Natriumchlorid

$1 \mathrm{~g}$

Glutardialdehydlösung

$20 \mathrm{ml}$

Paraformaldehyd

$8 \mathrm{~g}$ 


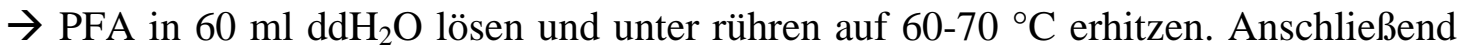
mit $\mathrm{ddH}_{2} \mathrm{O}$ auf $80 \mathrm{ml}$ auffüllen. Bis zum Aufklaren der Lösung tropfenweise $1 \mathrm{M} \mathrm{Na}$ $\mathrm{OH}$ hinzugeben. Lösung steril filtrieren und mit $1 \mathrm{M}$ HCL auf den pH-Wert 7,4 ein-

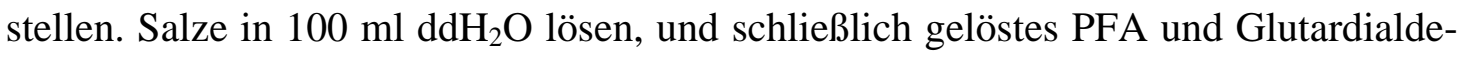
hydlösung hinzugeben.

\section{Kunstharzmischung Epon (Luft 1961)}

Epon Lösung A:

Glycidether $67,5 \mathrm{~g}$

DDSA $88,2 \mathrm{~g}$

$\rightarrow$ mit Magnetrührer $1 \mathrm{~h}$ rühren

Epon Lösung B:

Glycidether $82,3 \mathrm{~g}$

MNA $73,3 \mathrm{~g}$

$\rightarrow$ mit Magnetrührer $1 \mathrm{~h}$ rühren

Gebrauchslösung Epon:

$\rightarrow$ im Verhältnis 1: 1 Epon Lösungen A + B mischen und 1,8 \% DMP30 zugeben.

Methylen-Azur-II-Färbelösung (Richardson et al. 1960)

Methylenblau-Lösung

$1 \%$ Methylenblau in $1 \%$ wässriger Boraxlösung

Azur-II-Lösung

$1 \%$ Azur II in $\mathrm{H}_{2} \mathrm{O}$

Methylen-Azur-II-Färbelösung (Gebrauchslösung)

$\rightarrow$ beide Lösungen in einem Verhältnis von 1:1 mischen

\section{Paraformaldehyd, $4 \%$ (PFA) in PBS}

PFA Pulver $40 \mathrm{~g}$

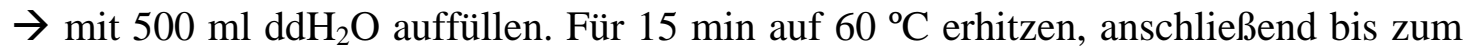
Aufklaren der Lösung tropfenweise $1 \mathrm{M} \mathrm{NaOH}$ hinzugeben. Steril filtriere, den $\mathrm{pH}-$ Wert auf 7,4 einstellen, und $500 \mathrm{ml} \mathrm{0,2} \mathrm{M}$ Phosphatpuffer hinzugeben. 


\section{PBS 10x}

$\mathrm{NaCl}$

$100 \mathrm{~g}$

$\mathrm{KCl}$

$2,5 \mathrm{~g}$

$\mathrm{Na}_{2} \mathrm{HPO}_{4} * \mathrm{H}_{2} \mathrm{O}$

$7,2 \mathrm{~g}$

$\mathrm{KH}_{2} \mathrm{PO}_{4} * 2 \mathrm{H}_{2} \mathrm{O}$ $2,5 \mathrm{~g}$

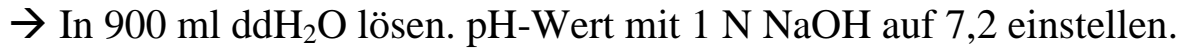

Puffer AE, AL/E, ATL, AW1, AW2 (Teile des DNeasy 96 Kit, Qiagen, Hilden)

Zusammensetzung vom Hersteller nicht angegeben

\section{TAE-Puffer $(50 x, 1000 \mathrm{ml})$}

Tris- $\mathrm{HCl}$ Base

Essigsäure $100 \%$

EDTA $(0,5 \mathrm{M}$ pH 8)
$242 \mathrm{~g}$

$57,1 \mathrm{ml}$

$100 \mathrm{ml}$

$\rightarrow$ mit doppelt destilliertem Wasser $\left(\mathrm{ddH}_{2} \mathrm{O}\right)$ auf $1000 \mathrm{ml}$ auffüllen.

Taq-Polymerase Puffer (Promega, Mannheim)

Zusammensetzung vom Hersteller nicht angegeben

\section{Trispuffer}

Stammlösung $(0,5 \mathrm{M}, \mathrm{pH} 7,6)$

TRIS

$60,75 \mathrm{~g}$

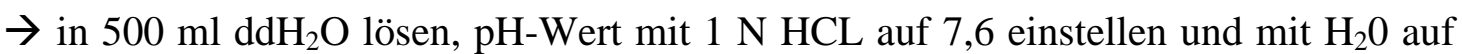
$1000 \mathrm{ml}$ auffüllen.

Gebrauchslösung (0,05 M, pH 7,6)

Stammlösung

$100 \mathrm{ml}$

$\mathrm{NaCl}$

$9 \mathrm{~g}$

$\rightarrow$ mit $\mathrm{H}_{2} \mathrm{O}$ auf $1000 \mathrm{ml}$ auffüllen.

\section{Trispuffer $+2 \%$ Magermilchpulver $(1000 \mathrm{ml})$}

Trispuffer Gebrauchslösung

$1000 \mathrm{ml}$

Magermilchpulver

$20 \mathrm{~g}$

$\rightarrow 20$ min unter rühren mischen und anschließend abfiltrieren 


\subsubsection{Enzyme und Reaktionskomplettsysteme}

DNeasy 96 Kit für DNA-Isolation

Power Sybr ${ }^{\circledR}$-Green PCR Master Mix

Proteinase K

RNA 6000 Nano Assay

RNeasy Mini Kit für RNA-Isolation

Superscript-III-RT Kit

Taq-DNA-Polymerase ( $5 \mathrm{U} / \mu \mathrm{l})$

TRIzol Reagent

Vectastain ${ }^{\circledR}$ Elite $^{\circledR}$ ABC Peroxidase KIT, PK6100
Qiagen, Hilden

Applied Biosystems, UK

Boehringer, Mannheim

Agilent Technologies, Böblingen

Qiagen, Hilden

Invitrogen, Carlsbad, USA

Boehringer, Mannheim

GibcoBRL, Karlsruhe

Vector Laboratories LTD., UK

\subsubsection{Nukleinsäuren}

Desoxyribonukleosid-Triphosphate (dNTPs)

DNA-Größenmarker „PhiX174/HaeIII“

randomisierte Nonamerprimer
Boehringer, Mannheim

Promega, Mannheim

Max-Planck-Institut für Experimentelle Medizin, Göttingen

\subsubsection{Oligonukleotide}

Die Primeroligonukleotide wurden mithilfe der Internet-basierten Software Universal Probe Library Assay Design Center entworfen, durch die Software Oligo Analyzer gegengetestet und am Max-Planck-Institut für Experimentelle Medizin (Göttingen) in der Abteilung Sequenzierung synthetisiert.

\section{Primer zur Genotypisierung transgener Ratten:}

Pmp22

Fwd 5'-GACAAACCCCAGACAGTTG-3'

Rev 5'-CCAGAAAGCCAGGGAACTC-3' 
Primer für Transkriptionsanalysen mittels semiquatitativen Real-Time-PCR mit Sybr ${ }^{\circledR}$ Green:

Actb

Fwd 5'-CTCTGAACCCTAAGGCCAACC-3'

Rev 5'-CTCTGAACCCTAAGGCCAACC-3'

Ppia (cyclophilin A) Fwd 5'-GTGTTCTTCGACATCACGGCT-3'

Rev 5'-ACCCCACCGTGTTCTTCGACA-3'

Pmp22 Exon 1b

Fwd 5'-GAACAGGATCCCCAACAAGAGTAG-3'

Rev 5'-GAACAGGATCCCCAACAAGAGTAG-3'

Igf1

Fwd 5'-TGTAAACGACCCGGGACG-3'

Rev 5'-GAGATGTGAAGACGACATGATGTG-3'

Igfbp5

Fwd 5'-GATGAGACAGGAATCTGACCAAG-3'

Rev 5'-TGCGTGGGCTGGCTTT-3'

Oaz1

Fwd 5'-CCAGAAGGCAGCAAGGAC-3'

Rev 5'-GGAGTAGGGCGGCTCTGT-3'

Pmp22

Fwd 5'-TGTACCACATCCGCCTTGG-3'

Rev 5'-GAGCTGGCAGAAGAACAGGAAC-3'

\subsubsection{Antikörper}

Goat anti-mouse IgG: HRP konjugiert

Mouse Anti-Rat CD68, monoclonal (ED1)
Jackson ImmunoResearch Europe Ltd., Großbritannien Linaris Biologische Produkte GmbH, Wertheim - Bettingen 


\subsubsection{Geräte}

Agarose-Gelkammer mit Gelkämmen

Agilent Bioanalyzer

Ausgießstation MICROM AP 280

Einbettautomat Leica EM TP

Elektrophysiologiegerät Jaeger-Toennis Neuroscreen

Gefrierschrank $-20{ }^{\circ} \mathrm{C}$

Gefrierschrank $-85{ }^{\circ} \mathrm{C}$ Ultra Low Freezer

Gewebeinfiltrationsautomaten MICROM HMP 110

Handkraftmessgerätstativ

Kryostat Leica Jung Cryocut

Lichtmikroskop Leica DM RXA2

Lightcycler LC480

Newtonmeter Erichsen Typ 708

PCR-Thermocycler „T3“

Präparationsbesteck

Probenmischgerät Vortex Genie 2

Reinstwasseranlage Arium 611 VF

Rotationsmikrotom Reichert Ultracut S

Schlittenmikrotom MICROM HM 400

Spannungsgeräte Elektrophorese

Stangentesteinrichtung

Trimmer Leica EM Trim

Ultraturrax T8 Gewebehomogenisator

UV-Illuminator

Videomikroskopiekamera

Zentrifuge 4K15C wissenschaftliche Werkstatt des MPI für experimentelle Medizin

Agilent Technologies, Böblingen

MICROM International GmbH, Walldorf

Leica Microsystems, Wetzlar

Jaeger-Toennies, Würzburg

Liebherr, Ochsenhausen

New Brunswick Scentific, Nürtingen

MICROM International GmbH, Walldorf

wissenschaftliche Werkstatt des MPI für

experimentelle Medizin

Leica Microsystems, Wetzlar

Leica Microsystems, Wetzlar

Roche Diagnostics, Mannheim

Erichsen, Wuppertal

Biometra, Göttingen

Fine Science Tools, Heidelberg

Bender \& Hobein, Zürich, Schweiz

Sartorius, Göttingen

Reichert, Wien, Österreich

MICROM International GmbH, Walldorf Amersham Pharmacia Biotech, Freiburg wissenschaftliche Werkstatt des MPI für experimentelle Medizin

Leica Microsystems, Wetzlar

IKA Labortechnik, Staufen

Amersham Pharmacia Biotech, Freiburg

Hamamatsu, Herrsching

Sigma, Osterode am Harz 


\subsubsection{Software}

Excel 2003

geNorm 3.5

Illustrator 13.0.2

Image J. $1.40 \mathrm{~g}$

OligoAnalyzer 1.1.2

Photoshop 10.0.1

PyRAT

qBase 1.3.5

Statistica 6.0

Universal Probe Library Assay Design Center

Word 2003
Microsoft Europe, Berlin

Center for Medical Genetics, Ghent, Belgien (Vandesompele et al. 2002)

Adobe Systems Software, Saggart, Irland NIH, USA

Teemu Kuulasmaa, Kuopio, Finnland

Adobe Systems Software, Saggart, Irland Scionics Computer Innovation, Dresden

Center for Medical Genetics, Belgium

Ghent, Belgien (Hellemans et al. 2007)

StatSoft Europe, Hamburg

Roche Applied Science, Mannheim

Microsoft Europe, Berlin

\subsection{Umgang mit Versuchstieren und in vivo-Analysen}

\subsubsection{Tierhaltung und Zucht}

Die 1996 generierten transgenen Ratten (Sereda et al. 1996) wurden in heterozygoter Zucht standarisiert gemäß der Empfehlung der Deutschen Gesellschaft für Versuchstierkunde im Tierhaus des Max-Planck-Instituts für Experimentelle Medizin gehalten.

Verpaart wurde stets eine Wildtyp-Ratte mit einem für die Pmp22-Duplikation heterozygotem Tier. Die Nachkommen wiesen somit entweder einen wildtyp oder Pmp22-heterozygoten Genotyp auf. Aus einer ca. 3 mm Hautprobe des Schwanzes wurde auf Ebene genomischer DNA durch PCR der Genotyp bestimmt. Je nach Studienprotokoll wurden die Tiere im Alter von einem Tag Schwanzbiopsiert und an den Füßen mit einem Tataucode markiert oder mit 21 
Tagen unter leichter $\mathrm{CO}_{2}$-Narkose biopsiert und mit einer Ohrlochcodierung versehen. Die Schwanzbiopsien wurden bis zur Genotypisierung bei $-20{ }^{\circ} \mathrm{C}$ gelagert. Auch die zu Anfangs tatauierten Tiere wurden ab dem Alter von 21 Tagen mit einem Ohrlochcode versetzt. Die Ohrlochmarkierungen ergaben zweistellige Zahlen, die eine Zuordnung zu der auf der Käfigkarte notierten siebenstelliger Tiernummer ermöglichten. Die letzten beiden Ziffern entsprachen der Ohrlochcodierung. Geburtsdatum, Geschlecht, Wurfgröße sowie Tiernummern der Elterntiere waren auf den Karten ersichtlich. Verwaltet wurden Tiere und Käfige mittels der Software PyRAT (Scionics Computer Innovation, Dresden Deutschland). Stammbaum und Historie der Tiere wurde somit dokumentiert.

\subsubsection{Probengewinnung}

Therapiebegleitende Hautbiopsien wurden unter Vollnarkose durch eine Injektion mit 5 $\mathrm{mg} / \mathrm{kg} \mathrm{KG} \mathrm{Ketamin}\left(\right.$ Ketanest $^{\circledR}$ ) und $2 \mathrm{mg} / \mathrm{kg} \mathrm{KG} \mathrm{Xylazin} \mathrm{(Rompun}{ }^{\circledR}$ ) entnommen. Waren die Tiere jünger als 21 Tage, wurde unter leichter $\mathrm{CO}_{2}$ Narkose biopsiert. Die Proben wurden in flüssigem Stickstoff gegeben und bei $-80^{\circ} \mathrm{C}$ gelagert. Durch Verödung mit einem Elektrokauter wurden Blutungen gestoppt.

Am Ende der Therapiestudie wurden nach Tötung der Tiere durch dreiminütige Überdosierung einer $\mathrm{CO}_{2}$-Narkose Gewebeproben präpariert. Bei der Entnahme von Gewebeproben und Blut half Herr Dipl.-Biol. Robert Fledrich. Die für molekularbiologische Untersuchungen verwandten Gewebe mussten um Degradationen zu reduzieren innerhalb von 10 min nach Eintritt des Todes entnommen und in flüssigen Stickstoff gegeben werden. Anschließend wurden sie bei $-80{ }^{\circ} \mathrm{C}$ gelagert. Gewebe für histologische Analysen wurden präpariert und entweder in Paraformaldehyd oder in dem Fixans nach Karlsson \& Schulz (K\&S) (Schultz und Karlsson 1965) immersionsfixiert. Sie wurden bei $-4{ }^{\circ} \mathrm{C}$ gelagert.

Blut wurde nach schneller Eröffnung des Thorax und Entfernung des Gekröses aus der linken Arteria renalis entnommen. Durch anschließendes Überführen in ein mit EDTA beschichtetes Probenröhrchen wurde ein Gerinnen der Blutprobe verhindert.

Durch die freigelegte Bauchhöhle wurde die Lendenwirbelsäule im ventralen Bereich der Wirbelbögen mit einer Knochenzange gefenstert. Spinalganglien, die ausschließlich neuronale Perikarya und somit keine Schwannzellkerne enthalten, wurden für Expressionsanalysen entnommen. Im Folgenden wurde der Rückenmarkskanal mithilfe eines Skalpells eröffnet, so- 
dass das Rückenmark freilag. Auf Höhe des 2. Lendenwirbels wurde ein etwa $10 \mathrm{~mm}$ langes Stück Rückenmark entnommen, auf einem Trockeneisblock in einer mit Shandon Cryomatrix ${ }^{\mathrm{TM}}$ gefüllten Einbettform auf $-78{ }^{\circ} \mathrm{C}$ heruntergekühlt und bei $-80{ }^{\circ} \mathrm{C}$ gelagert.

Eine ca. $3 \mathrm{~mm}$ lange Hautprobe des Schwanzes wurde biopsiert und bis zur Regenotypisierung bei $-20{ }^{\circ} \mathrm{C}$ gelagert. Weitere Hautproben wurden von der Fußsohle entnommen. Um eine Kontamination von Muskelgewebe zu vermeiden wurde mit einer chirurgischen Pinzette ein Stück Haut der Fußsohle gefasst, durch Zug vom subkutanen Gewebe gelöst, mit einer Schere abgetrennt und in flüssigem Stickstoff gegeben.

Zur Präparation des Nervus ischiadicus wurde die Ratte auf dem Bauch liegend fixiert. Fell und subkutanes Fettgewebe wurde im Bereich des Beckens abpräpariert. Scharf wurden die Musculi glutei major et minor durchtrennt, sodass die Sicht auf den Austritt der Fasern des Plexus lumbosakralis, die sich im Verlauf zum Nervus ischiadicus vereinen, freilag. Noch vor dem Abgang der ersten Rami musculares wurde ein Stück Nervengewebe entfernt. Das Perineurium wurde mit einem Skalpell abgekratzt, das Gewebe in flüssigem Stickstoff gegeben und bei $-80{ }^{\circ} \mathrm{C}$ gelagert. Anschließend wurde zur Entnahme der beiden Nervi tibiales die Ratte gewendet, der Nerv von ventral medial am Unterschenkel freigelegt und distal der Abzweigung des Nervus fibularis entnommen. Ein Nerv wurde in Paraformaldehyd, der andere in K\&S immersionsfixiert. Der distal gelegene Musculus tibialis cranialis wurde ebenfalls für histologische Analysen in K\&S immersionsfixiert.

Den mit T0901317 therapierten Tieren wurde die Leber im Ganzen entnommen. Dazu wurde das Peritoneum mit einem queren Oberbauchschnitt eröffnet, die zu- und abführenden Gefäße gekappt, die Ligamenta durchtrennt und die Leber herauspräpariert. Auf $-20{ }^{\circ} \mathrm{C}$ wurde das Gewebe gelagert um zu anderer Zeit das Lebergewicht zu bestimmen.

\subsubsection{Studienabläufe}

Drei Arten von Studienentwürfen wurden unterschieden. In kurzen Pilotexperimenten wurden Applikationsform und Verträglichkeit der Substanzen überprüft. In drei aufsteigenden Dosierungen wurde therapiert um bei einem biologischen Effekt eine Dosis-Wirkungs-Beziehung zu erstellen. Im „Proof-of-Principle Paradigm“ begann die Therapie vor Auftreten der ersten Krankheitssymptome. Zu unterscheiden ist dieses von dem „Clinical Paradigm“ mit spätem Behandlungsbeginn, wenn -vergleichbar mit der Situation von Patienten zur Diagnosestellung und Therapiebeginn- erste Symptome nachzuweisen waren. 


\subsubsection{Pilotexperiment mit T0901317}

Gruppen von 5 CMT-Ratten im Alter von vier Wochen wurden über 5 Tage täglich durch Schlundsondierung von 5, 20 und $50 \mathrm{mg} / \mathrm{kg}$ Körpergewicht (KG) mit dem LXR-Agonisten T0901317 therapiert. Als Kontrollgruppen erhielten 5 CMT-Ratten sowie 5 Wildtyp-Ratten in äquivalenten Volumen das alleinige Vehikel. Zur Gruppeneinteilung, der Stratifizierung, wurden Alter, Geschlecht, Wurfzugehörigkeit und Gewicht beachtet. Geschwistertiere gleichen Alters und gleichen Geschlechts wurden verschiedenen Gruppen zugeteilt. Leichte und schwerere Tiere wurden gleichmäßig auf die Gruppen verteilt. Ausschließlich männliche Tiere wurden behandelt. Nach fünftägiger Therapie wurden den getöteten Tieren zur Analyse Nerven- und Hautgewebe und die Leber entnommen.

\subsubsection{Stratifizierung}

Die Studien wurden stets geblindet und placebokontrolliert vollzogen. Drei homogene Therapiegruppen wurden im Zuge der Stratifizierung gebildet. Dabei fanden Alter, Geschlecht, Wurfzugehörigkeit, Gewicht und im „Clinical Paradigm“ auch der Phänotyp Beachtung. Geschwistertiere gleichen Alters wurden gleichmäßig auf die Gruppen verteilt. Auch Gewichtsunterschiede waren in allen Gruppen gleich vertreten. Bei den Therapiestudien nach dem „Clinical Paradigm“ wurden außerdem zuvor erhobene Phänotypdaten des Griffstärketests bei der Gruppeneinteilung berücksichtigt. Somit erhielt man eine homogene Verteilung stark und schwach betroffener Tiere. In allen Studien wurden ausschließlich männliche Ratten therapiert. Die derart gebildeten Gruppen schafften zum Therapiebeginn gleiche Voraussetzungen. Eine Gruppe CMT-Ratten erhielt die zu überprüfende Substanz (Lonaprisan, Curcumin, ASS oder EPO). Eine weitere Gruppe CMT-Ratten sowie eine Gruppe Wildtyp-Ratten bekam in äquivalentem Volumen als Placebo das alleinige Vehikel verabreicht.

\subsubsection{Lonaprisan-Therapiestudie nach dem „Proof-of-Principle Paradigm“}

CMT-Ratten wurden ab dem Alter von 5 Tagen über 7 Wochen täglich durch subkutane Injektionen in der Dosis $50 \mathrm{mg} / \mathrm{kg}$ KG behandelt. Eine Gruppe von 15 CMT-Ratten erhielt den 
PA Lonaprisan. Als Kontrollegruppen erhielten 15 weitere CMT-Ratten und 15 WildtypRatten das Vehikel. Im Alter von 3, 4 und 7 Wochen wurde zur Phänotypanalyse der Stangentest durchgeführt, zum Ende der Therapie zusätzlich der Griffstärketest und elektrophysiologische Messungen. Im Verlauf der Therapie und an deren Ende wurden biologische Materialien für weitere Analysen präpariert (Abbildung 4).

\begin{tabular}{|l|lllll|}
\hline & \\
\hline
\end{tabular}

\begin{abstract}
Abbildung 4: Synopsis der Lonaprisan-Therapiestudie nach dem „Proof-of-Principle Paradigm“
Fünf Tage alte Tiere wurden für 7 Wochen mit Lonaprisan therapiert. Eie Schwanzbiopsie wurde zu Beginn sowie einmalig während laufender Therapie entnommen. Nach 3-, 4- und 7-wöchiger Therapie wurde der Phänotyp mit dem Stangentests analysiert, zum Endzeitpunkt noch zusätzlich durch den Griffstärketest und elektrophysiologische Messungen. Nach 7wöchiger Therapie wurden die Tiere getötet, um biologische Materialien für weitere Analysen zu sammeln.
\end{abstract}

\title{
2.2.7. Therapiestudie mit Curcumin, Acetylsalicylsäure und Erythropoetin nach dem ,Clinical Paradigm“
}

Therapiebeginn erfolgte im Alter von 4 Wochen. Im Alter von 3 Wochen wurde mit dem Griffstärketest Phänotypdaten zur Stratifizierung erhoben. Die zu prüfende Substanz Curcumin wurde mit einem speziellen Futter oral verabreicht. Acetylsalicylsäure und Erythropoetin wurden intraperitoneal jeden zweiten Tag injiziert, ASS in der Dosis $20 \mathrm{mg} / \mathrm{kg} \mathrm{KG}$ und EPO mit 5000 IE/kg KG. Prüfsubstanz- sowie Placebo-Kontrollgruppen enthielten je 15 CMTRatten. Die Gruppen der Wildtyp-Kontrolltiere waren je 12 Tiere stark. Die Erythropoetin- 
Therapie betrug 6 Wochen, ASS und Curcumin wurde für 12 Wochen verabreicht. Alle 3 Wochen wurde zur Phänotypanalyse der Griffstärketest durchgeführt. Am Ende der Therapie wurden zusätzlich elektrophysiologische Messungen vollzogen und Gewebe zur weiteren Analyse präpariert (Abbildung 5).

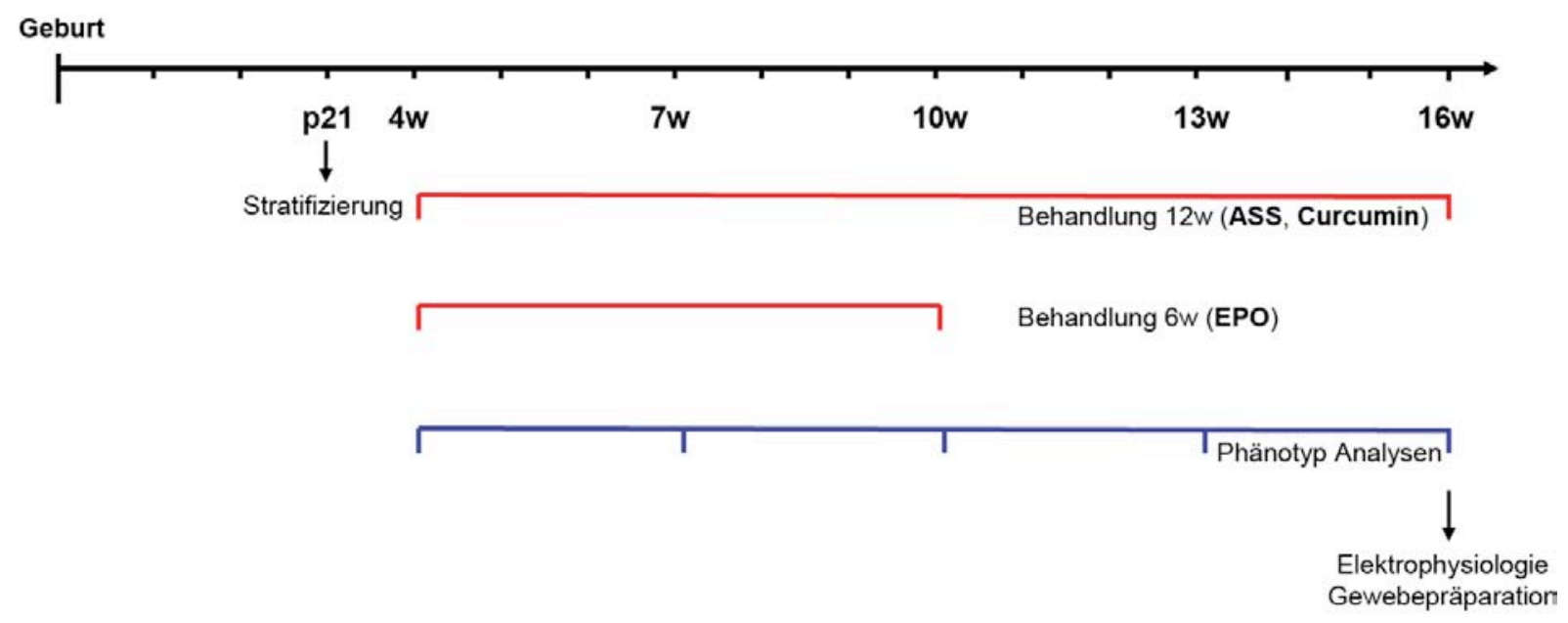

\begin{abstract}
Abbildung 5: Synopsis der Therapiestudie mit Curcumin, Acetylsalicylsäure und Erythropoetin nach dem ,Clinical Paradigm“

Vier Wochen alte Tiere wurden für 3 Monate mit Acetylsalicylsäure oder Curcumin therapiert. Erythropoetin wurde 6 Wochen verabreicht. Eine Schwanzbiopsie wurde zu Beginn sowie nach 3-wöchiger Therapie entnommen. Alle drei Wochen wurde durch den Griffstärketest der Phänotyp analysiert. Nach vollendeter Therapie wurden zusätzlich elektrophysiologische Messungen vollzogen, anschließend wurden biologische Materialien für weitere Analysen präpariert.
\end{abstract}

\title{
2.2.8. Medikamentenanmischung
}

Als Vehikel zur subkutanen Injektion von Lonaprisan diente Sesamöl und Benzylbenzoat im Verhältnis 9:1. Zur intraperitonealen Injektion wurde EPO in der Injektionslösung Eprex angesetzt; ASS in Wasser für Inkjektionszwecke und 0,9 \% NaCl-Lösung. Die Injektionsvolumina wurden gemäß den Empfehlungen der Deutschen Gesellschaft für Versuchstierkunde festgelegt.

Das Gewürzextrakt Curcumin wurde im Verhältnis 1:6 dem Rattenfutter zugesetzt. Die Herstellung, Mischung und Pelletierung dieses Prüffutters geschah durch die Firma Sniff Spezialdiäten GmbH, Soest. Neben der Reinsubstanz Diferuloylmethan enthält das Gewürzextrakt, bzw. das Prüffutter auch die weiteren Bestandteile. Zur Vereinfachung wird im Folgenden stets von Curcumin gesprochen. 


\subsubsection{Stangentest}

Vornehmlich mit jungen Ratten wurde der Stangentest durchgeführt. Eine horizontale Stange mit einem Durchmesser von $15 \mathrm{~mm}$ bei drei Wochen alten Tieren, bzw. $25 \mathrm{~mm}$ Durchmesser bei fünf und sieben Wochen alten Tieren wurde über einer, mit weichem Käfigeinstreu ausgelegten Fläche befestigt. In 5 Versuchen wurden die Tiere auf die Stange gesetzt und dabei
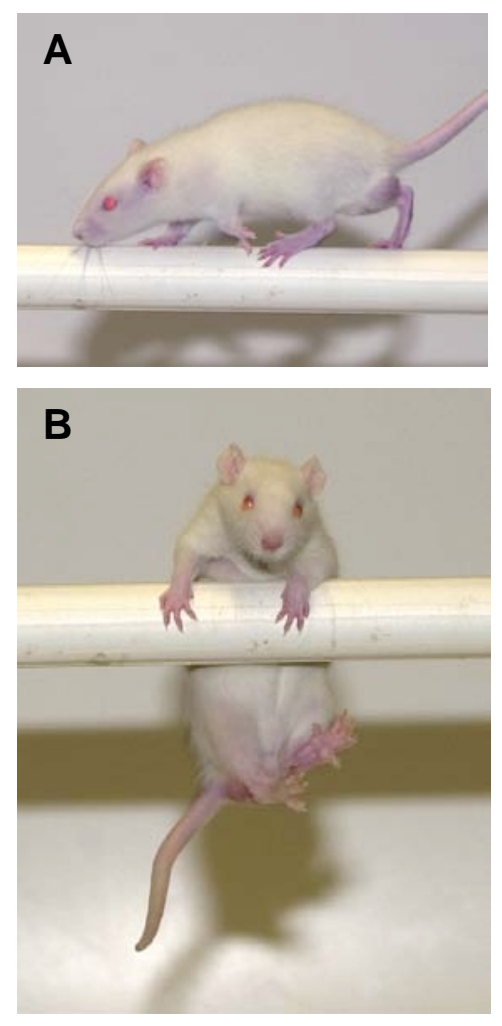

jeweils die Zeit gemessen, die sie sich oben halten konnten. Die maximale Zeit eines Versuchs wurde auf $240 \mathrm{~s}$ festgelegt. Aufgrund der Notwendigkeit zur Eingewöhnung wurde zur statistischen Auswertung lediglich aus den Zeiten der letzten drei Versuche der Mittelwert genommen (Abbildung 6).

\footnotetext{
Abbildung 6: Stangentest

Fünfmalig werden die Ratten auf die Stange gesetzt. Es wurde jeweils die Zeit gemessen, bis sie herabfielen. Beendet wurden die Versuche nach 240 s. Der Mittelwert der Haltezeit der Versuche 3 - 5 wurde für die statistische Auswertung verwandt. Die Bilder wurden freundlicherweise von Herrn Dr. Thomas Prukop, Max-Planck-Institut für Experimentelle Medizin Göttingen, zur Verfügung gestellt.
} 


\subsubsection{Griffstärketest}

Ältere Tiere wurden durch den Griffstärketest untersucht. Dazu wurden die Tiere am Schwanz gehalten passiv über eine mit einem Newtonmeter verbundene T-Stange gezogen. Die Tiere krallten sich an der T-Stange fest und ließen erst los, als ihre maximale Griff- und Haltestärke erreicht war. Mit dem Newtonmeter wurde diese erfasst. Für die Vorder- und Hinterläufe wurde die Messung fünfmal vollzogen und anschließend der Mittelwert für die jeweiligen Läufe ermittelt (Abbildung 7). Grundsätzlich wurde bei jeder Phänotypisierungsrunde das Gewicht der Tiere dokumentiert.
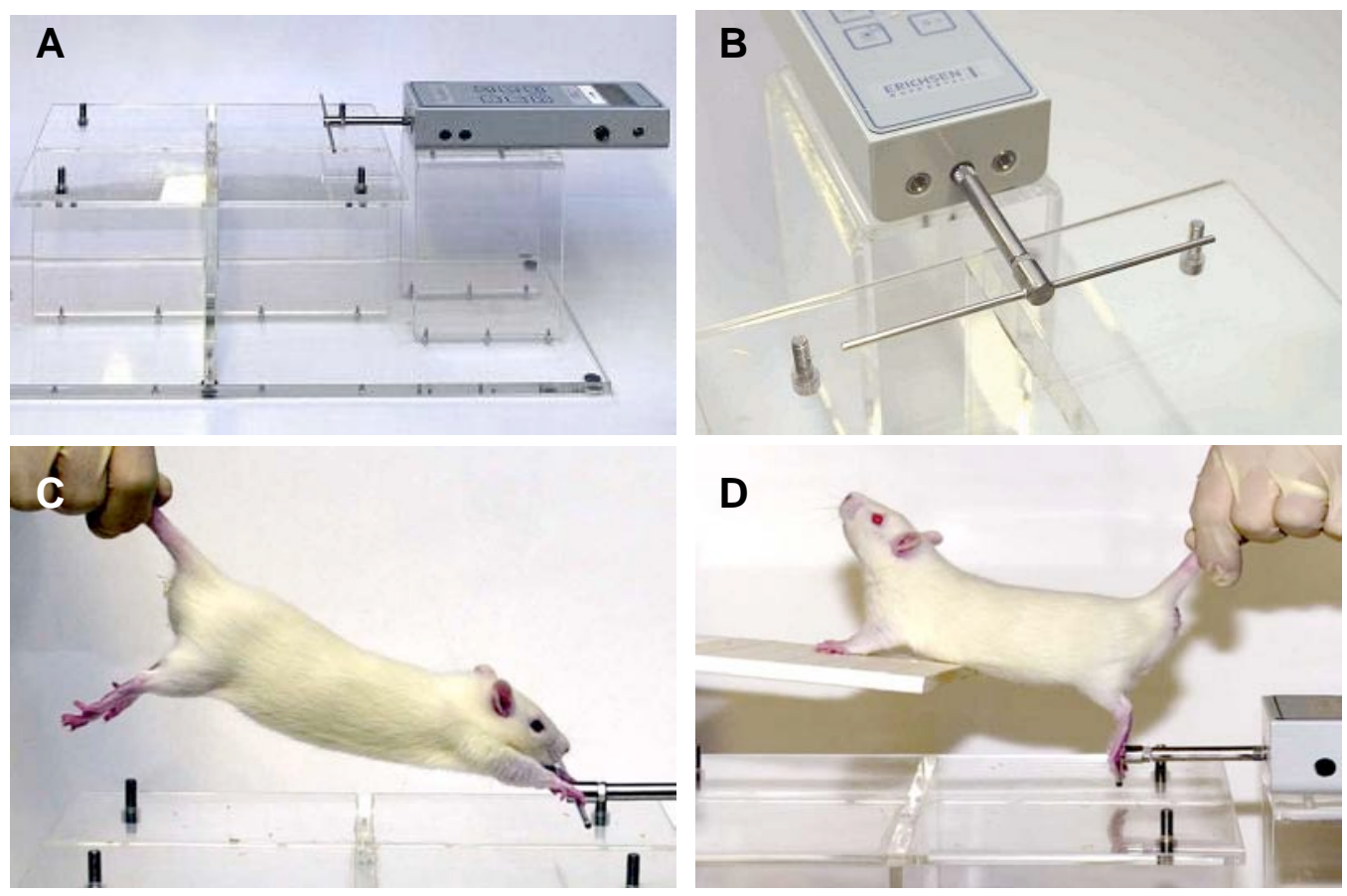

\section{Abbildung 7: Griffstärketest}

Das Newtonmeter registriert die maximale Zug- und Druckkraft an der angeschlossenen T-Stange (A, B). Zur Durchführung des Griffstärketests wird die am Schwanz gehaltene Ratte passiv über die T-Stange gezogen. Dabei greift sie sich reflektorisch fest und lässt die Stange erst wieder frei, wenn ihre maximale Kraft, sich zu halten, erreicht ist. Für Vorder- wie Hinterläufe wird dieser Test jeweils fünfmal vollzogen. Die Bilder wurden freundlicherweise von Herrn Dr. Thomas Prukop, MaxPlanck-Institut für Experimentelle Medizin Göttingen, zur Verfügung gestellt. 


\subsubsection{Elektrophysiologische Messungen}

Die elektrophysiologischen Messungen wurden in Zusammenarbeit mit Herrn Dipl.-Biol. Robert Fledrich durchgeführt. Der Untersucher war bezüglich des Genotyps und der Behandlungsgruppe der Tiere geblindet, stand somit zu keiner Zeit darüber in Kenntnis. Die Messungen erfolgten unter Vollnarkose. Gemäß der Narkoseempfehlung der Deutschen Gesellschaft für Versuchstierkunde wurden die Tiere durch eine Injektion mit 5 mg/kg KG Ketamin (Ketanest $^{\circledR}$ ) und $2 \mathrm{mg} / \mathrm{kg} \mathrm{KG} \mathrm{Xylazin}\left(\right.$ Rompun $^{\circledR}$ ) narkotisiert und analgesiert. Um ein Auskühlen der Tiere zu vermeiden wurden die Tiere auf eine Heizdecke gebettet und die rektal gemessene Körperkerntemperatur wurde überwacht. Mit dem Jaeger-Toennis Neuroscreen wurden Nervenleitgeschwindigkeit (NLG) und Muskelsummenaktionspotentiale (CMAP) am Schwanz der Tiere gemessen.

Die CMAPs wurden durch elektrische Stimuli von 0,1 Millisekunden an den Schwanznerven der Tiere ausgelöst. Abgeleitet wurden sie von subkutan platzierten Elektroden. Die Amplitude zwischen größtem und kleinstem Ausschlag wurde gemessen.

Zur Berechnung der NLG wurden zwei Reizungen der Nerven im Abstand von $2 \mathrm{~cm}$ ausgelöst. Eine Elektrode wurde zur Detektion platziert. Anhand der Differenz beider hintereinander eintreffenden Signale wurde die NLG durch das Gerät automatisch berechnet.

\subsubsection{Blutanalysen}

Unmittelbar nach dem Ableben der Tiere wurde nach schneller Eröffnung des Thorax Blut aus der linken Arteria renalis entnommen. Zur Hämatokritbestimmung wurde am Ende der EPO-Therapiestudie in einer Mikro-Hämatokritkapillare (Brand, Wertheim, Germany) die Probe 5 min bei 10000 rpm zentrifugiert. Eine zelluläre (zu $96 \%$ bestehend aus Erythrozyten) und aquatische Phase bildete sich und ermöglichte das Ablesen des Hämatokritwertes. Zum Ausschluss einer Antikörperbildung gegen EPO wurde durch Herrn Dr. Arno Kromminga, IPM Biotech (Hamburg, Germany), ein Enzyme-linked Immunosorbent Assay (ELISA) durchgeführt. 


\subsubsection{Berechnung der humanen Äquivalenzdosis unter Normalisie- rung auf die Körperoberfläche}

Für eine adäquate Umrechnung der in der tierexperimentellen Studie gebrauchten Dosis in eine humane Äquivalenzdosis (HED) eignet sich die Körperoberflächen- Normalisierungsmethode. Die Körperoberflächen (body surface area, BSA) verschiedener Säugetierspezies korreliert gut mit biologischen Parametern, wie Sauerstoffausnutzung, Energieverbrauch, metabolischer Grundumsatz, Blutvolumen, zirkulierende Plasmaproteine und Nierenfunktion (Reagan-Shaw et al. 2008). Die Körperoberfläche verschiedener Spezies, wie auch ein spezifischer Multiplikationsfaktor, der $\mathrm{Km}$-Faktor werden zur Berechnung herangezogen. Der $\mathrm{Km}$ Faktor ist definiert als der Quotient des durchschnittlichen Körpergewichts [kg] und der Körperoberfläche $\left[\mathrm{m}^{2}\right]$ einer Spezies (Abbildung 8).

$$
K m\left[\mathrm{~kg} / \mathrm{m}^{2}\right]=\frac{K \ddot{o r p e r g e w i c h t}[\mathrm{~kg}]}{B S A\left[\mathrm{~m}^{2}\right]}
$$

Die Formel zur Errechnung der humanen Äquivalenzdosis [mg/kg] lautet wie folgt:

$$
H E D[m g / k g]=\text { Tierdosis }[m g / k g] \times \frac{\text { Tierspezies } K m\left[\mathrm{~kg} / \mathrm{m}^{2}\right]}{\text { HumanerKm }\left[\mathrm{kg} / \mathrm{m}^{2}\right]}
$$

\begin{tabular}{lclc} 
Species & Weight $(\mathrm{kg})$ & BSA $\left(\mathrm{m}^{2}\right)$ & $K_{m}$ factor \\
\hline Human & & & \\
Adult & 60 & 1.6 & 37 \\
Child & 20 & 0.8 & 25 \\
Baboon & 12 & 0.6 & 20 \\
Dog & 10 & 0.5 & 20 \\
Monkey & 3 & 0.24 & 12 \\
Rabbit & 1.8 & 0.15 & 12 \\
Guinea pig & 0.4 & 0.05 & 8 \\
Rat & 0.15 & 0.025 & 6 \\
Hamster & 0.08 & 0.02 & 5 \\
Mouse & 0.02 & 0.007 & 3 \\
\hline
\end{tabular}

Values based on data from FDA Draft Guidelines (7). To convert dose in $\mathrm{mg} / \mathrm{kg}$ to dose in $\mathrm{mg} / \mathrm{m}^{2}$, multiply by $K_{m}$ value.

\footnotetext{
Abbildung 8: Km-Faktoren verschiedener Spezies zur Berechnung der Humanen Äquivalenzdosis Durchschnittliches Körpergewicht und Körperoberfläche (BSA) und die daraus zu resultierenden $\mathrm{Km}$-Faktoren verschiedener Spezies (Reagan-Shaw et al. 2008, S. 660).
} 


\subsubsection{Berechnung der humanen Äquivalenzdosis der Lonaprisan-Therapie}

Die Berechnung der Humanen Äquivalenzdosis (HED) nach der KörperoberflächenNormalisierungsmethode erfolgte nach der Gleichung:

$H E D[m g / k g]=$ Tierdosis $[m g / k g] \times \frac{\text { Tierspezies } K m\left[\mathrm{~kg} / \mathrm{m}^{2}\right]}{\text { HumanerKm }\left[\mathrm{kg} / \mathrm{m}^{2}\right]}$

$H E D=50 m g / \mathrm{kg} \times \frac{6 \mathrm{~kg} / \mathrm{m}^{2}}{37 \mathrm{~kg} / \mathrm{m}^{2}}=8,1 \mathrm{mg} / \mathrm{kg}$

Die den Ratten täglich applizierte Dosis von $50 \mathrm{mg} / \mathrm{kg} \mathrm{KG}$ entspricht somit einer äquivalenten humanen Dosis von ca. 8 mg/kg KG. Für einen durchschnittlich schweren Erwachsenen (60 $\mathrm{kg}$ ) liegt die Dosis bei knapp $500 \mathrm{mg}$.

\subsubsection{Berechnung der Curcumin-Reindosis und humanen Äquivalenzdosis der Curcumin-Therapie}

Ein mit 16,6 \% Curcumin-Gewürzextrakt versetztes Prüffutter wurde den Ratten verabreicht. Der Anteil puren Curcumins (Diferuloylmethan, biologisch aktivste Substanz) am Gewürzextrakt liegt im Mittel bei $3 \%$ (Goel et al. 2008). Folglich enthalten 1000 g Prüffutter 4,98 g pures Curcumin.

Die tägliche Futteraufnahme einer adoleszenten Ratte liegt bei etwa 20 g. Dieser Wert ist aus der Literatur bekannt und konnte durch eigene Messungen auch für die Prüfsubstanz als zutreffend bestätigt werden. Eine etwa $200 \mathrm{~g}$ schwere Ratte erhielt somit 0,0996 g pures Curcumin, was einer täglichen oralen Dosis von $498 \mathrm{mg} / \mathrm{kg} \mathrm{KG}$ entspricht.

$H E D[m g / k g]=$ Tierdosis $[m g / k g] \times \frac{\text { Tierspezies } K m\left[\mathrm{~kg} / \mathrm{m}^{2}\right]}{\text { HumanerKm }\left[\mathrm{kg} / \mathrm{m}^{2}\right]}$

$H E D=498 m g / \mathrm{kg} \times \frac{6 \mathrm{~kg} / \mathrm{m}^{2}}{37 \mathrm{~kg} / \mathrm{m}^{2}}=80,8 \mathrm{mg} / \mathrm{kg}$ 
Die durch das Prüffutter von den Ratten täglich oral aufgenommene Dosis von 498 mg/kg KG entspricht einer humanen Äquivalenzdosis von 80,8 mg/kg KG. Ein durchschnittlich schwerer Erwachsener (60 kg) bekäme dem entsprechend ca. 5 g (4848 mg) pures Curcumin per os appliziert. 


\subsection{Histologische und histochemische Methoden}

\subsubsection{Kunstharzeinbettung und Semidünnschnitte}

Die in K\&S fixierten Nerven wurden mittig senkrecht zerteilt. Um ein Wiedererkennen dieser Region sicherzustellen wurden die Enden durch Schnitte im $45^{\circ}$ Winkel gekennzeichnet. Die Epon Kunstharzeinbettung erfolgte nach Luft (Luft 1961).

In speziellen Körbchen des Einbettautomaten Leica EM TP wurden die Nerventeile platziert, und automatisiert nach folgendem Schema in den verschiedenen Lösungen der Einbettung geschwenkt:

$\begin{array}{lll}\text { Reagenz } & \text { Dauer } & \text { Temperatur } \\ \text { 1. Puffer } & 15 \mathrm{~min} & 4{ }^{\circ} \mathrm{C} \\ \text { 2. } 2 \% \text { OsO4 } & 4 \mathrm{~h} & 4{ }^{\circ} \mathrm{C} \\ \text { 3. A. dest. } & 20 \mathrm{~min} & \text { Raumtemperatur (RT) } \\ \text { 4. A. dest. } & 20 \mathrm{~min} & \mathrm{RT} \\ \text { 5. A. dest. } & 20 \mathrm{~min} & \mathrm{RT} \\ \text { 6. } 30 \% \text { Ethanol } & 30 \mathrm{~min} & \mathrm{RT} \\ \text { 7. } 50 \% \text { Ethanol } & 30 \mathrm{~min} & \mathrm{RT} \\ \text { 8. } 70 \% \text { Ethanol } & 30 \mathrm{~min} & \mathrm{RT} \\ \text { 9. } 90 \% \text { Ethanol } & 30 \mathrm{~min} & \mathrm{RT} \\ \text { 10. } 100 \% \text { Ethanol } & 15 \mathrm{~min} & \mathrm{RT} \\ \text { 11. } 100 \% \text { Ethanol } & 15 \mathrm{~min} & \mathrm{RT} \\ \text { 12. } 100 \% \text { Ethanol } & 15 \mathrm{~min} & \mathrm{RT} \\ \text { 13. } 100 \% \text { Ethanol } & 15 \mathrm{~min} & \mathrm{RT} \\ \text { 14. Propylenoxid } & 15 \mathrm{~min} & \mathrm{RT} \\ \text { 15. Propylenoxid } & 15 \mathrm{~min} & \mathrm{RT} \\ \text { 16. Propylenoxid } & 15 \mathrm{~min} & \mathrm{RT} \\ \text { 17.Propylenoxid/Epon } 2: 1 & 2 \mathrm{~h} & \mathrm{RT} \\ \text { 18. Propylenoxid/Epon } 1: 1 & 2 \mathrm{~h} & \mathrm{RT} \\ \text { 19. Propylenoxid/Epon } 1: 2 & 4 \mathrm{~h} & \mathrm{RT} \\ \text { 20. Epon rein } & 4 \mathrm{~h} & \mathrm{RT} \\ & & \end{array}$

Nach $21 \mathrm{~h}$ waren die Gewebeproben vollständig von Epon infiltriert. In Silikonförmchen wurden sie anschließend mit der zu analysierenden Seite (senkrechte Schnittkante) nach auBen platziert und mit Epon übergossen. Der nach $24 \mathrm{~h}$ bei $60{ }^{\circ} \mathrm{C}$ polymerisierte Eponblock wurde mit dem Trimmer Leica EM Trim in Pyramidenform geschliffen, um sich dem zu ana- 
lysierenden Nervenende anzunähern. Mittels Rotationsmikrotom Reichert Ultracut S wurden $0,5 \mu \mathrm{m}$ semidünne Nervenquerschnitte erstellt, die auf einem Objektträger transferiert und für eine Stunde bei $60{ }^{\circ} \mathrm{C}$ getrocknet wurden.

\subsubsection{Färbung, Mikroskopie und Quantifizierungen myelinisierter und un- physiologisch unmyelinisierter Axone und der Myelindicke}

Die Semidünnschnitte wurden zur Darstellung der Axone, Myelinscheiden und Schwannzellen mit Methylen-Azur-II (Richardson et al. 1960) gefärbt. Im Verhältnis 1:1 wurde eine Methylenblau- und eine Azur-II-Stammlösung zur Gebrauchslösung gemischt, filtriert und auf die Schnitte gegeben. Nach einminütiger Inkubation wurde die überschüssige Färbelösung mit destilliertem Wasser abgespült für 10 min bei $60{ }^{\circ} \mathrm{C}$ getrocknet und mit dem histologischen Einschlussmittel Eukitt eingedeckt. Zur lichtmikroskopischen Analyse der Nerven wurden Aufnahmen in 100-facher Vergrößerung erstellt. Die Bilder wurden mit dem Mikroskop Leica DM RXA2 mit angeschlossener Videomikroskopiekamera erstellt. Zur weiteren Verarbeitung wurde Photoshop 10.0.1 verwendet.

Die 100-fach vergrößerten Bilder wurden mit dem Programm Image J. 1.40g analysiert. Der Untersucher war zu keiner Zeit im Bilde des Phänotyps noch der Therapiegruppe. Quantifiziert wurde die Anzahl der Axone eines Nervenquerschnittes mit einem Durchmesser von >1 $\mu \mathrm{m}$, welche den Erwartungen nach myelinisiert sein sollten. Dabei wurde unterschieden zwischen normal myelinisierten und unphysiologisch unmyelinisierten Axonen. Das g-Ratio wurde als Maß für die Myelindicke bestimmt. Das g-Ratio als der Quotient aus innerem und äußerem Umfang der Myelinscheide wurde von 100 zufällig ausgewählten Axonen pro Nerv bestimmt.

\subsubsection{Erstellen von Gefrierschnitten, Färbung und Mikroskopie von alpha- Motoneuronen in Rückenmarksquerschnitten}

Die Erstellung von Rückenmarksquerschnitten und die Quantifizierung der alphaMotoneurone wurden von Herrn Dipl.-Biol. Robert Fledrich durchgeführt. Von den in Shan- 
don Cryomatrix ${ }^{\mathrm{TM}}$ eingebetteten Rückenmarksproben wurden mit einem Kryostaten Leica Jung Cryocut $10 \mu \mathrm{m}$ dicke, horizontale Gefrierschnitte erstellt. Die Schnitte wurden auf einen Superfrost ${ }^{\circledR}$ Objektträger transferiert und bei Raumtemperatur getrocknet. Zur Darstellung der alpha-Motoneurone wurden die Schnitte nach Nissl mit Kresylviolett gefärbt. Die Zellorganellen und Perikarya stellten sich somit kräftig violett dar. Dazu wurden die Schnitte vorerst in einer Entfetterlösung $10 \mathrm{~min}$ gewaschen und durchliefen anschließend die absteigende Ethanolreihe von $100 \%, 90 \%, 70 \%, 50 \%$, jeweils 2 min. Dann wurde 5 min in 0,5\% Kresylviolett gefärbt. Nach einem 30 min Diferenzierungsschritt in $1 \%$ Essigsäure wurde in destilliertem Wasser gewaschen und in der aufsteigenden Ethanolreihe 30 \%, 70 \%, 90 \%, 100 $\%$ jeweils 2 min entwässert. Die dehydrierten und fertig gefärbten Schnitte wurden mit dem Kleber Eukitt eingedeckt.

Die eingedeckten Schnitte wurden mit dem Mikroskop Leica DM RXA2 in 20-facher Vergrößerung fotografiert und die Einzelbilder mit Photoshop 10.0.1 zusammengefügt. Jeweils 20 horizontale Rückenmarksschnitte pro Tier wurden analysiert, wobei der Abstand zwischen den einzelnen Schnitten groß genug war um Doppeltzählungen auszuschließen. Die in den Vorderhörnern des Rückenmarks gelegenen alpha-Motoneurone wurden mit der Software Image J. 1.40g quantifiziert. Pro Gruppe wurden 3 Tiere analysiert; Wildtyptiere, Placebound Prüfsubstanz-behandelte transgene Ratten.

\subsubsection{Paraffineinbettung und Immunhistologie von Nervenquerschnitten mit Quantifizierung der intraneuralen Makrophagen}

Die in Paraformaldehyd immersionsfixierten Tibialisnerven wurden in dem Gewebeinfiltrationsautomaten MICROM HMP 110 nach folgendem Schema von Paraffin infiltriert: 


$\begin{array}{ll}\text { Reagenz } & \text { Dauer } \\ \text { 1. } 50 \% \text { Ethanol } & 1 \mathrm{~h} \\ \text { 2. } 70 \% \text { Ethanol } & 2 \mathrm{~h} \\ \text { 3. } 70 \% \text { Ethanol } & 2 \mathrm{~h} \\ \text { 4. } 96 \% \text { Ethanol } & 1 \mathrm{~h} \\ \text { 5. } 96 \% \text { Ethanol } & 1 \mathrm{~h} \\ \text { 6. } 100 \% \text { Ethanol } & 1 \mathrm{~h} \\ \text { 7. } 100 \% \text { Ethanol } & 1 \mathrm{~h} \\ \text { 8. Isopropanol } & 1 \mathrm{~h} \\ \text { 9. Xylol } & 2 \mathrm{~h} \\ \text { 10. Xylol } & 2 \mathrm{~h} \\ \text { 11. Paraffin } & 2 \mathrm{~h} \\ \text { 12. Paraffin } & 2 \mathrm{~h}\end{array}$

Anschließend wurden die Nerven zentral in zwei Hälften zerteilt um an der Schnittkante eine standardisierte Analyse zu gewährleisten. Mit dieser Schnittkante nach außen wurden sie mit der Ausgießstation MICROM AP 280 in Paraffinblöcke gegossen. Mit dem Schlittenmikrotom MICROM HM 400 wurden Querschnitte einer Dicke von $10 \mu \mathrm{m}$ erstellt und zur weiteren Färbung auf Superfrost ${ }^{\circledR}$ Objektträger übertragen.

Makrophagen wurden mit dem Antikörper ED1 immunhistochemisch gefärbt. ED1 bindet ein makrophagenspezifisches Antigen entsprechend dem humanen CD68. Die Färbung erfolgte nach der indirekten Methode mit Primärantikörper, biotinylierten Sekundärantikörper und Avitin-Biotin-Enzymkomplex zur Signalverstärkung.

Zur Entparaffinierung wurden die Objektträger der Nervenquerschnitte für $30 \mathrm{~min}$ in Xylol inkubiert. Anschließend durchliefen sie für jeweils 2 min eine absteigende Ethanolreihe von $100 \%, 90 \%, 70 \%, 50 \%$ mit darauffolgenden 5 min Spülschritten in destilliertem Wasser und Trispuffer mit $2 \%$ Milchpulver (TBS+M). Um unspezifische Hintergrundfärbungen zu vermeiden wurden die Schnitte schließlich 30 min mit $10 \%$ Rinderserumalbumin geblockt. Nach dekantieren der Blockerlösung wurden $100 \mu \mathrm{l}$ des 1:500 in $1 \%$ Rinderserumalbumin verdünnten Primärantikörpers ED1 auf die Nervenquerschnitte pipettiert. Nach einstündiger Inkubation wurde überschüssiger Antikörper in drei fünfminütigen Spülschritten mit TBS+M entfernt. Zur Vermeidung unspezifischer Färbungen des später verwendete Chromogens 3,3'Diaminobenzidine wurde die endogene Peroxidase mit 9:1 Methanol und 30\% Wasserstoffperoxid geblockt. Nach erneuten Spülschritten wurde der Sekundärantikörper aus biotinyliert Goat anti-mouse IgG, 1:100 in 1\% Rinderserumalbumin für 45 min hinzugegeben und an- 
schließend gespült. An den biotinylierten Sekundärantikörper werden enzymmarkierte Avidin-Biotin-Komplexe (Vectastain ${ }^{\circledR}$ Elite $^{\circledR}$ ABC Peroxidase KIT, PK-6100) durch 30 min Inkubation gebunden und anschließend mit TBS ohne Milchpulver abgespült. Diese Komplexe führen im Folgenden zur Umwandlung des Chromogens. Mit dem 3,3'-Diaminobenzidine Chromogen werden die Schnitte für 8 min inkubiert, bevor die Farbreaktion in destilliertem Wasser gestoppt wurde.

Zur Gegenfärbung wurden die immunhistochemisch gefärbten Nervenquerschnitte mit einer Hämatoxylin-Färbung kontrastiert. Die Kerne färbten sich dadurch blau. Dazu wurden die Schnitte $30 \mathrm{~s}$ in saurem Hämalaun (Mayer 1891) gefärbt. Es folgte ein kurzer Spülschritt in destilliertem Wasser, einmaliges Eintauchen in HCL-Alkohol und ein fünfminütiger Spülschritt in Scott's Lösung. Zum Schluss wurde für jeweils 2 min durch die aufsteigende Ethanolreihe in $30 \%, 70 \%, 90 \%, 100 \%$ dehydriert. Die fertigen Schnitte wurden mit dem Kleber Eukitt eingedeckt.

Die eingedeckten Schnitte wurden in 40-facher Vergrößerung fotografiert und die Einzelbilder mit Photoshop 10.0.1 zusammengefügt. In drei Nervenquerschnitten pro Tier wurden die endoneuralen Makrophagen quantifiziert. Dabei wurden Primärantikörper positive Schnitte mit Negativkontrollen ohne Primärantikörper verglichen. Jeweils von 5 Tieren pro Gruppe, Wildtyptiere, Placebo- und Prüfsubstanz-behandelte transgene Ratten, wurden die endoneuralen Makrophagen quantifiziert. Verwendet wurde dazu die Software Image J. 1.40g.

\subsection{Molekularbiologische Methoden}

\subsubsection{Isolation genomischer DNA}

Zur Bestimmung des Genotyps der Versuchstiere wurden Schwanzbiopsien der Ratten molekularbiologisch analysiert.

Nach dem Protokoll des Herstellers wurde mit dem „DNeasy 96“ Kit von Quiagen DNA aus den Biopsien isoliert. Dazu wurde die Biopsie mit $180 \mu$ l ALT Puffer und $20 \mu$ l Proteinase K versetzt. Nach gründlichem Mischen und einem einminütigen Zentrifugationsschritt (3000 $\mathrm{rpm}$ ) in einer Zentrifuge $4 \mathrm{~K} 15 \mathrm{C}$ wurde der Ansatz zur Lyse durch die Proteinase $\mathrm{K}$ bei $55^{\circ} \mathrm{C}$ 
über Nacht gelagert. Anschließend wurden zur Verdünnung $400 \mu \mathrm{l}$ Puffer AL/E hinzugegeben und nach kurzem Mischen für eine Minute zentrifugiert (3000 rpm). Der entstandene Überstand von ca. $900 \mu \mathrm{l}$ wurde auf die Silicamembran der DNeasy Säulchen pipettiert. Mit einem „Air Pore Tape Sheet“ wurde die DNeasy Platte verschlossen und für 10 min zentrifugiert (6000 rpm). Es folgten zwei Spülschritte mit $500 \mu \mathrm{l}$ AW1 Puffer und $500 \mu \mathrm{l}$ AW2 Puffer, wobei jeweils 5 min zentrifugiert wurde (6000 rpm). Nach einer 15 min Inkubation der DNeasy Platte bei $60{ }^{\circ} \mathrm{C}$ wurde die an die Silicamembran der Säulchen gebundene DNA eluiert. Dazu wurde die Säule in zwei Schritten zuerst mit $200 \mu l$ anschließend mit $100 \mu 1$ vorgewärmten $\mathrm{AE}$ Puffer für 5 min bei $60{ }^{\circ} \mathrm{C}$ inkubiert und für $2 \mathrm{~min}$ zentrifugiert (6000 rpm). Die eluierte DNA wurde bei $4{ }^{\circ} \mathrm{C}$ gelagert.

\subsubsection{Isolation von RNA aus Ischiasnerven und Hautgewebe}

Das „RNeasy Mini Kit“ von Quiagen wurde verwendet. Je nach Gewebeart unterschied sich das Protokoll.

Zur Isolation aus Ischiasnerven nach dem Protokoll für fettige Gewebe des „RNeasy Mini Kit“" wurde das Perineurium entfernt um einen möglichst homogenen Gewebetyp zu analysieren.

Die bei $-80{ }^{\circ} \mathrm{C}$ gelagerten Proben wurden noch in gefrorenem Zustand in ein mit $1 \mathrm{ml}$ TRIzol Lysereagenz gefülltes Rundboden-Falconröhrchen transferiert und mit dem Ultraturrax T8 zerkleinert. Um Vermischungen zu vermeiden wurde der Ultraturrax zwischen jeder Probe dreimal $10 \mathrm{~s}$ mit destilliertem Wasser gereinigt. Die Nukleoproteinkomplexe wurden durch einen Inkubationsschritt von 5 min zerlegt. Nach Zugabe von $200 \mu$ l Chloroform wurde die Probe durch einen Vortex gemischt und für $3 \mathrm{~min}$ inkubiert. Es folgte ein Zentrifugationsschritt bei $4{ }^{\circ} \mathrm{C}$ (12000 g). Die somit entstandene obere klare Phase wurde in ein Eppendorfgefäß überführt und mit einer Volumeneinheit $70 \%$ Ethanol vermischt. $700 \mu$ dieses Gemisches wurden nun auf die Silicatmembran der „RNeasy Mini Spin“-Säule übertragen, 15 s bei RT zentrifugiert (8000 g) und der Durchfluss verworfen. Mit dem restlichen Gemisch wurde gleich verfahren. Es folgten zwei Waschschritte mit je $700 \mu \mathrm{RW} 1$ Waschpuffer, Durchflusszentrifugiert für 15 Sekunden $(8000 \mathrm{~g})$. Ein letzter Waschschritt wurde mit $500 \mu \mathrm{l}$ RPE Puffer in Ethanol für 3 min (zentrifugiert bei 8000 g) durchgeführt. Somit wurde sämtliches Ethanol von der Membran entfernt. Anschließend wurde die Säule in das Eppendorfge- 
fäß zur Lagerung überführt. Zur Elution der RNA wurde zweimalig mit jeweils $50 \mu 1$ RNasefreiem Wasser für eine Minute zentrifugiert $(8000 \mathrm{~g})$. Die RNA wurde bei $-80^{\circ} \mathrm{C}$ gelagert.

Die RNA-Isolation aus Hautgewebe erfolgte nach dem Standardprotokoll für tierisches Gewebe des „RNeasy Mini Kit“, Quiagen.

Von den gefrorenen Schwanzbiopsien wurde auf einem Trockeneisblock Hautgewebe abpräpariert und zerkleinert. Die noch gefrorenen Hautstücke wurden in ein mit RLT-Puffer gefülltes Eppendorfgefäß überführt und mit dem Ultraturrax T8 zerkleinert. Zum Absetzten der Zelltrümmer wurde 3 min zentrifugiert (10000 g). Der Überstand wurde in einem Eppendorfgefäß überführt und mit einer Volumeneinheit $70 \%$ Ethanol versetzt. Die folgenden Schritte entsprechen dem des oben beschriebenen Vorgehens.

\subsubsection{Bestimmung von Qualität und Quantität der RNA}

Die aus Haut- und Nervengewebe isolierte RNA wurde im „Agilent Bioanalyzer“ mit dem RNA 600 Nano Assay untersucht.

Das Prinzip basiert auf einer kapillaren Elektrophorese auf einem Chip, bei der nur geringe Mengen an RNA ( $1 \mu \mathrm{L}$ Probe, ca. 50 pg RNA) benötigt werden. Es wird das Laufmuster der zu analysierenden RNA (Proben-RNA) mit einer Standard-RNA verglichen. Auf etwaige Degradierung oder Kontamination kann somit untersucht werden (Abbildung 11). Maßgeblich die ribosomale RNA (90 \% der Gesamt-RNA) wird dabei vermessen. Die durch das in der Kapillare befindliche Gel laufende RNA bindet dort einen fluoreszenten Farbstoff. Durch diesen eingelagerten Fluoreszenzfarbstoff lassen sich die Komponenten nachweisen und in gelartige Bilder (Banden) und Elektropherogramme (Peaks) übersetzten. Ein genügend aufgereinigtes RNA-Extrakt liefert dabei in der Elektrophorese zwei intensive scharfe Banden, entsprechend der beiden $18 \mathrm{~S}$ und $28 \mathrm{~S}$ Hauptbestandteile der ribosomalen RNA (Abbildung 11 A). Der Vergleich der fluoreszenten Signalintensitäten von Proben-RNA und Referenz-RNA (RNA-Leiter) bekannter Konzentration ermöglicht die Bestimmung der Konzentration.

Analysiert wurde nach dem Protokoll des Herstellers. Es wurden $400 \mu$ RNA-Gelmatrix in einer Tischzentrifuge zentrifugiert (2500 rpm), anschließend $130 \mu$ l RNA-Farbstoff hinzugefügt. $9 \mu \mathrm{l}$ dieses Gel-Farbstoff-Gemisches wurden in der Gelladestation (Agilent Technologies) in die Kapillaren eines RNA-Chips gepresst, ein Nano Marker als Ausrichtungsreferenz 
des kapillären Gels sowie die RNA-Leiter als RNA-Größen- und Mengenreferenz wurden hinzugegeben.

Die Integrale der fluoreszenten Signale der $18 \mathrm{~S}$ und $28 \mathrm{~S}$ RNA (Abbildung $11 \mathrm{~B}$ ) wurden mit dem optimalen Verhältnis von 28S/18S = 2,1 verglichen. Eine Degradierung der RNA würde zu einer Dispersion beider RNA-Zacken führen, während Verunreinigungen der Probe Signale mit hoher Retentionszeit liefern.

\subsection{4. cDNA-Synthese durch Reverse Transkription}

Die aus Haut oder Nervengewebe isolierte RNA wurde mit dem „Superscript-III-RT“ Kit (Invitrogen) in cDNA umgeschrieben. 500 ng dienten als Transkript. Um im Folgenden die Transkription von Genen zu analysieren wurden zur cDNA-Synthese Primer mit einem PolyT-Schwanz (dT-Primer, 0,6 $\mu \mathrm{M}$ ) verwendet um spezifisch Boten-RNA (mRNA) mit einem Poly-A-Schwanz umzuschreiben. Zur Erhöhung der Effizienz wurden zusätzlich randomisierte Nonamer-Primer (N9-Primer, $120 \mu \mathrm{M}$ ) verwendet. Die Umschreibung erfolgte damit unidirektional (sense) und auch in die Gegenrichtung (antisense).

Der Reaktionsansatz enthielt: $1 \mu \mathrm{l}$ dT- und N9-Primer und 500 ng RNA-Transkript. Nach zweiminütiger Inkubation bei $70{ }^{\circ} \mathrm{C}$ (Annealing) wurden die Ansätze auf Eis zwischengelagert und mit dem Reaktionsmix aus $12 \mu \mathrm{l}$ 5-fach konzentriertem „1 ${ }^{\text {st }}$ Strand“-Puffer, $6 \mu 1$ Dichlordiphenyltrichlorethan (DDT, $100 \mathrm{mM}), 3 \mu \mathrm{l}$ gemischte Nukleotide $(10 \mathrm{mM})$ sowie 1 $\mu 1$ „Superscript-III“-Polymerase mit einer Wechselzahl von $200 \mathrm{U} / \mu 1$ versetzt. Das Reaktionsgemisch wurde 10 min bei $25{ }^{\circ} \mathrm{C}, 45$ min bei $45^{\circ} \mathrm{C}$ und 45 min bei $55^{\circ} \mathrm{C}$ inkubiert um mit der Elongation die reverse Transkription zu vollenden.

\subsubsection{Genotypisierung durch PCR und Gelelektrophorese}

Mithilfe der PCR-Technik ist es möglich geringe DNA-Mengen in vitro zu amplifizieren. Die Durchführung erfolgte nach dem Prinzip von Mullis et al (Mullis et al. 1986).

Die DNA-Polymerase des Bakteriums Thermus aquaticus (Taq-Polymerase) synthetisiert bei ihrem Temperaturoptimum von $72{ }^{\circ} \mathrm{C}$, ausgehend von sequenzspezifisch an die MatritzenDNA bindenden Oligonukleotiden (Primer), einen komplementären DNA-Strang. Die Verwendung zweier Primer und die zyklisch ablaufenden Reaktionsschritte vervielfältigen die 
DNA-Abschnitte exponentiell. Die DNA-Denaturierung lief bei $95{ }^{\circ} \mathrm{C}$, das Binden der sequenzspezifischen Primer bei $56{ }^{\circ} \mathrm{C}$ (Annealing) und die Synthese neuer DNA bei $72{ }^{\circ} \mathrm{C}$ (Elongation).

Zur Genotypisierung der Versuchstiere wurden spezifische Primer für das transgene Pmp22Gen der Maus verwendet. Eine Amplifizierung dieses Genabschnittes ließ die Untersuchung zwischen Wildtyp-Ratten und Pmp22-transgenen Ratten zu (Sereda et al. 1996).

Das Reaktionskit von Promega und ein PCR-Thermocykler von Biometra (Göttingen) wurden verwendet. Der Reaktionsansatz enthielt $1 \mu$ l Matritzen-DNA, $5 \mu$ 1 10x PCR-Puffer Promega, $5 \mu \mathrm{l}$ dNTPs (je Nukleotid f.c. $200 \mu \mathrm{M}$ ), $1 \mu \mathrm{l}$ CPMP-Forward-Primer (f.c. $300 \mathrm{nM}$ ), $1 \mu \mathrm{l}$ CPMP-Reverse-Primer (f.c. $300 \mathrm{nM}$ ) und 0,3 $\mu$ l Taq DNA-Polymerase (f.c.1,6 U / $50 \mu \mathrm{l}$ ). Nach 3 min Inkubation bei $95{ }^{\circ} \mathrm{C}$ folgten 35 Zyklen mit jeweils 30 s bei $56{ }^{\circ} \mathrm{C}$, 90 s bei $72{ }^{\circ} \mathrm{C}$ und $60 \mathrm{~s}$ bei $95^{\circ} \mathrm{C}$. Beendet wurde mit 60 s bei $55^{\circ} \mathrm{C}$ und 10 min bei $72{ }^{\circ} \mathrm{C}$.

Die amplifizierten DNA-Fragmente wurden durch Elektrophorese in einem 1,5\% Agarosegel der Größe nach aufgetrennt.

Durch Aufkochen wurde die Agarose in 1x TAE-Puffer in Lösung gebracht. Ethidiumbromid $(1 \mu \mathrm{g} / \mathrm{ml})$ wurde zugesetzt. In eine Kammer mit Kämmen zur Erstellung von Taschen für die PCR-Produkte wurde die gelöste flüssige Agarose hineingegossen und bei Raumtemperatur 60 min ausgehärtet. Das ausgehärtete Gel wurde in einer mit 1x TAE-Puffer als Laufmittel gefüllten Elektrophoresekammer platziert und die mit Probenpuffer 1/10 verdünnten PCRProdukte in die Geltaschen pipettiert. Im Falle der Pmp22-Genotypisierungs-PCR wurde als Größenmarker $1 \mu \mathrm{g}$ mit Hae III verdaute DNA des Phagen $\varphi$ X174 (70-1350 Basenpaare) von Promega verwendet. Das in der DNA interkalierende Ethidiumbromid wurde nach der elektrophoretischen Auftrennung mit einem UV-Illuminator sichtbar gemacht und fotografiert.

Die Pmp22-transgenen Ratten unterschieden sich durch eine 501 Basenpaare große Bande von den Wildtyptieren, die in dieser PCR keine Bande aufwiesen.

\subsubsection{Semiquantitative Real-Time-PCR}

Um breite Transkriptionsanalysen kostengünstig durchzuführen eignet sich vornehmlich die Methode der semiquatitativen Real-Time-PCR mit Sybr ${ }^{\circledR}-$ Green. Der hierbei verwendete Fluoreszenzfarbstoff (Sybr ${ }^{\circledR}$-Green) lagert sich spezifisch in doppelsträngige DNA ein und 
sendet anschließend ein fluoreszentes Signal aus. Die Menge dieses Lichtsignals korreliert dabei mit der Menge an Target-DNA. Es lässt sich somit die Zunahme an PCR-Produkten in Echtzeit (real time) verfolgen, indem jeweils am Ende einer Elongationsphase die Fluoreszenz gemessen wird.

Da Sybr ${ }^{\circledR}$-Green an jegliche doppelsträngige Nukleinsäuren bindet, somit auch an Primerdimere oder Kontaminationen genomischer DNA, werden zusätzliche Anforderungen an die Primer gestellt. Diese wurden so konstruiert, dass sie ein Intron flankieren. Die Zeit eines Zyklus reicht somit nicht aus um genomische DNA zu amplifizieren, sondern lediglich die der mRNA komplementären DNA. Ob die Primer Schleifen oder Dimere bilden wurde mithilfe der Software „Oligo Analyzer 1.1.2“ getestet. Auch wurden Real-Time-PCR Kontrollläufe ohne Transkript durchgeführt.

Indem die Fluoreszenzintensität während der PCR kontinuierlich gemessen wurde ließ sich die Zykluszahl bestimmen, bei der das Signal eine gesetzte Schwelle (threshold) überschreitet. Diese Zykluszahl wurde als $\mathrm{C}_{\mathrm{T}}$-Wert (cycle threshold) bezeichnet und war kleiner, je gröBer die Menge eingesetzter DNA-Zielsequenz war. Idealerweise wurde die Schwelle in die exponentielle Phase der Amplifikation gelegt um ein möglichst akkurates Ablesen zu ermöglichen (Abbildung 12).

Ausgewertet wurde, indem die $\mathrm{C}_{\mathrm{T}}$-Werte jeder Probe auf ein so genanntes „Haushaltsgen“ normalisiert wurden. „Haushaltsgene“ oder Standards sind Gene, dessen Expressionsniveau in allen Proben als Konstant angenommen wird, differentielle Regulierung sollte bei diesen Standards möglichst schwach ausgeprägt sein. Die Menge an cDNA wurde in jeder Probe auch für die definierten Standards bestimmt. Um möglichst valide Ergebnisse zu erzielen wurde auf mehrere Standards, bzw. den Mittelwerten derer Expression normalisiert. Die am besten geeignete Kombination aus „Haushaltsgenen“ wurde mit der Software „geNorm 3.5“ (Vandesompele et al. 2002) identifiziert. Aufgrund der Normalisierung auf „Haushaltsgene“ bezeichnet man diese Art der Real-Time-PCR als „,semiquantitativ“.

Die $\mathrm{C}_{\mathrm{T}}$-Rohdaten aller analysierter Gene wurden mithilfe der Software „q-Base 1.3.5“ (Hellemans et al. 2007) analysiert. Reaktionsansatz und Amplifikationsprotokoll entsprachen den Empfehlungen zum Fluoreszenzfarbstoff Sybr ${ }^{\circledR}$-Green: 
Reaktionsansatz:

$\begin{array}{ll}2 \mu \mathrm{l} & \text { cDNA } \\ 1 \mu \mathrm{l} & 5^{\prime} \text {-Primer }(10 \mathrm{pmol} / \mu \mathrm{l}) \\ 1 \mu \mathrm{l} & 3^{\prime} \text {-Primer }(10 \mathrm{pmol} / \mu \mathrm{l}) \\ 5 \mu \mathrm{l} & \text { Sybr }^{\circledR} \text {-Green Master Mix } \\ 1 \mu \mathrm{l} & \mathrm{H}_{2} \mathrm{O}\end{array}$

Amplifikationsprotokoll:

$\left.\begin{array}{lll}10 \mathrm{~min} & - & 95^{\circ} \mathrm{C} \\ 15 \mathrm{~s} & - & 95^{\circ} \mathrm{C} \\ 20 \mathrm{~s} & - & 60{ }^{\circ} \mathrm{C} \\ 40 \mathrm{~s} & - & 72{ }^{\circ} \mathrm{C}\end{array}\right]$ 40 Zyklen

\subsubsection{Etablierung biologischer Marker aus Hautgewebe}

Aus Hautbiopsien vom Therapieende wurden diagnostische Marker etabliert, deren Expressionslevel mit der Ausprägung des pathologischen Phänotyps korreliert. Sie sollen bei Therapiestudien eine Aussage über die Erkrankungsschwere bzw. den Erfolg der Therapie zum Jetzt-Zeitpunkt zulassen. Analysiert wurden daher Hautbiopsien von Placebo- und Lonaprisan-behandelten transgenen Tiere.

In einem weiteren Ansatz sollten prognostische Marker etabliert werden, also Gene, deren Expression zu einem frühen Zeitpunkt (Hautbiopsien von 4 Wochen alten Tieren) mit dem Phänotyp zu einem späteren Zeitpunkt (Phänotyp von 7 Wochen alten Tieren) korreliet. Der Phänotyp wurde anhand des Charcot-Marie-Tooth(Ratten)Neuropathiescores (CMTrNS) quantifiziert (Fledrich et al. 2012), der angelehnt an den in der Klinik verwandten CharcotMarie-Tooth Neuropathy Score (CMTNS) phänotypische Merkmale kumuliert und ein einer Punktzahl zusammenfasst. Der CMTrNS beachtet die Parameter Griffstärke und Axonanzahl der Ratten, bei denen jeweils 0 bis 5 Punkte erreicht werden (geringste Griffstärkewerte $=5$ Punkte, geringste Axonzahl im Tibialisnerv = 5 Punkte). Im CMTrNS mit Werten von $0-10$ sind die bei Griffstärke und Axonzahl erreichten Punkte zusammengefasst, wobei 10 die am stärksten ausgeprägte Neuropathie widerspiegelt. Mithilfe eines prognostischen Markers soll es möglich sein zu einem frühen Zeitpunkt die zu erwartende Schwere der Erkrankung vorherzusagen. Somit kann die Entscheidungsfindung für oder gegen eine nebenwirkungsreiche Therapie erleichtert werden. Analysiert wurde daher ausschließlich die Kohorte Placebobehandelter Tiere.

Die Liste der zu analysierenden Gene entstammt einer DNA-Mikroarray-Analyse stark und schwach betroffener CMT-Ratten, welche anschließend mittels Real-Time-PCR validiert wurde (Fledrich et al. 2012). Die Übertragbarkeit auf eine Therapiesituation wurde im Zuge dieser Arbeit überprüft. 


\subsection{Statistische Methoden}

Alle Daten wurden mit Excel 2003 sortiert und verwaltet, ausgewertet wurde mit Statistica 6.0. Der Student's T-Test für unverbundene Stichproben wurde zur Auswertung histologischer Ergebnisse und der Expressionsdaten verwandt. Phenotypanalysen wurden mit dem Wilcoxon-Mann-Whitney-Test auf Signifikanz überprüft. Als statistisch Signifikant wurden Abweichungen mit einem $\mathrm{p}<0,05$ gewertet. Korrelationen wurden mit dem Spearman's Rang Korrelationstest überprüft, auch hier galt ein $\mathrm{p}<0,05$ als statistisch signifikant. Abbildungen zeigen den Mittelwert und den Standardfehler. 


\section{Ergebnisse}

\subsection{Therapieerfolge mit Lonaprisan}

\subsubsection{Längere Haltezeit und erhöhte Griffstärke}

Entsprechend dem „Proof-of-Principle Paradigm“ begann die Therapie der CMT-Ratten im Alter von 5 Tagen, noch bevor sich erste Krankheitssymptome manifestierten. Nach dreiwöchiger Therapie wurde ein erstes Mal mit dem Stangentest untersucht. Als Ausdruck der inzwischen symptomatischen Erkrankung war die Haltezeit der transgenen Tiere verglichen mit den Wildtyp-Ratten signifikant verringert. Zwischen den Placebo- und Lonaprisanbehandelten CMT-Ratten zeigte sich Anfangs kein signifikanter Unterschied, ein Trend in Richtung längere Haltezeit war bei Lonaprisan-behandelten Tieren jedoch zu erkennen und bereits eine Therapiewoche später zeigte sich ein signifikanter Unterschied in den Haltezeiten. Auch am Ende der siebenwöchigen Therapie konnte der signifikante Unterschied zwischen allen Therapiegruppen bestätigt werden (Abbildung 9 A). Die durchschnittliche Verringerung der Haltezeit zwischen Wildtyp-Ratten und Placebo-behandelten CMT-Ratten wurde als 100 $\%$ angesehen. Somit ergab die Lonaprisan-Behandlung nach siebenwöchiger Therapie eine um $42 \%$ verlängerte Haltezeit (Abbildung 9A). In absoluten Werten zeigte sich ab dem Erreichen eines bestimmten Alters bei allen Gruppen eine Verschlechterung der Haltezeit (Abbildung 9 B). Das zunehmende Körpergewicht, die Trägheit und die Teilnahmslosigkeit der Tiere beeinflussten die Ergebnisse, sodass der Stangentest ab einem gewissen Alter sein Limit erreichte. Der Griffstärketest hingegen eignete sich auch für ältere Tiere. Differenziertere Phänotypwerte wurden erzielt und das Ergebnis des Stangentests damit bestätigt. Denn erneut zeigte der signifikante Unterschied eine gesteigerte Griffstärke nach LonaprisanBehandlung, verglichen mit der Placebogruppe (Abbildung 9 C). 
A

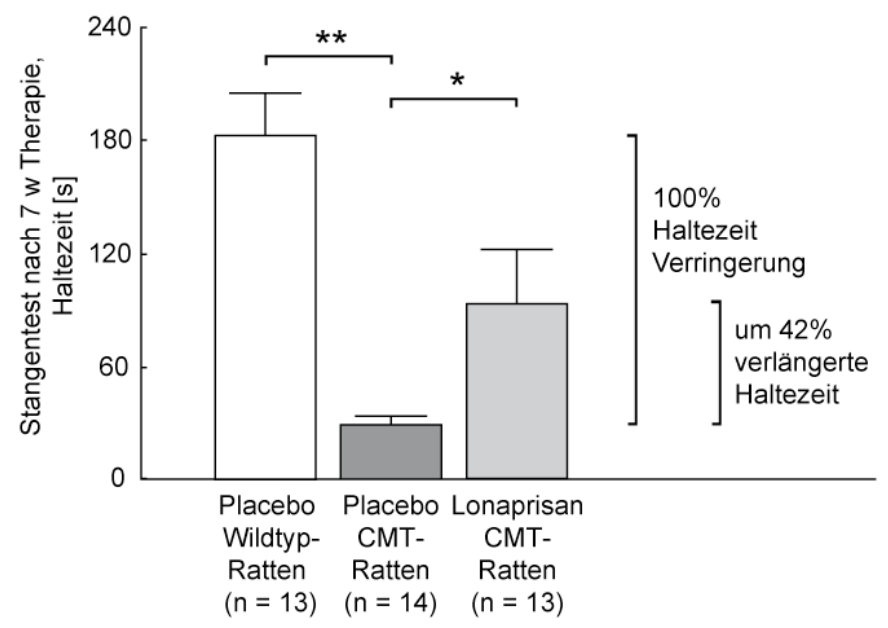

B

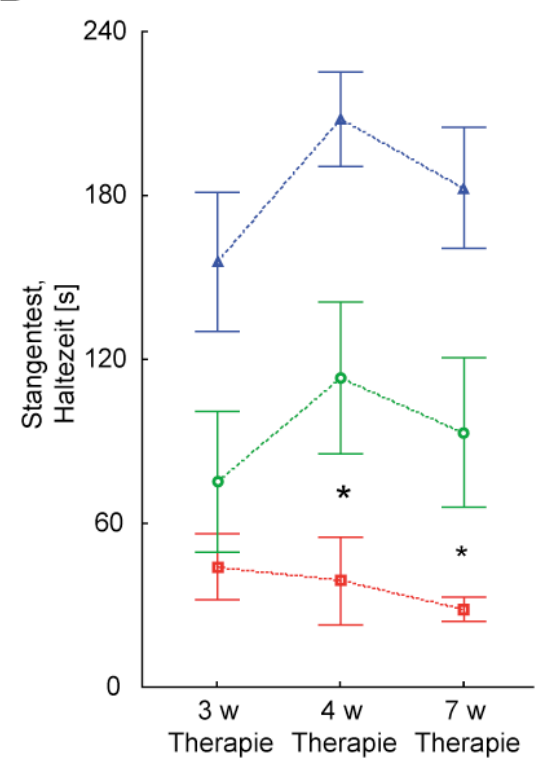

4 Placebo Wildtyp-Ratten $(n=13)$

1 Placebo CMT-Ratten $(n=14)$

@ Lonaprisan CMT-Ratten $(n=13)$

* $\mathrm{p}<0,05$

Placebo gegen Lonaprisan CMT-Ratten
C

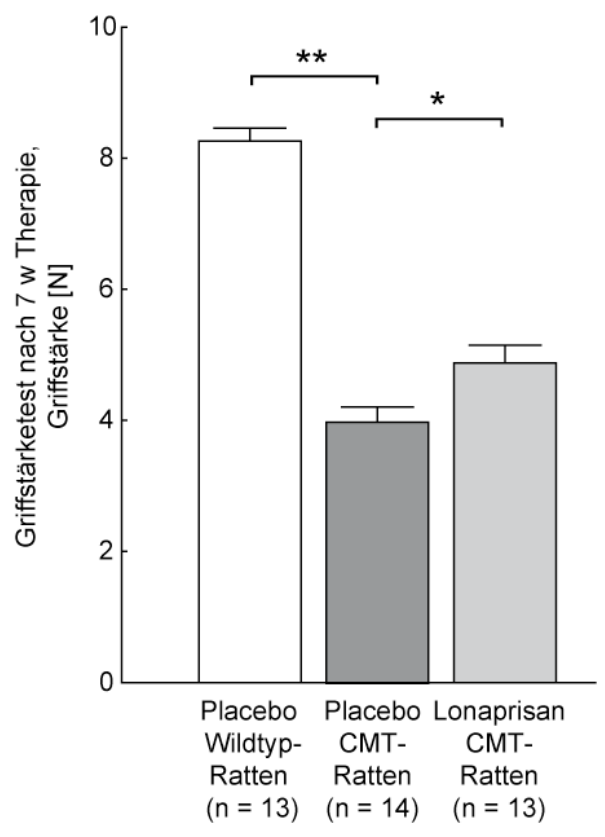

Abbildung 9: Verbesserung des klinischen Phänotyps der CMT-Ratten im Verlauf der Lonaprisan-

\section{Therapie}

Siebenwöchige Therapie mit Lonaprisan ergab beim Stangentest eine signifikant verlängerte Haltezeit, verglichen mit Placebo-Behandlung (A). An allen drei Phänotypisierungszeitpunkten zeigt sich ein signifikanter Unterschied in den Haltezeiten zwischen Wildtyp- und CMT-Ratten. Nach vier- und siebenwöchiger Therapie konnte auch eine signifikante Veränderung des Phänotyps zwischen Lonaprisan- und Placebo-behandelten Tieren gezeigt werden. Mit zunehmendem Alter und Gewicht verringerte sich die Haltezeit bei allen drei Therapiegruppen (B). Der Griffstärketest bestätigte die Verbesserung des Phänotyps nach Lonaprisan-Behandlung $(\mathrm{C})$. 


\subsubsection{Erhöhtes Muskelsummenaktionspotential}

In Zusammenarbeit mit Herrn Dipl.-Biol. Robert Fledrich wurde elektrophysiologisch das Muskelsummenaktionspotential (CMAP) und die Nervenleitgeschwindigkeit (NLG) bestimmt. Im Alter von sieben Wochen war erwartungsgemäß beides bei den CMT-Ratten signifikant reduziert. Wie auch bei den vorherigen Studien mit dem PA Onapriston hatte die Therapie mit Lonaprisan keine Veränderung der NLG zur Folge. Das CMAP hingegen, als Ausdruck der in ihrer Funktion erhaltenen und reizbaren Axone, war signifikant erhöht. Somit ist eine erhöhte Anzahl an Axonen anzunehmen, während die Lonaprisan-Therapie keinen Einfluss auf die Myelinisierung zeigte (Abbildung 10 A, B). 
A

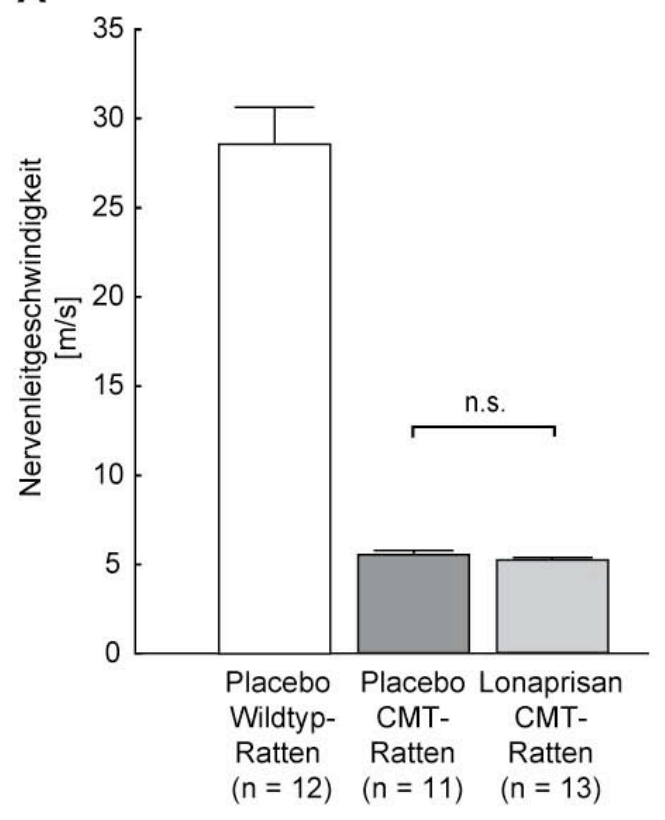

B

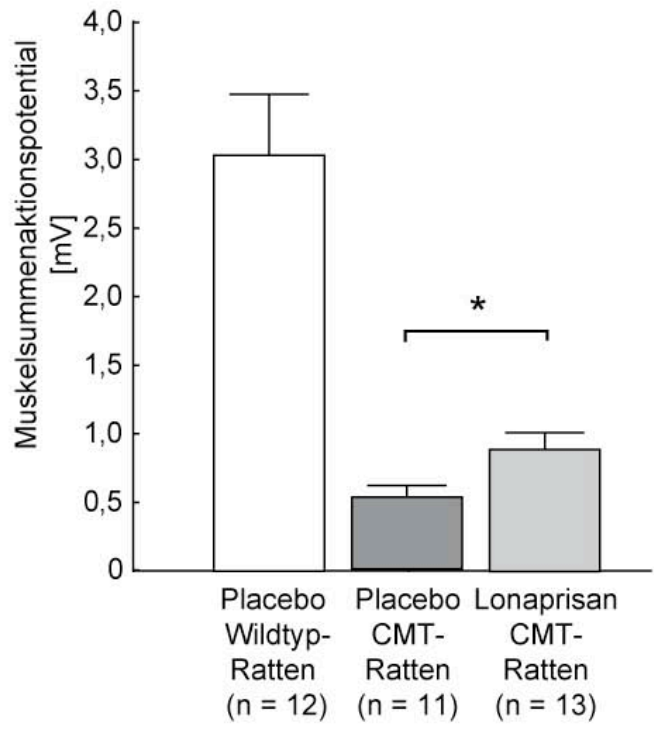

C

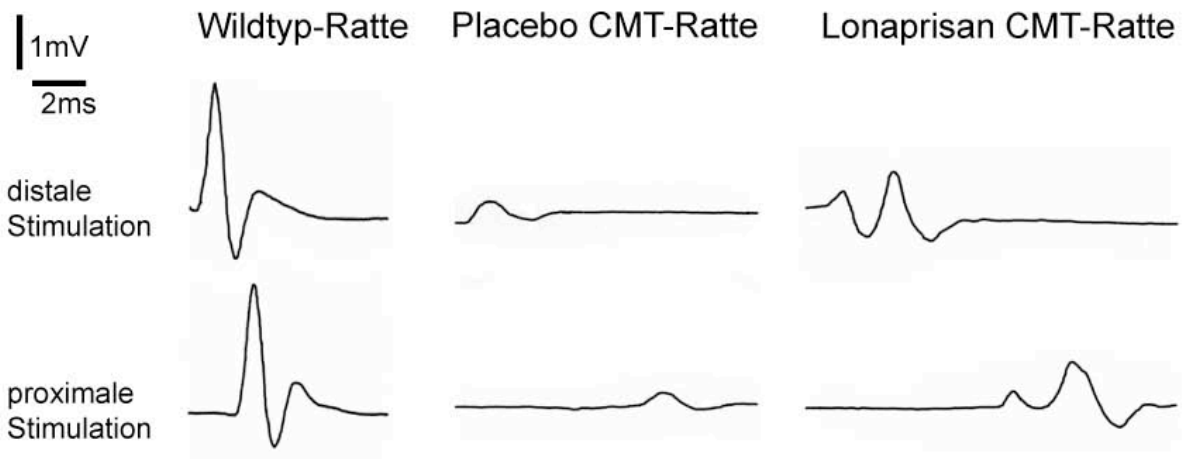

Abbildung 10: Elektrophysiologischer Befund einer demyelinisierenden Neuropathie mit axonalem Verlust (reduziertes Muskelsummenaktionspotential und Nervenleitgeschwindigkeit)

Nervenleitgeschwindigkeit (NLG) wie auch das Muskelsummenaktionspotential (CMAP) zeigen sich bei den CMT-Ratten im Sinne einer demyelinisierenden Neuropathie mit axonalem Verlust verringert. Bei Wildtyp-Ratten hingegen zeigten sich regelrechte Werte. Während die siebenwöchige Therapie mit Lonaprisan keinen Einfluss auf die NLG hatte, konnten bei diesen Tieren erhöhte Werte des CMAPs gemessen werden. Die Demyelinisierung scheint somit unbeeinflusst, die Anzahl der Axone hingegen erhöht (A, B). Repräsentative Aufnahmen eines Wildtyptiers, einer Placebo-behandelten CMT-Ratte sowie einer CMT-Ratte nach Lonaprisan-Therapie zeigen Ausschläge nach distaler und proximaler Reizung. Deutlich zu erkennen sind die größeren Amplituden der Wildtyp-Ratten. Die Amplituden der Lonaprisan-behandelten CMT-Ratte liegen zwischen der mit Placebo therapierten CMT- und der Wildtyp-Ratte (C). 


\title{
3.1.3. Verringerte PMP22-Expression
}

Die aus Nervengewebe isolierte RNA wurde im „Agilent Bioanalyzer“ mit dem RNA 600 Nano Assay untersucht. Nicht degradierte und kontaminierte RNA-Isolate wurden zur weiteren Analyse verwendet (Abbildung 11). Die mRNA-Expression in Schwannzellen wurde durch die semiquantitative Real-Time-PCR mit Sybr ${ }^{\circledR}$-Green aus Lysaten des Nervus ischiadicus bestimmt (Abbildung 12).
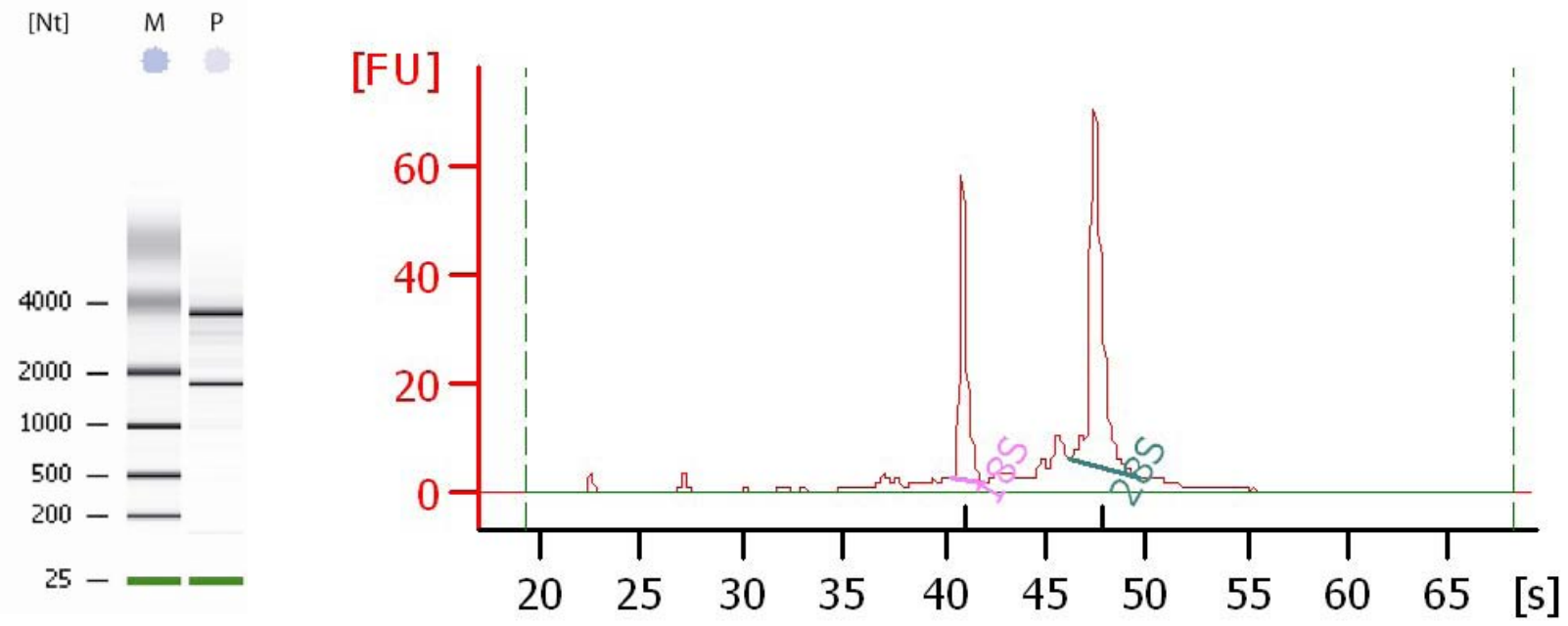

\begin{abstract}
Abbildung 11: Nicht degradierte und kontaminierte RNA aus Haut- oder Nervengewebe
Repräsentative Vermessung einer Proben-RNA (P) im „Agilent Bioanalyzer“. Durch den eingelagerten Fluoreszenzfarbstoff lassen sich nach der Gelelektrophorese Banden aufgetrennter RNA Bestandteile detektieren. Die genügend aufgereinigte Proben-RNA zeigt zwei scharfe Banden, entsprechend den beiden Hauptbestandteilen der ribosomalen RNA mit dem Sedimentationskoeffizienten $18 \mathrm{~S}$ und $28 \mathrm{~S}$ (A). Bei der Auftragung der Fluoreszenz gegen die Retentionszeit zeigen sich zwei Zacken bei 41 und bei 48 Sekunden, entsprechend den $18 \mathrm{~S}$ und $28 \mathrm{~S}$ Untereinheiten der ribosomalen RNA. Das Verhältnis der Integrale beider Zacken (18 S / 28 S) sollte nahe dem Idealwert von 2,1 sein (B) (FU: Fluoreszenzeinheiten).
\end{abstract}




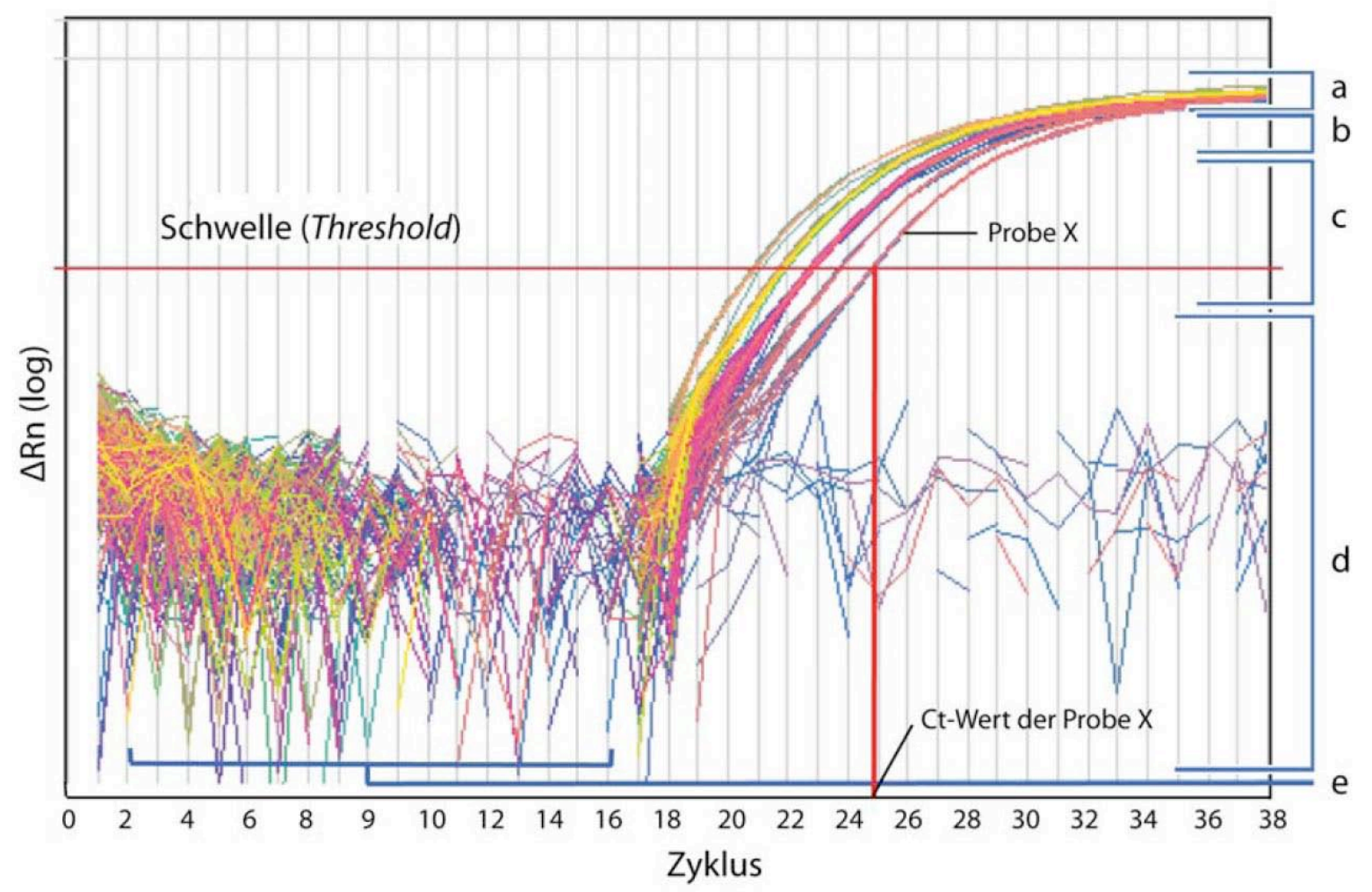

\section{Abbildung 12: Repräsentative grafische Datenerfassung einer semiquantitativen Real-Time-PCR}

Anfänglich bleibt die Signalintensität des in die DNA-Doppelstränge eingelagerten Sybr ${ }^{\circledR}$-Green unterhalb der Detektionsschwelle (e, baseline). Die aus diesen ersten Zyklen gewonnenen Daten werden dem Hintergrundsignal (d, background) zugeordnet. Eine Probe X erreicht ab einer bestimmten Zykluszahl die exponentielle Vermehrung des zu amplifizierenden Transkipts. Die Zykluszahl, bei der die unterschiedlichen Proben einen Schwellenwert (threshold) an Signalintensität überschritten haben $\left(\mathrm{C}_{\mathrm{T}}\right.$-Wert), wird miteinander verglichen. Diese Schwelle wird in den Bereich der exponentiellen Amplifikation (c, exponential phase) gelegt, die bei logarithmischer Auftragung, normalisiert auf den backround, linear erscheint.

Die Hypothese unterstreichend, dass die PMP22-Expression von endogenem Progesteron reguliert wird und durch einen Progesteronantagonisten verringert werden kann, zeigte sich nach der Therapie mit Lonaprisan eine signifikant verringerte PMP22-Expression. Die Überexpressionssituation der CMT-Ratten ließ sich erneut darstellen (Abbildung 13). Als „Haushaltsgen“, mit angenommener konstanter Expression, diente bei dieser Real-Time-PCR das Exon1B, als ein nicht von Steroiden in der Expression reguliertes Gen. 


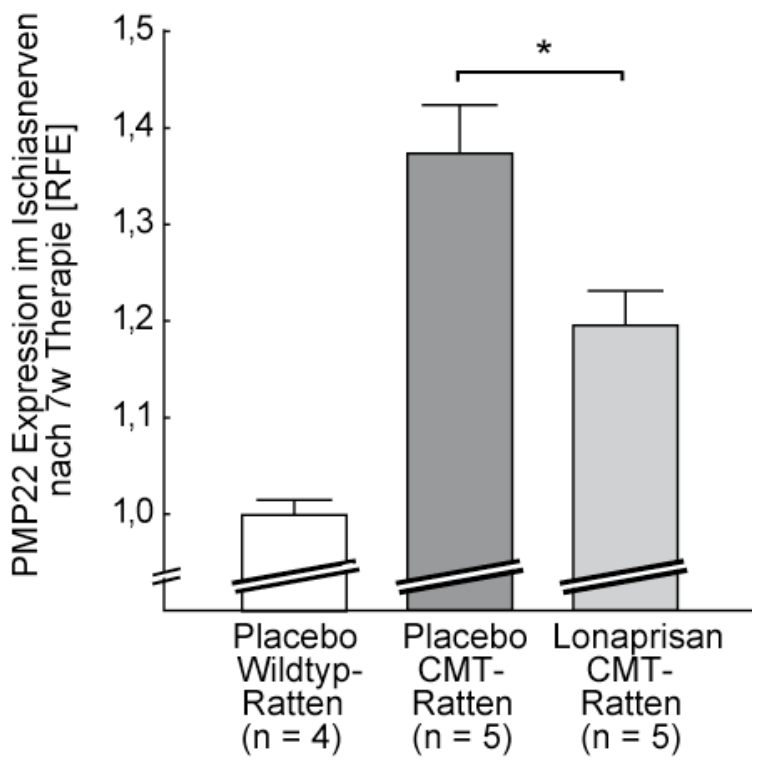

\begin{abstract}
Abbildung 13: Reduktion der Pmp22-Überexpression durch den Progesteronantagonisten Lonaprisan
Durch die semiquantitative Real-Time-PCR mit Sybr ${ }^{\circledR}$-Green aus Nervenlysaten Pmp22-transgener Ratten konnte, verglichen mit Wildtypsituation, eine Pmp22-Überexpression dargestellt werden. Durch siebenwöchige Therapie mit dem Progesteronantagonisten Lonaprisan wurde diese Überexpression signifikant verringert. Als interner Standard diente das „Haushaltsgen“ Exon1B (RFE: relative Fluorezenzeinheiten).
\end{abstract}

\title{
3.1.4. Axonerhalt im Nervus ischiadicus
}

Querschnitte des Nervus ischiadicus wurden mit Methylen-Azur-II gefärbt und auf die typischen Pathologien der Charcot-Marie-Tooth-Erkrankung hin analysiert. Die Querschnitte zeigten in der Wildtypsituation regelrecht myelinisierte, großkalibriger Axone (Abbildung 14 A links). CMT-Tiere wiesen zusätzlich hypo- und unphysiologisch unmyelinisierte Axone auf (Abbildung 14 A geschlossener Pfeilkopf und Pfeil respektive). Kleinkalibrige Axone zeigen oft eine inadäquate Hypermyelinisierung (Abbildung 14 A offener Pfeilkopf).

Die Gesamtzahl der Axone in Querschnitten des Nervus ischiadicus war bei CMT-Ratten verglichen mit der Placebo-Wildtypkohorte signifikant verringert. Die Therapie mit Lonaprisan -kongruent mit den erhöhten Muskelsummenaktionspotentialen in der elektrophysiologischen Untersuchung- verhinderte den axonalen Verlust (Abbildung 14 B). Dennoch waren die Zeichen der demyelinisierenden Neuropathie auch in diesen Tieren noch präsent (unphysiologisch unmyelinisierte Axone, hypo- und hypermyelinisierte Axone, vergleiche Abbildung 14 A Mitte und rechts). 
A

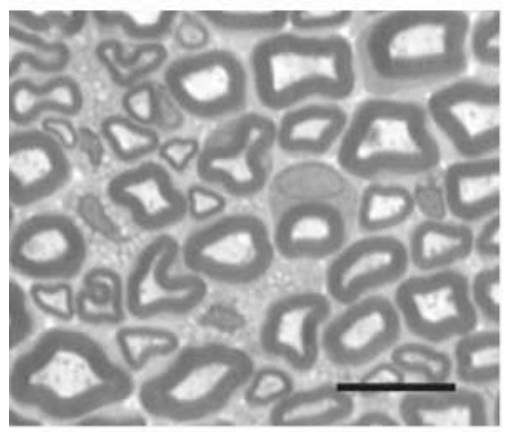

Placebo Wildtyp-Ratte

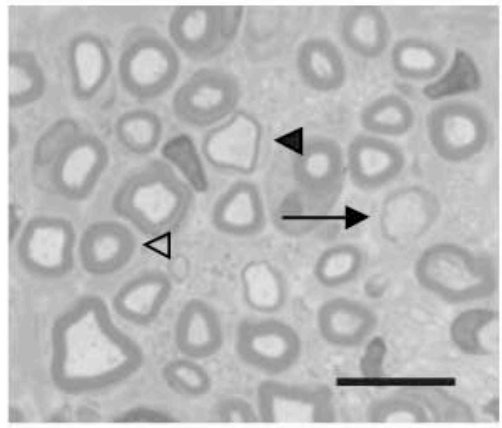

Placebo CMT-Ratte

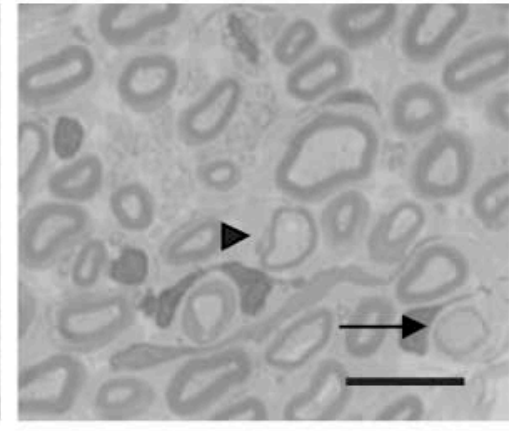

Lonaprisan CMT-Ratte

\section{B}

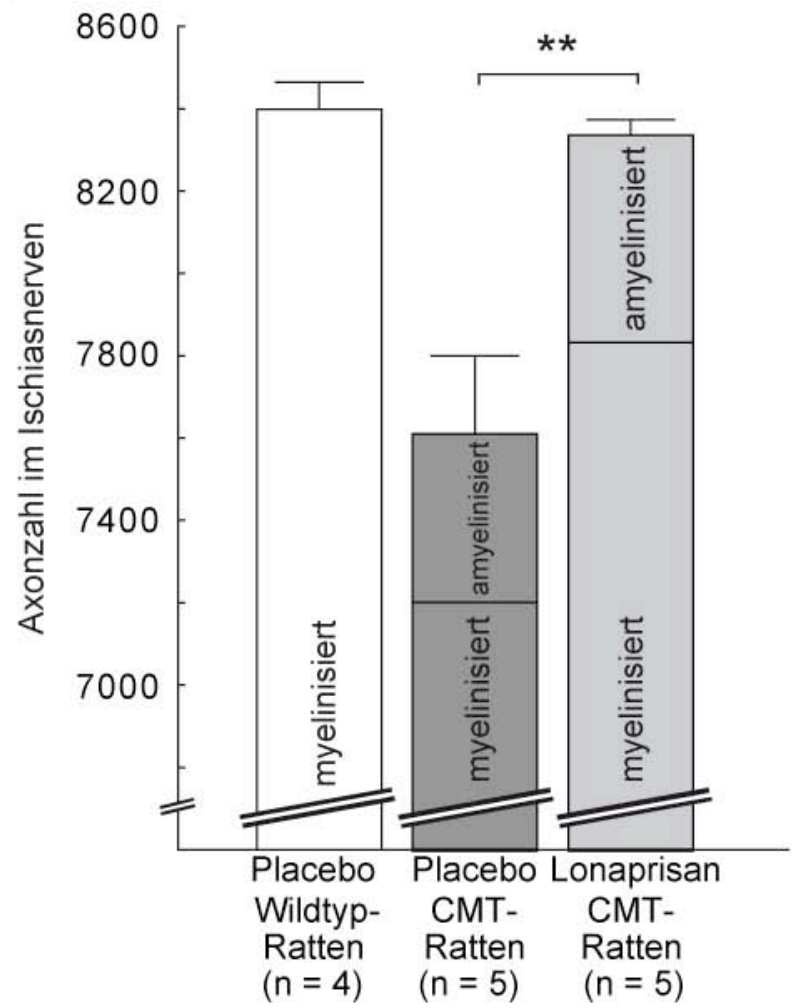

\section{Abbildung 14: Lonaprisan erhält die Axone im Nervus ischiadicus}

Repräsentative Ausschnitte aus Nervus ischiadicus Querschnitten zeigen großkalibrige myelinisierte Axone. Während eine Wildtyp-Ratte regelrecht myelinisierte Axone aufweist (A links) zeigen sich bei den CMT-Ratten als Ausdruck einer vorangeschrittenen demyelinisierenden Neuropathie zusätzlich hypo- (geschlossener Pfeilkopf), hyper- (offener Pfeilkopf) und unphysiologisch unmyelinisierte Axone (Pfeil) (Mitte und rechts). Verglichen mit Wildtyptieren zeigte sich bei CMT-Ratten ein axonaler Verlust, der durch die Behandlung mit Lonaprisan verhindert wurde (B). 


\subsubsection{Verringerter alpha-Motoneuronverlust in Rückenmarksquerschnit- ten}

Die in diesem Abschnitt berichteten Befunde wurden von Herrn Dipl.-Biol. Robert Fledrich erstellt. In Rückenmarksquerschnitten von Wildtyptieren, Placebo- und Lonaprisanbehandelten CMT-Ratten wurden die Nissl-gefärbten alpha-Motoneurone der Vorderhörner quantifiziert (Abbildung 15 A). Signifikant reduziert zeigte sich die Anzahl der alphaMotoneurone bei den CMT-Tieren. Im Vergleich mit Wildtyp-Ratten waren ca. 30 \% weniger Neurone zu sehen. Bei den mit Lonaprisan-behandelten Tieren zeigte sich diese Reduktion weniger stark ausgeprägt, verglichen mit den Placebo-behandelten Tieren wurden nach Lonaprisan-Therapie signifikant mehr alpha-Motoneurone gefunden (Abbildung $15 \mathrm{~A}, \mathrm{~B}$ ). 
A
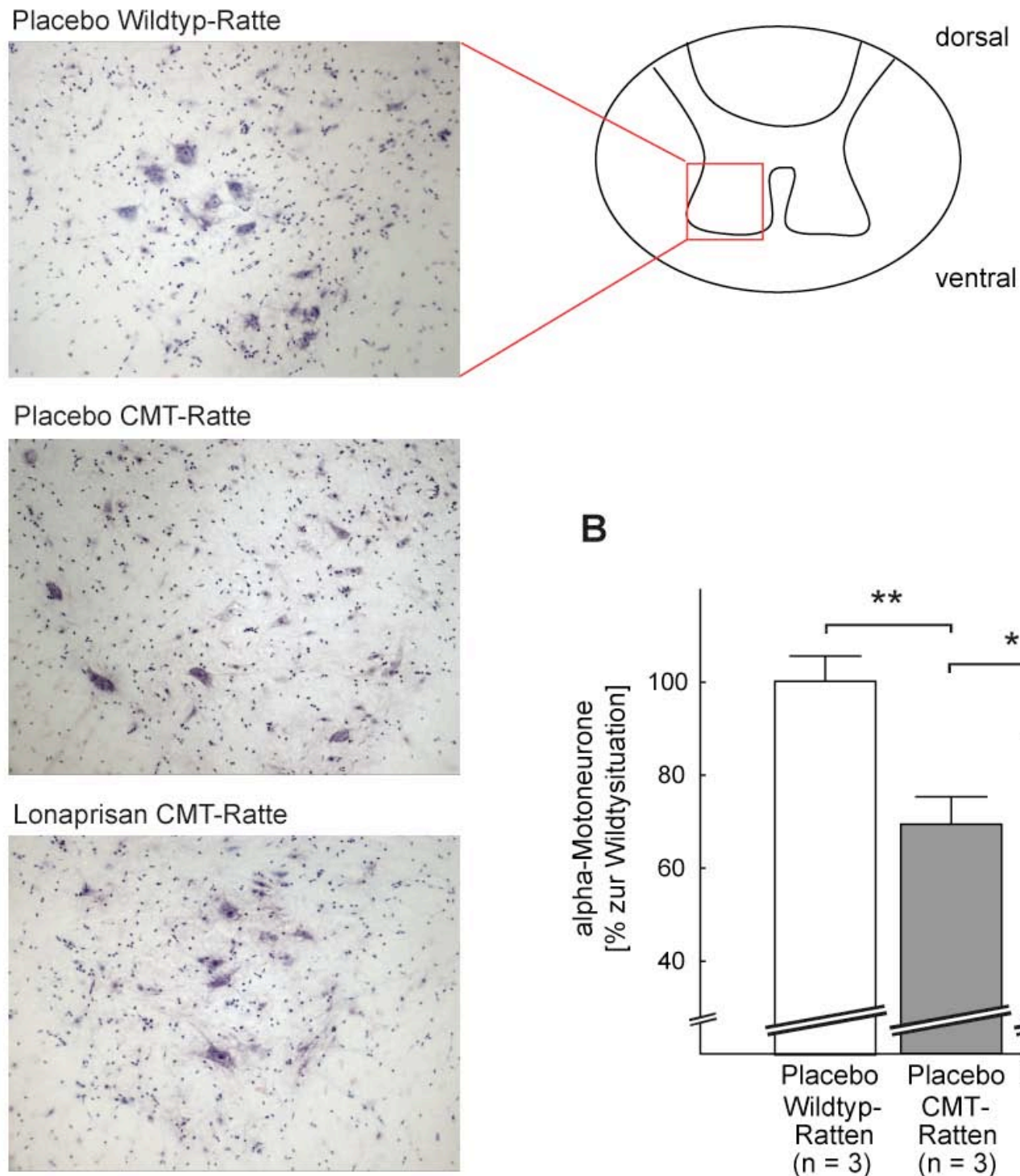

B

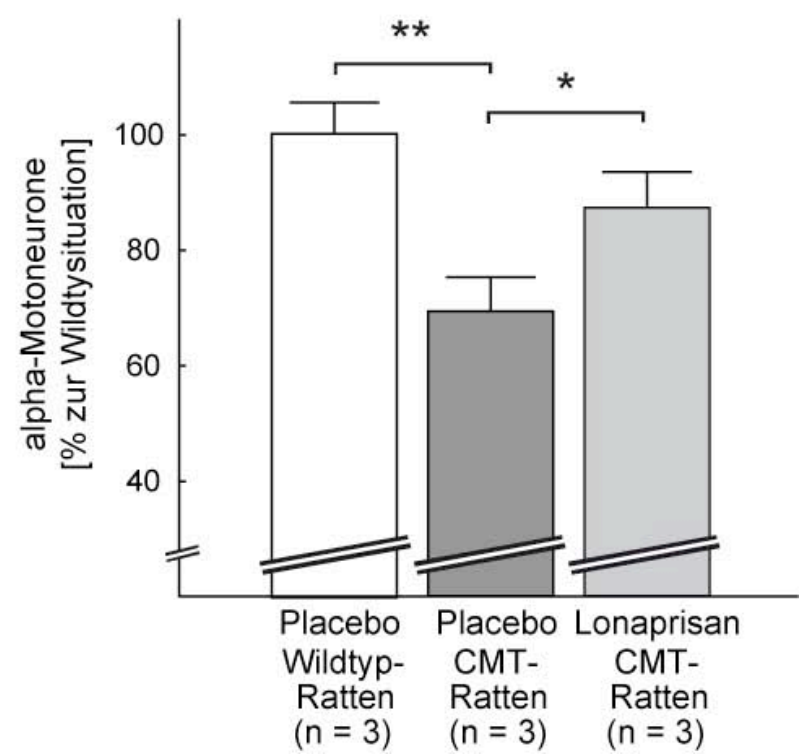

Abbildung 15: Verringerung des alpha-Motoneuronverlusts bei CMT-Ratten nach LonaprisanBehandlung

Perikarya wurden in Rückenmarksquerschnitten mit der Färbung nach Nissl markiert. In jeweils 20 Querschnitten pro Tier wurden die alpha-Motneurone der Vorderhörner quantifiziert (A). Verglichen mit Wildtyptieren zeigten sich bei transgenen CMT-Ratten signifikant weniger alpha-Motoneurone. Der alpha-Motoneuronverlust konnte durch die Therapie mit Lonaprisan signifikant reduziert werden (A, B).

\subsubsection{Verringerte Anzahl intraneuraler Makrophagen}

Mit dem monoklonalen Antikörper ED1 gegen ein makrophagenspezifisches lysosomales Membranprotein wurden Makrophagen in peripheren Nerven angefärbt (Abbildung 16 A). Pro Tier wurde die Anzahl der immunhistochemisch markierten Makrophagen in je drei 
Querschnitten des Nervus tibialis bestimmt. Es zeigte sich eine deutlich erhöhte Anzahl an Makrophagen in CMT-Ratten gegenüber Wildtyptieren, die in ihren peripheren Nerven nahezu keine Makrophagen enthielten. Verglichen mit den Placebo-behandelten CMT-Ratten war die Anzahl der Makrophagen nach Lonaprisan-Therapie stark reduziert. Von im Mittel 3-4 Makrophagen pro Querschnitt verringerte sich die Anzahl auf 1. Die Unterschiede zwischen den drei Therapiegruppen waren mit einem p-Wert < 0,01 signifikant (Abbildung 16 B). Des Weiteren zeigte sich eine negative Korrelation zwischen der Anzahl intraneuraler Makrophagen und der Anzahl myelinisierter Axone. Sowohl unter Einschluss der Wildtyptiere (Abbildung 17 A) als auch bei alleiniger Betrachtung der CMT-Ratten (Abbildung 17 B) war diese Korrelation signifikant (CMT- und Wildtyp-Ratten: $\mathrm{p}<0,01$; CMT-Ratten allein: $\mathrm{p}<$ $0,05)$.

A

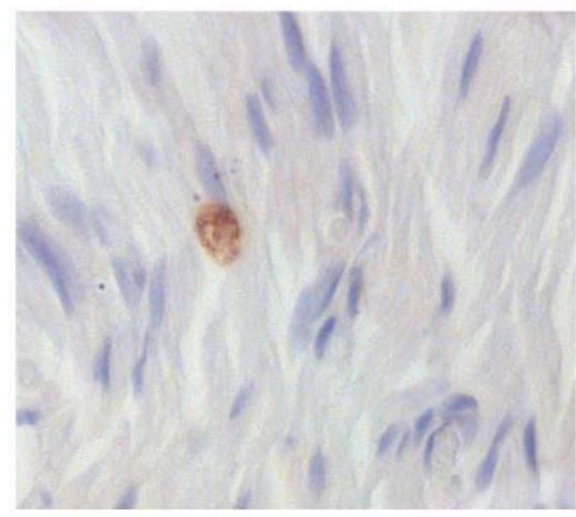

B

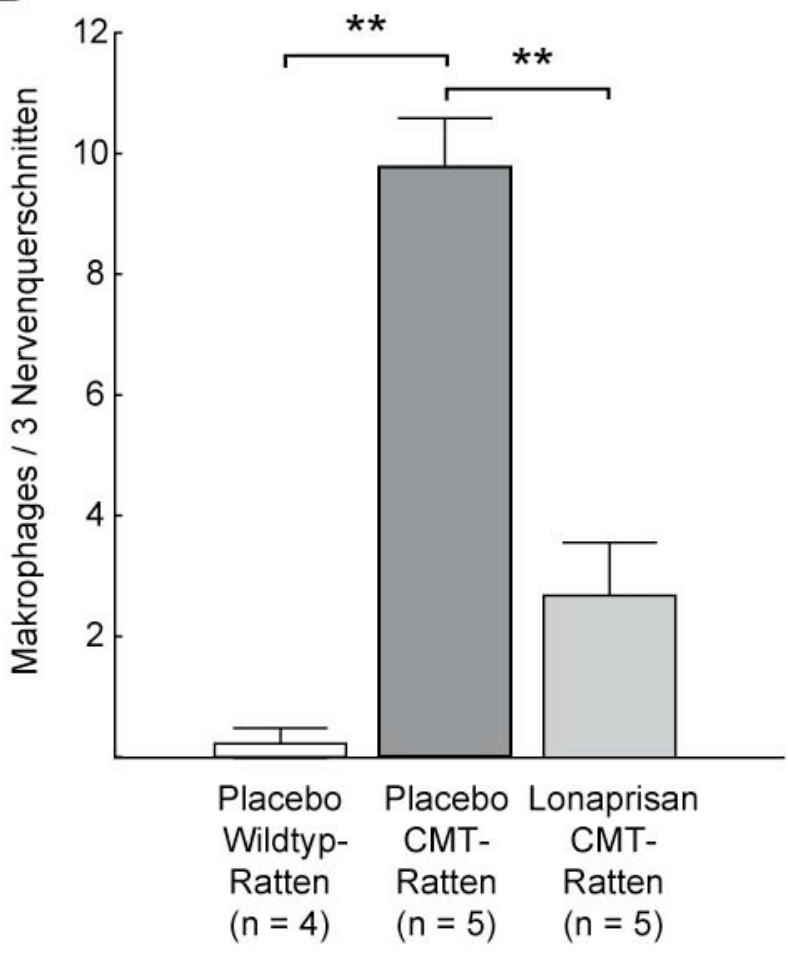

\section{Abbildung 16: Erhöhte Anzahl an Makrophagen in Nerven von CMT-Ratten}

Der repräsentative Ausschnitt eines Nervenquerschnittes zeigt eine ED1-positive Makrophage. Zellkörper von Schwannzellen sind durch die Haemalaun-Gegenfärbung in blau zu erkennen (A). Je drei Querschnitte wurden pro Tier analysiert. Gegenüber den Wildtyptieren war die Anzahl der ED1-positiven Makrophagen in CMT-Ratten deutlich erhöht. Nach siebenwöchiger Therapie mit Lonaprisan näherte sich die Anzahl der Makrophagen dem Wildtypniveau (B). 
A

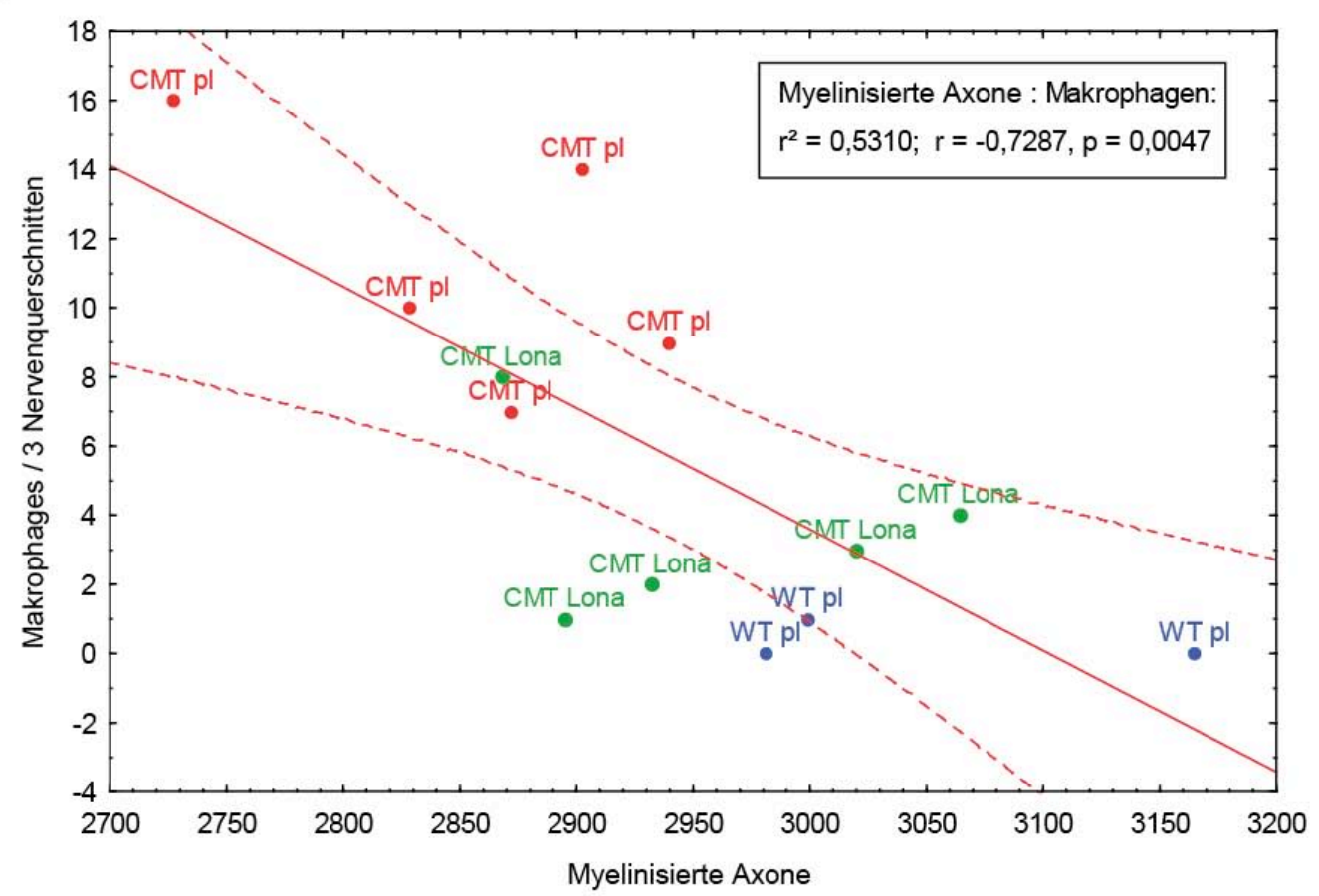

B

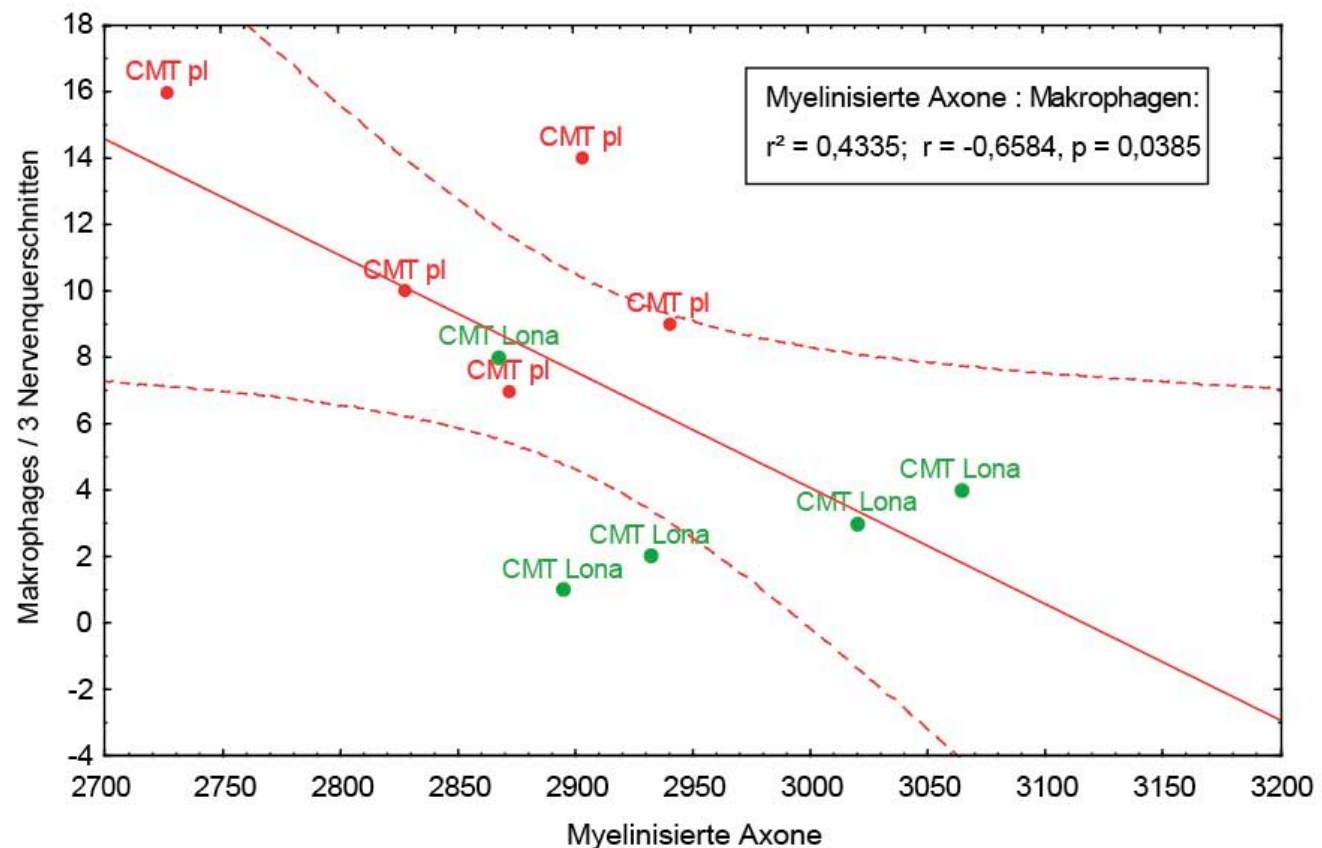

\section{Abbildung 17: Anzahl der Makrophagen korrelierte negativ mit der Anzahl myelinisierter Axone}

Die Anzahl der Makrophagen korrelierte mit dem axonalen Verlust. Je weniger Axone ein Nerv enthielt umso mehr Makrophagen ließen sich nachweisen. Sowohl unter Einschluss der Wildtyptiere (A) als auch bei alleiniger Betrachtung der CMT-Ratten (B) zeigte sich diese signifikante Korrelation (WT pl: Wildtyptier Placebo-behandelt, CMT pl: CMT-Ratte Placebo-behandelt, CMT Lona: CMT-Ratte Lonaprisan-behandelt). 


\subsubsection{Igfbp5 als ein biologischer Marker aus Hautgewebe mit diagnosti- scher Aussagekraft}

Durch semiquantitative Real-Time-PCR wurden in Hautgewebe differentiell regulierte Gene analysiert mit dem Ziel prognostische und diagnostische Marker zu etablieren (Abbildung 12). Zuvor wurde die isolierte RNA im „Agilent Bioanalyzer“ mit dem RNA 600 Nano Assay untersucht. Nicht degradierte und kontaminierte RNA-Isolate wurde zur weiteren Analyse verwendet (Abbildung 11). Die verstärkte Expression des Wachstumsfaktors Igfbp5 (insulinlike growth factor binding protein 5) zeigte eine signifikante Korrelation mit der Erkrankungsschwere. Dieser Marker war in der Hautbiopsie von Tieren mit niedrigen Griffstärkewerten hochreguliert. Tiere, die nach Lonaprisan-Therapie höhere Griffstärkewerte aufwiesen zeigten ein geringeres Expressionslevel (Abbildung 18 A). Normalisiert wurde auf die drei „Haushaltsgene“ Actb, Cycph und Oazl deren Expression in beiden Gruppen (Placebo- und Lonaprisan-behandelte CMT-Ratten) konstant war. Auch als prognostischer Marker wurde Igfbp5 valdiert. Wie auch bei Igfl (insulin-like growth factor 1) bestand eine signifikante Korrelation der Expression in Hautbiopsien eines frühen Zeitpunkts (4 Wochen) mit dem späteren Phänotyp (7 Wochen). Der Phänotyp wurde durch den CMTrNS widerspiegelt. CMT-Ratten mit hoher Expression von Igfbp5 und Igfl entwickelten im Verlauf einen ausgeprägteren Phänotyp (viele Punkte beim CMTrNS), während eine geringe Expressionsrate eher bei Tieren mit milderem Krankheitsverlauf zu finden war (Abbildung 18 B, C). Auch diese Analysen wurden auf mehrere Standards normalisiert. 

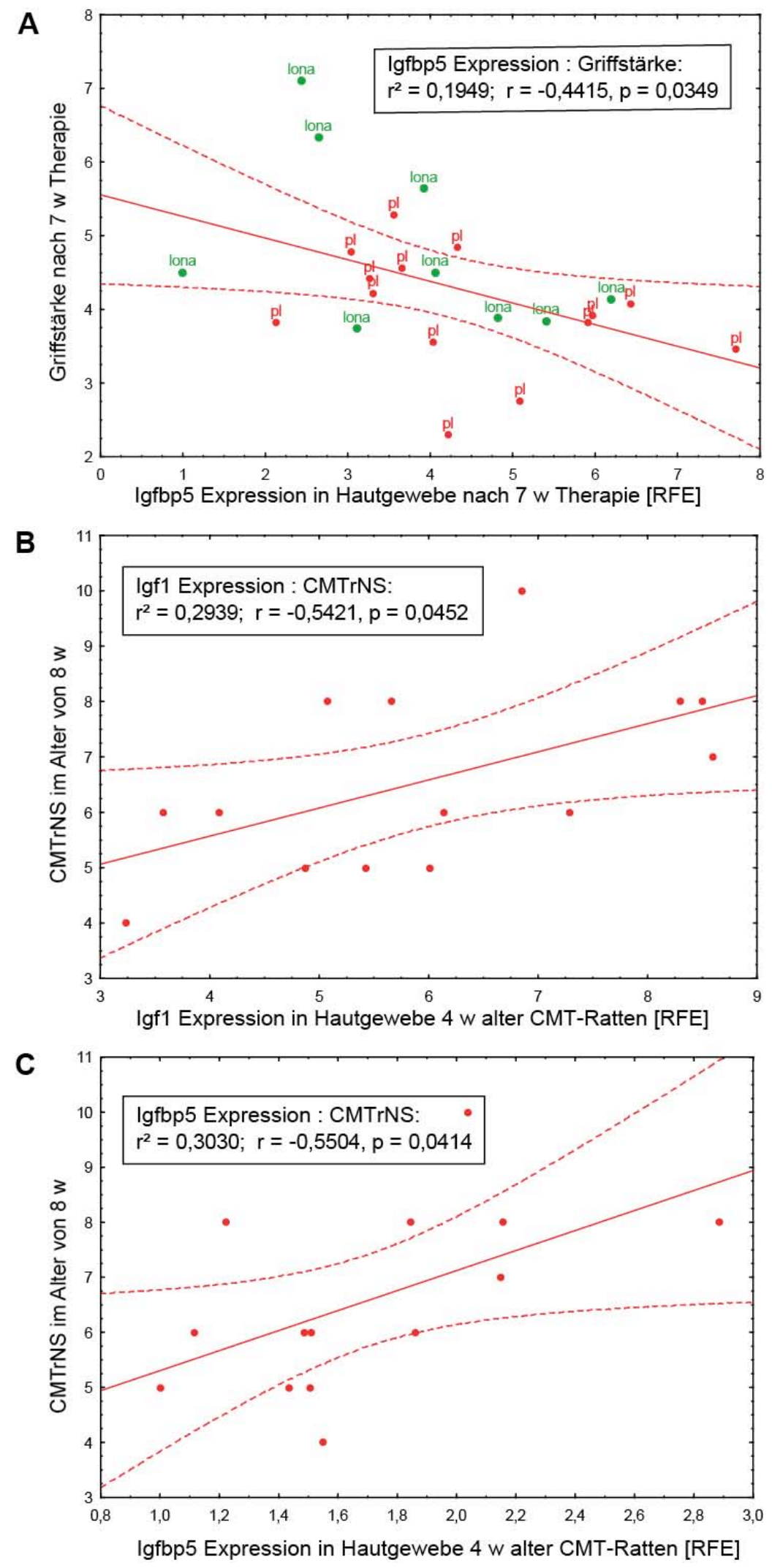

\section{Abbildung 18: Igfbp5 als diagnostischer und prognostische Marker für die Lonaprisan-Therapie}

Prognostische und diagnostische Marker wurden aus Hautbiopsien mittels Real-Time-PCR validiert. Als diagnostischer Marker korreliert die Expression von Igfbp5 mit der Erkrankungsschwere. Je höher die Expression war umso ausgeprägter zeigte sich auch der pathologische Phänotyp (geringere Griffstärkewerte). Prognostische Aussagekraft hatten sowohl Igfbp5 
als auch Igfl. War die Expression dieser Gene in den Hautbiopsien vierwochen alter CMT-Ratten hochreguliert zeigte sich ein dramatischerer Erkrankungsverlauf mit hohen Werten des CMTrNS im Alter von sieben Wochen (pl: CMT-Ratte Placebo-behandelt, lona: CMT-Ratte Lonaprisan-behandelt, RFE: relative Fluorezenzeinheiten). 


\subsection{Therapieerfolge mit Curcumin}

\subsubsection{Relative Verbesserung des klinischen Phänotyps}

Entsprechend dem „Clinical Paradigm“ wurde im Verlauf der dreimonatigen CurcuminBehandlung in dreiwöchigem Abstand der Griffstärketest als Phänotypanalyse durchgeführt. So war es möglich die Progression der bereits vorhandenen Krankheitssymptomatik und den Einfluss der Therapie zu beurteilen.

Bereits im Alter von vier Wochen war ein signifikanter Unterschied in den Griffstärken der Vorder- und Hinterläufe von Wildtyp- zu den CMT-Ratten zu beobachten. Innerhalb der Gruppen von CMT-Ratten zeigte sich die für die Erkrankung charakteristische interindividuelle Variabilität des Phänotyps. Stark und schwach betroffene Tiere wurden identifiziert, und diese im Zuge der Stratifizierung gleichmäßig auf die Therapiegruppen verteilt.

Im Verlauf der dreimonatigen Studie wurde die Differenz der mittleren Griffstärken von Wildtyp- und transgenen Tieren zunehmend ausgeprägter. Eine signifikante Verbesserung des Phänotyps durch die Behandlung mit Curcumin zeigte sich nicht, obwohl die Tiere einem nicht geblindeten Untersucher subjektiv deutlich stärker erschienen (Abbildung 19 A, B).

Bei den mit Curcumin Spezialfutter-behandelten Tieren war jedoch eine signifikant verzögerte Gewichtszunahme zu beobachten. Bereits nach dreiwöchiger Therapie lag die Differenz zu den Placebotieren bei $7 \%$, am Ende der Studie belief sie sich auf $12 \%$ (Abbildung 19 C). In einem parallel laufenden Kontrollexperiment zeigten auch die mit Curcumin-behandelten Wildtyp-Ratten eine verzögerte Gewichtszunahme. Die an Curcumin Spezialfutter aufgenommene Absolutfuttermenge unterschied sich $\mathrm{zu}$ der Menge aufgenommenem normalen Futter der Kontrolltiere hingegen nicht (Abbildung 19 D).

Unter der Annahme, dass deutlich kleinere Tiere eine geringere Leistung bei dem auch von der Körpermasse abhängigen Griffstärketest vollbringen, wurde im Nachhinein eine Korrektur der absoluten Griffstärkewerten vorgenommen. Dazu wurden die Ergebnisse der Griffstärketests durch das Körpergewicht geteilt. Die derart auf das Körpergewicht normalisierten relativen Griffstärkewerte ergaben nach erneuter statistischer Auswertung eine signifikante Verbesserung des Phänotyps der mit Curcumin-behandelten Tiere (Abbildung 19 E, F). 


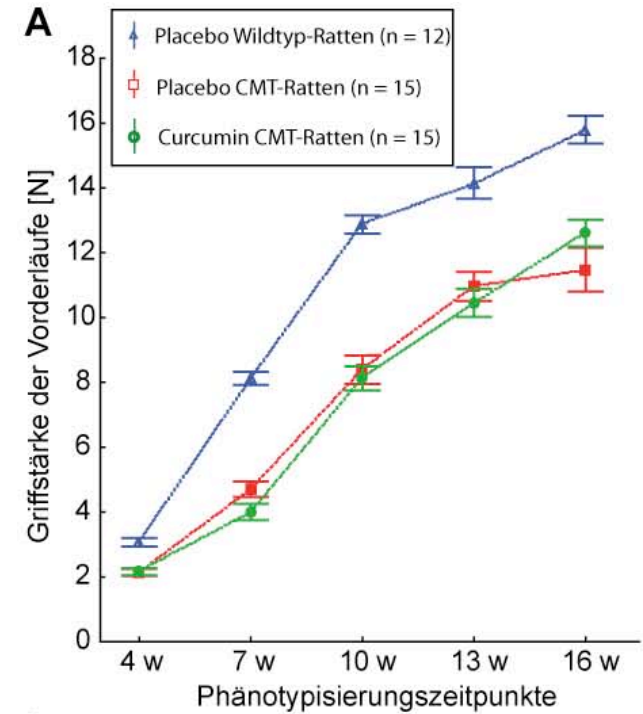

C
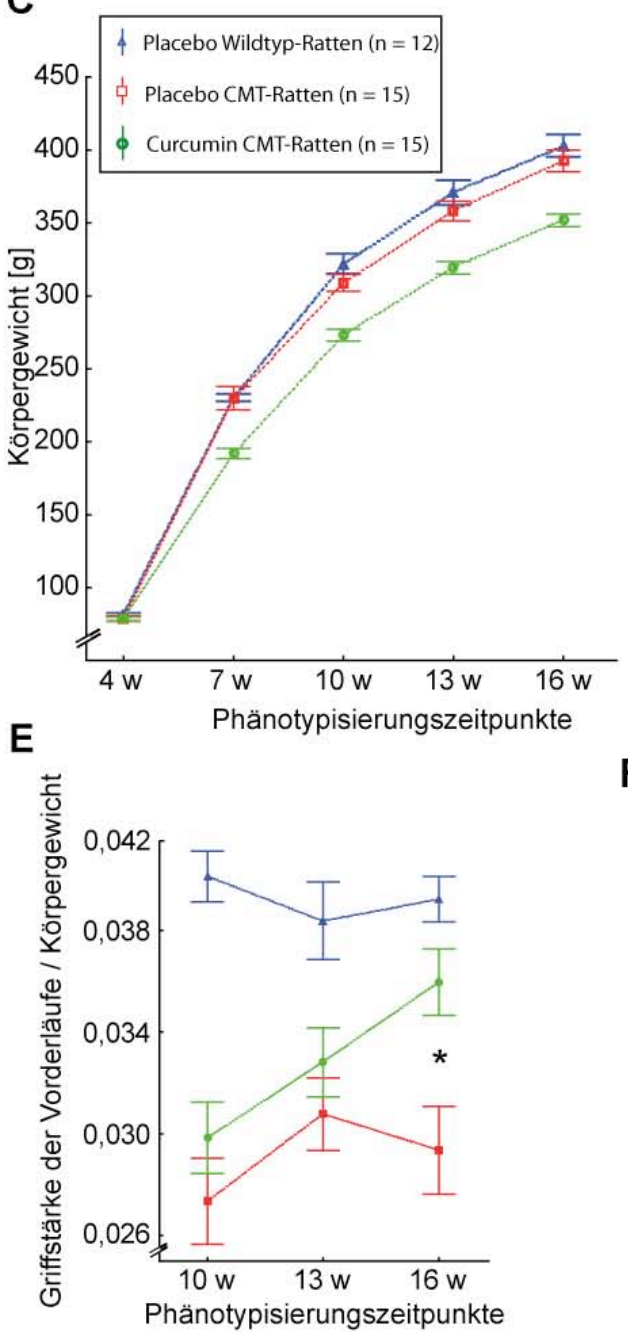

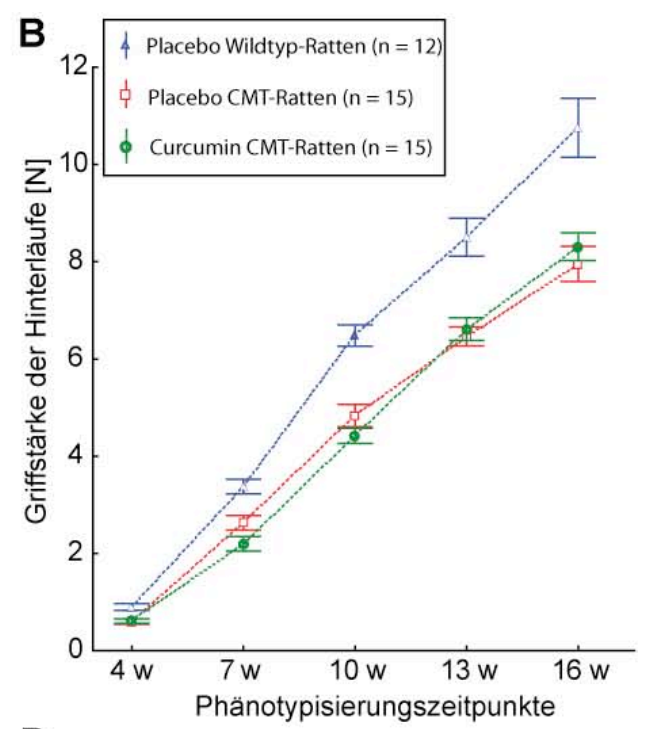

D

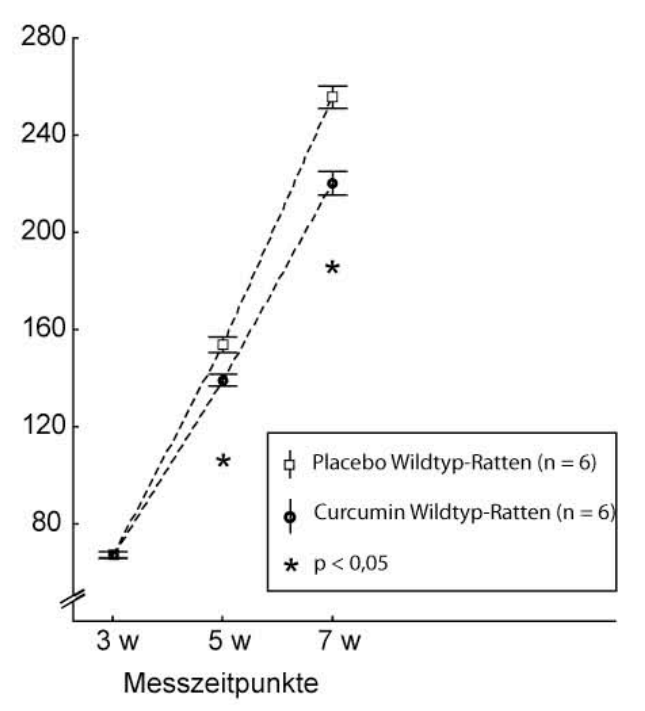

$\mathbf{F}$

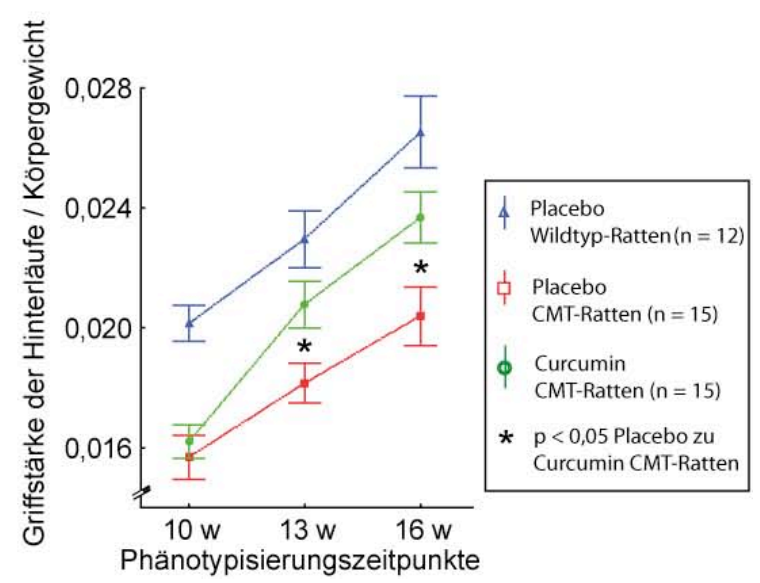

Abbildung 19: Verzögerte Gewichtszunahme und relative Verbesserung des klinischen Phänotyps nach Curcumin-Behandlung

Bereits vor Therapiebeginn im Alter von vier Wochen zeigten transgene Ratten geringere Griffstärken als die Wildtyptiere. Diese Differenz wurde mit zunehmendem Alter ausgeprägter. Placebo- oder Curcumin-behandelte transgene Ratten zeigten zueinander keinen signifikanten Unterschied der absoluten Griffstärkewerte (A, B). Hingegen kam es bei den Curcumin- 
behandelten transgenen Tieren zu einer signifikant verzögerten Gewichtszunahme (C). Ein Kontrollexeperiment mit WildtypRatten demonstrierte Gleiches (D). Die durch eine Normalisierung der absoluten Griffstärkewerte auf das Körpergewicht errechneten relativen Phänotypwerte ergaben einen signifikanten Unterschied zwischen Curcumin- und Placebo-behandelten Tieren (E, F).

\subsubsection{Erhöhte Muskelsummenaktionspotentiale und Nervenleitgeschwin- digkeiten}

Am Ende der dreimonatigen Therapiestudie wurde der Phänotyp der Tiere in Zusammenarbeit mit Herrn Dipl.-Biol. Robert Fledrich zusätzlich durch elektrophysiologische Messungen der Nervenleitgeschwindigkeit (NLG) und des Muskelsummenaktionspotentials (CMAP) untersucht. Als Abbild der demyelinisierenden Neuropathie mit axonalem Verlust demonstrierten transgenen Ratten reduzierte NLG und CMAPs. Bei den Curcumin-behandelten CMT-Ratten waren im Vergleich zu den Placebotieren die Werte erhöht, was als ein Indiz für weniger stark ausgeprägte Demyelinisierung und Axonverlust zu bewerten ist (Abbildung 20). 


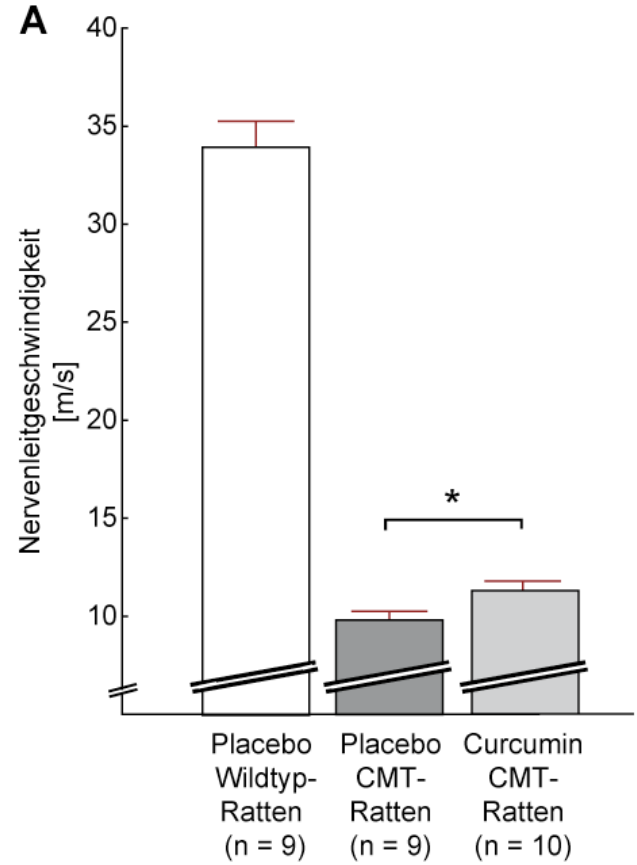

B

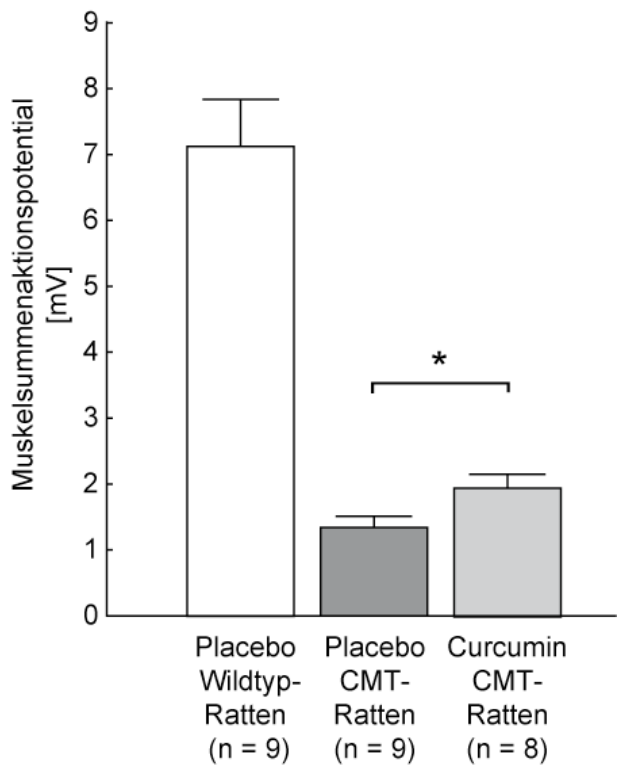

C

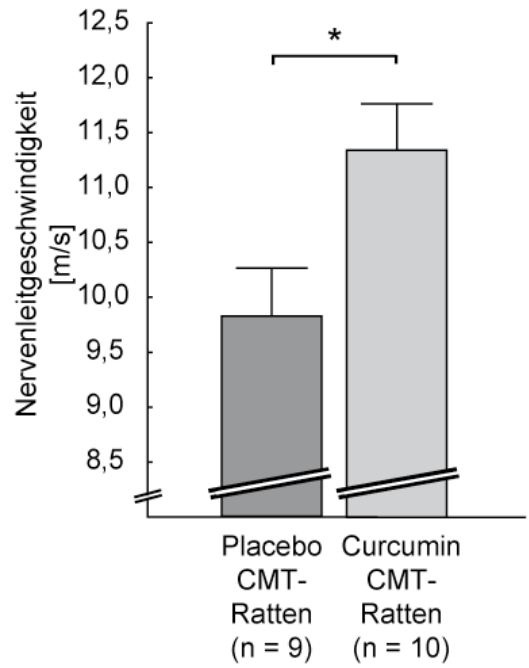

D

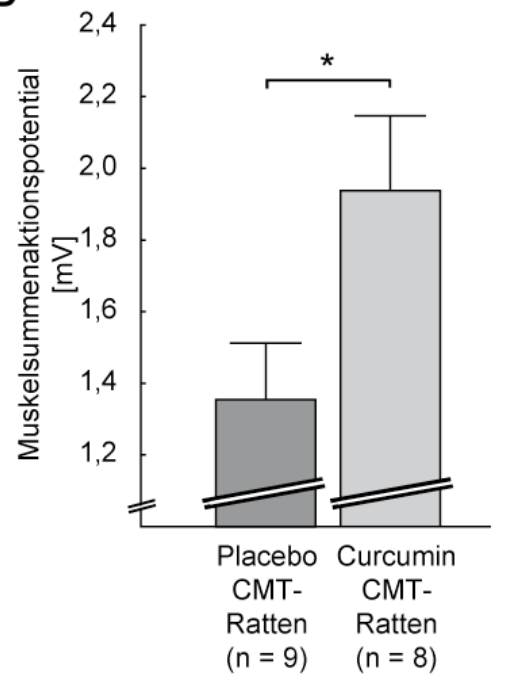

Abbildung 20: Erhöhte Nervenleitgeschwindigkeiten und Muskelsummenaktionspotentiale nach Curcumin-Therapie

Im Sinne der demyelinisierenden Neuropathie mit axonalem Verlust zeigten die CMT-Ratten signifikant verringerte Nervenleitgeschwindigkeiten und Muskelsummenaktionspotentiale (A, B). Weniger stark ausgeprägt waren diese Befunde nach dreimonatiger Therapie mit Curcumin (C, D). 


\subsubsection{Verringerter axonaler Verlust im Nervus tibialis}

Aufgrund des erhöhten Muskelsummenaktionspotentials wurde eine Präservation des Axonverlustes durch die Curcumin-Therapie angenommen. Zur Bestätigung wurde die Anzahl myelinisierter Axone im Querschnitt des Nervus tibialis analysiert. Auch hierbei zeigte sich, dass bei Wildtyp-Ratten jedes großkalibrige Axon mit einer regelrechten Myelinscheide umgeben war während bei CMT-Ratten zusätzlich hypo- und unphysiologisch unmyelinisierte großkalibrige Axone vorkamen. Dieser demyelinisierende Phänotyp erschien weniger ausgeprägt in Nervenquerschnitten von Curcumin-behandelten Tieren (Abbildung 21 A-C). Die Quantifizierung der Axone des gesamten Nervenquerschnitts ergab eine signifikant höhere Anzahl nach Curcumin-Therapie. Eine um $27 \%$ deutliche Reduktion des axonalen Verlustes demonstrierte verglichen mit der Placebogruppe die Gruppe der Curcumin-behandelten Tiere (Abbildung $21 \mathrm{D}$ ).

Die nach Curcumin-Therapie erhöhte Nervenleitgeschwindigkeit lässt Veränderungen der Myelinisierung vermuten. Zur Quantifizierung des Grads der Myelinisierung wurde bei 100 zufällig ausgewählten Axonen eines gemischten Nervens lichtmikroskopisch das g-Ratio bestimmt. Unterschiede zwischen Wildtyptieren und CMT-Ratten wurden damit verdeutlicht. Kein Unterschied zeigte sich zwischen Placebo- und Curcumin-behandelten Tieren (Abbildung $21 \mathrm{E}$ ). Jedoch bestand in der Gruppe Curcumin-behandelter Tiere eine Verschie-

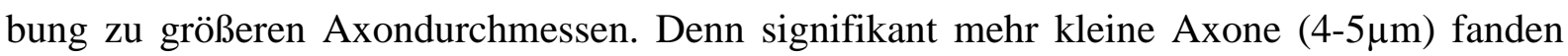
sich in der Placebogruppe, während in der Curcumingruppe signifikant mehr größerkalibrige Axone zu finden waren (Abbildung $21 \mathrm{~F}$ ). 
A Placebo Wildtyp-Ratte

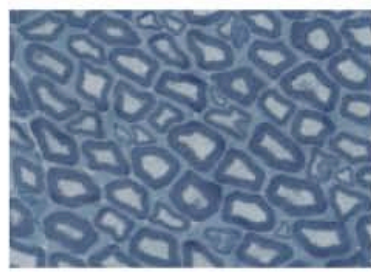

B Placebo CMT-Ratte

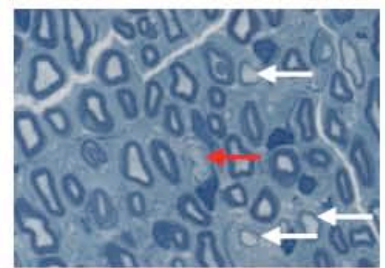

C Curcumin CMT-Ratte

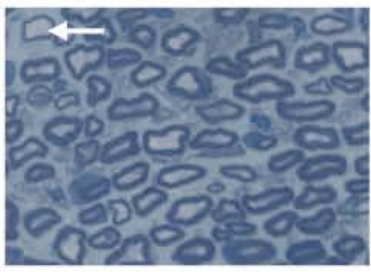

D

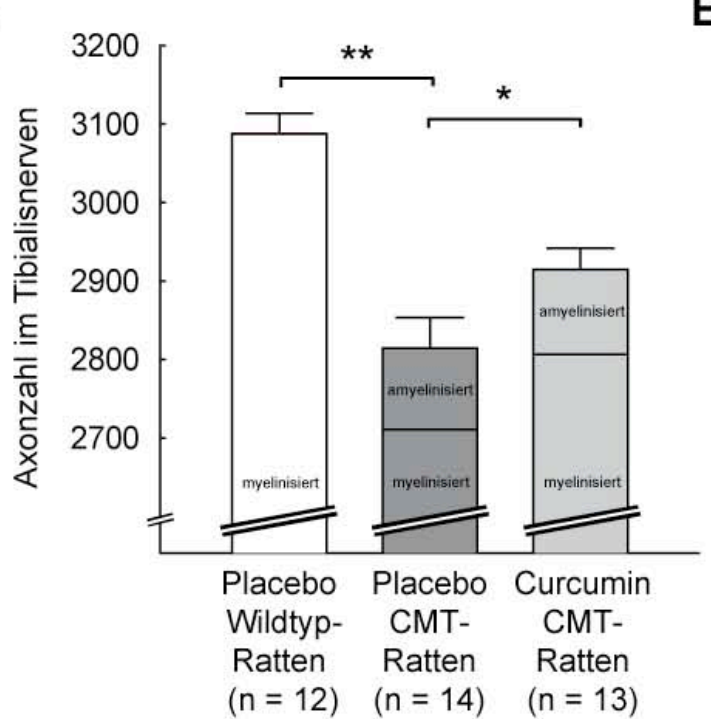

E

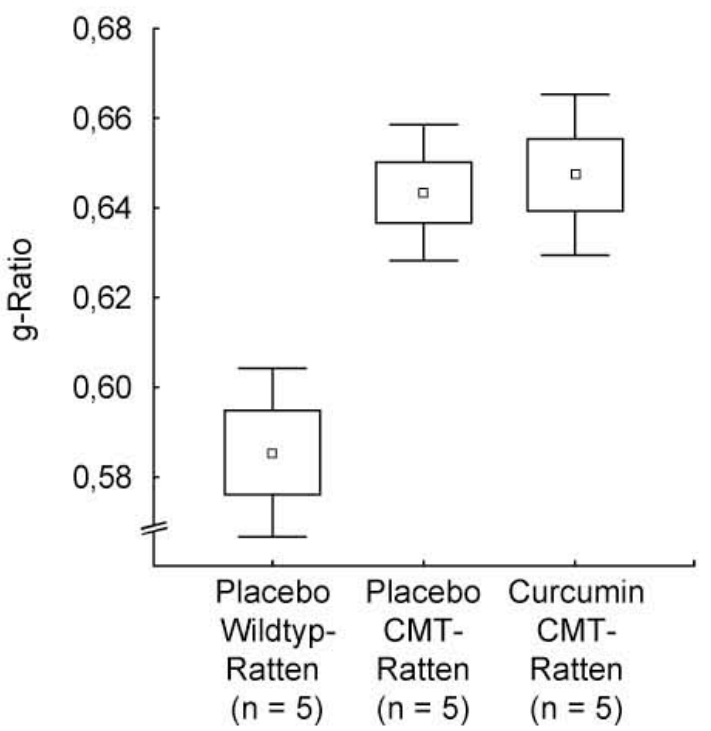

F

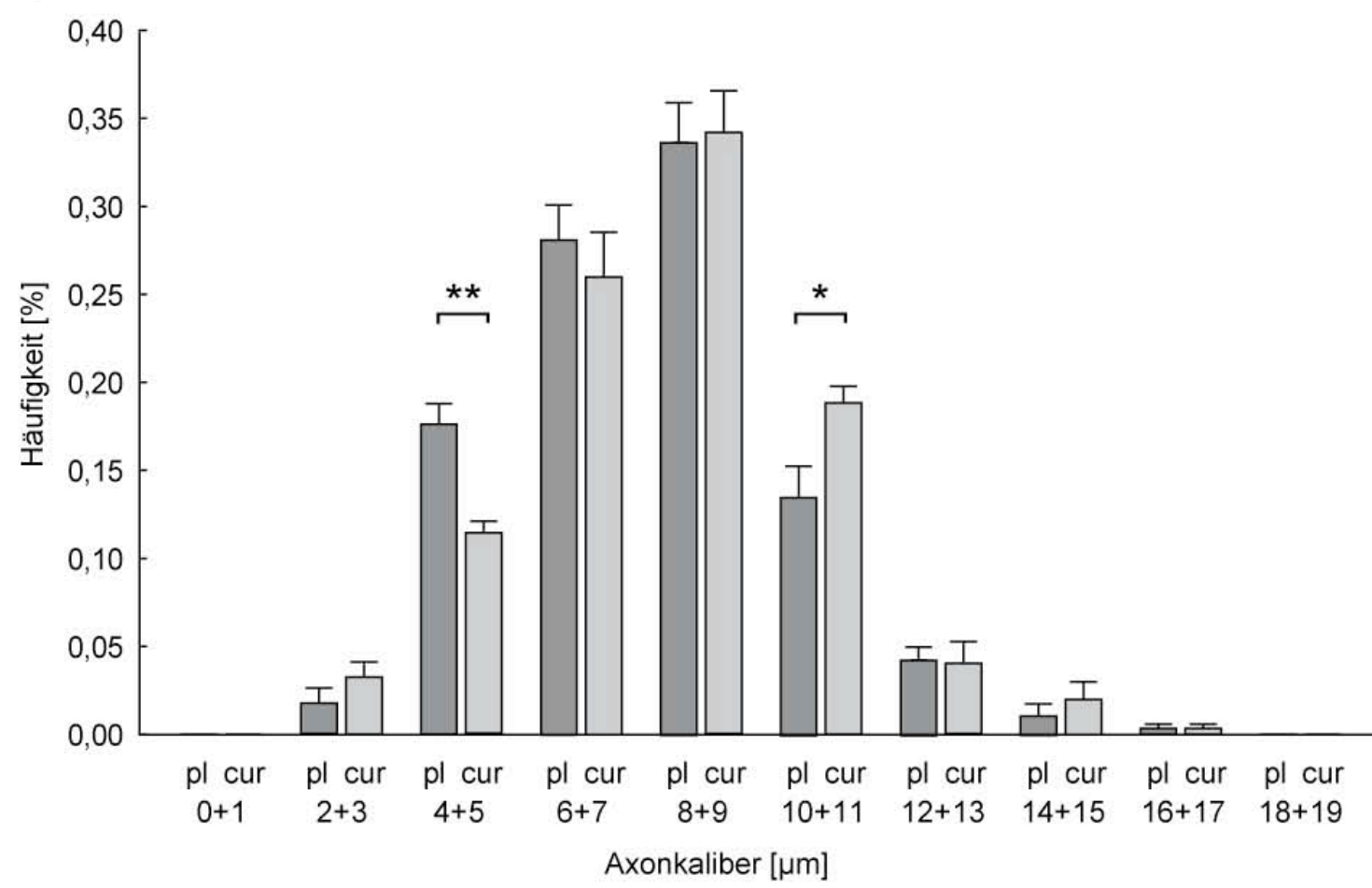

\section{Abbildung 21: Verringerter axonaler Verlust und erhöhtes Axonkaliber nach Curcumin-Therapie}

Repräsentative Ausschnitte histologischer Präparate peripherer Nerven zeigen myelinisierte Axone im Querschnitt. Wildtyptiere weisen ein regelrechtes Myelinisierungsmuster auf (A), wohingegen bei CMT-Ratten zusätzlich hypo- und unphysiolo- 
gisch unmyelinisierte Axone imponieren (B, C). Nach Curcumin-Therapie scheinen diese Pathologien weniger stark ausgeprägt (C). Bei der Quantifizierung aller Axone eines Nervenquerschnittes kamen CMT-Ratten verglichen mit Wildtyptieren auf eine geringere Gesamtzahl. Dieser axonale Verlust wurde durch die Curcumin-Therapie um $27 \%$ reduziert (D). Als Ausdruck für den Grad der Myelinisierung zeigte sich ein g-Ratio-Unterschied zwischen Wildtyp- und CMT-Ratten. Auf lichtmikroskopischer Ebene konnte hingegen kein Unterschied zwischen den Curcumin- und Placebo-behandelten Tieren dargestellt werden (E), lediglich das Axonkaliber war nach Curcumin-Therapie erhöht (F) (pl: Placebo behandelte CMTRatten, cur: Curcumin behandelte CMT-Ratten). 


\subsection{Keine Therapieerfolge mit Acetylsalicylsäure}

\subsubsection{Keine Verbesserung der Griffstärken}

Der Phänotyp wurde im Verlauf der Therapie in dreiwöchigem Abstand durch den Griffstärketest bestimmt. Stets war ein signifikanter Unterschied zwischen Wildtyp- und CMT-Ratten darzustellen. Die Therapie mit ASS zeigte keinen Einfluss auf den klinischen Phänotyp (Abbildung $22 \mathrm{~A}, \mathrm{~B}$ ).

\subsubsection{Unveränderte Nervenleitgeschwindigkeiten und Muskelsummen- aktionspotentiale}

In Zusammenarbeit mit Herrn Dipl.-Biol. Robert Fledrich wurden elektrophysiologische Messungen durchgeführt. Auch hierbei war die wildtyp-transgen-Differenz messbar. Die ASSbehandelten Tiere zeigten keine signifikanten Verbesserungen, ein Trend zu höherer Nervenleitgeschwindigkeit war mit einem p-Wert von 0,12 jedoch zu erkennen (Abbildung $22 \mathrm{C}, \mathrm{D}$ ).

\subsubsection{Unbeeinflusster axonaler Verlust}

Durch Quantifizierung der Axone von Nervus tibialis Querschnitten wurden die histologischen Merkmale der demyelinisierenden Neuropathie dargestellt. Ein Trend zu weniger axonalem Verlust und einem geringeren Anteil unphysiologisch unmyelinisierter Axone war zu erahnen. Der p-Wert lag jeweils bei 0,14 (Abbildung 22 E, F). 


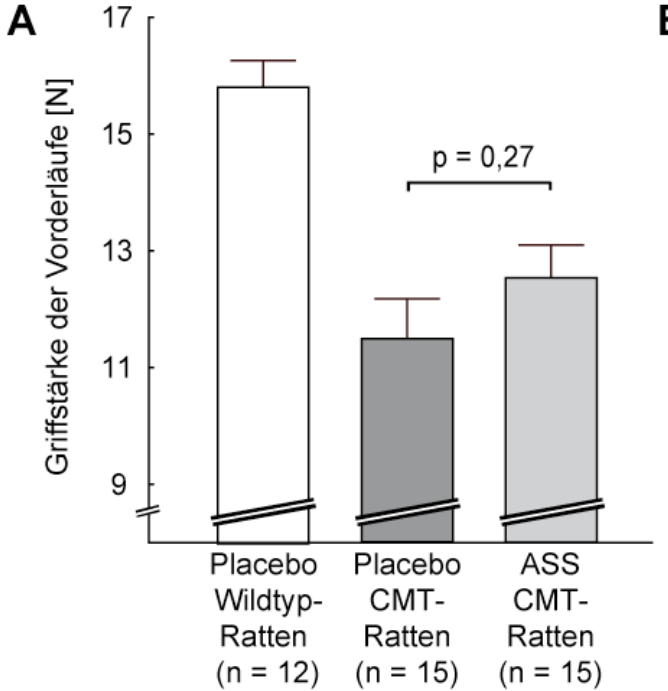

B

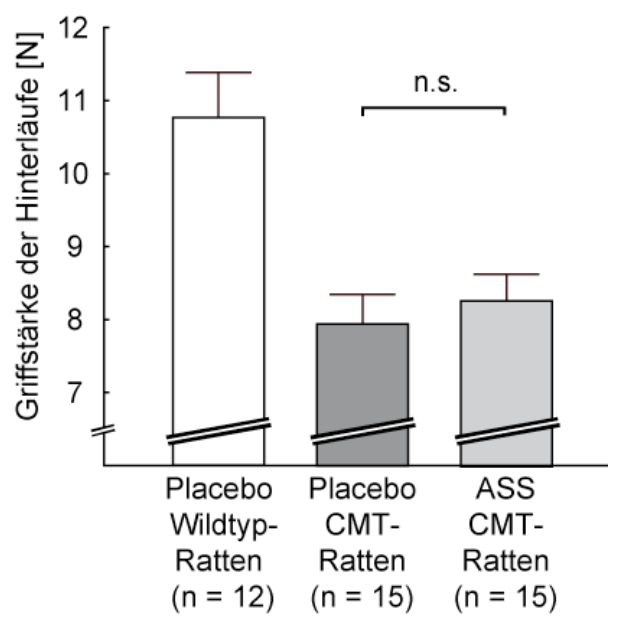

C

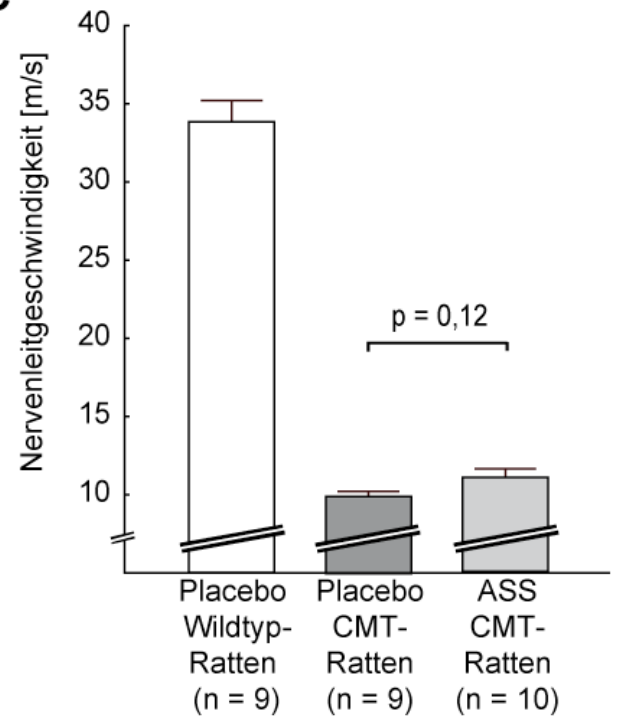

D

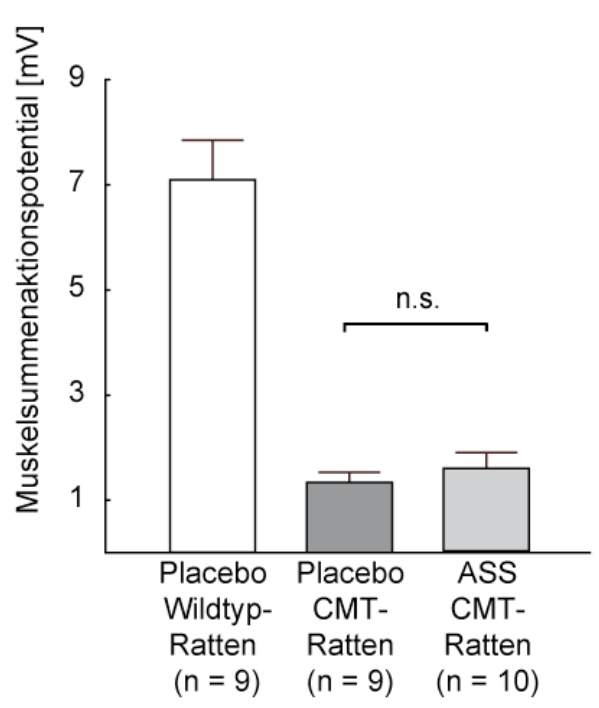

E

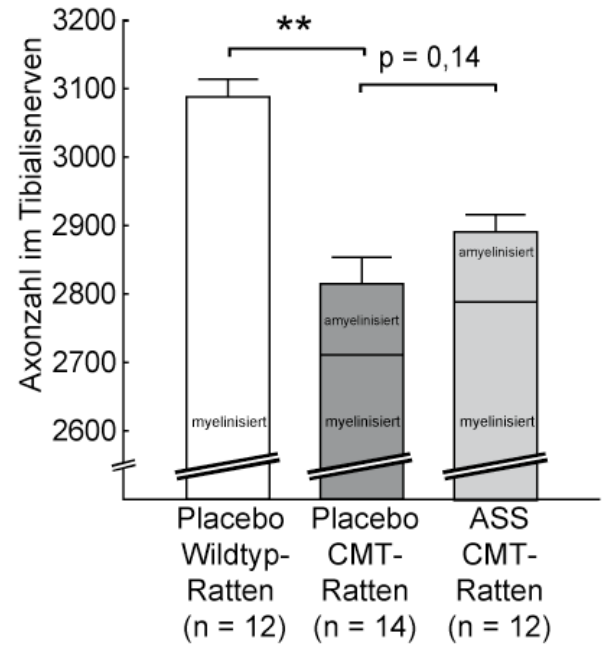

$\mathbf{F}$

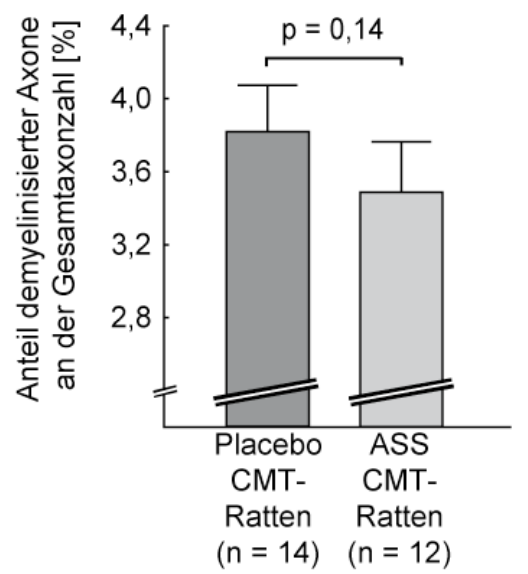

Abbildung 22: Keine Auswirkungen der Therapie mit Acetylsalicylsäure auf Nervenleitgeschwindigkeit,

\section{Muskelsummenaktionspotential und axonalem Verlust}

Eine Verbesserung von Phänotyp (A, B), elektrophysiologischen Messparametern (C, D) und histologischen Merkmalen (E, F) wurde durch die Therapie mit Acetylsalicylsäure nicht erzielt. 


\subsection{Unsichere Therapieergebnisse mit Erythropoetin}

\subsubsection{Verbesserungen der Griffstärken einiger Tiere}

Nach erfolgter Stratifizierung wurde der Phänotyp der Tiere nach drei und am Ende der Therapie nach sechs Wochen bestimmt. Der wildtyp-transgen-Unterschied war stets darzustellen, eine signifikante Verbesserung nach erfolgter EPO-Therapie wurde indes nicht gezeigt (Abbildung 23 A). Innerhalb der Gruppe EPO-behandelter Tiere zeigten sich klinisch jedoch Auffälligkeiten. Einige Tiere präsentierten mit dem Nachziehen einer hinteren Extremität ein gestörtes Gangbild. Zudem wurde an den Hinterläufen dieser Tiere eine auffällige Rötung mit Übererwärmung und Umfangzunahme beobachtet. Unter Ausschluss dieser Tiere von der statistischen Auswertung zeigte sich eine signifikante Verbesserung im Griffstärketest (Abbildung $23 \mathrm{~B}$ ).

\subsubsection{Erhöhter Hämatokrit und keine Antikörperbildung gegen endogenes Erythropoetin}

Um die Entwicklung einer Erythroblastopenie durch Antikörper gegen endogenes Erythropoetin infolge chronischer Behandlung mit exogenem EPO auszuschließen, wurde durch Herrn Dr. Arno Kromminga, IPM Biotech (Hamburg, Germany) ein ELISA Antikörpersuchtest durchgeführt. In den Seren der behandelten Ratten konnten keine Antikörper nachgewiesen werden.

Der Hämatokrit (Hk) wurde am Ende der Therapiestudie bestimmt. Bei den EPO-behandelten Tieren lag der Hk erwartungsgemäß über dem der Placebo-behandelten Tiere. Während letztere einen mittleren Wert von $53 \%$ aufwiesen lag der Hk nach EPO-Behandlung bei ca. $68 \%$. Bei den Tieren mit klinischen Auffälligkeiten wurden Spitzen von bis zu $78 \%$ erreicht. Interessanterweise war der Hk verglichen mit den Wildtyptieren auch bei Placebo-behandelten CMT-Ratten signifikant erhöht (Abbildung 23 C). 


\subsubsection{Fehlender Einfluss auf den axonalen Verlust}

Die am Ende der Studie präparierten Tibialisnerven wurden lichtmikroskopisch auf Pathologien untersucht. Der Unterschied in der Axonanzahl war zwischen Wildtyp- und transgenen Ratten signifikant. Die sechswöchige EPO-Behandlung hatte auf die Axonzahl der CMTRatten keinen Einfluss (Abbildung 23 D).

A

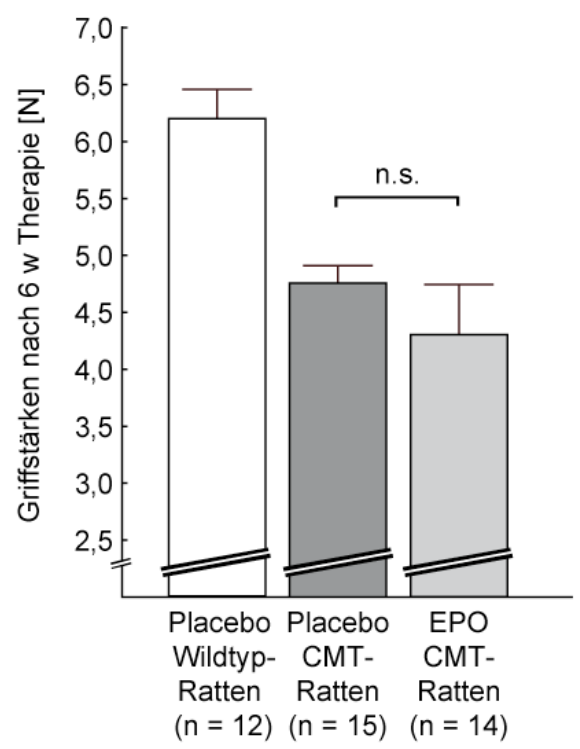

C

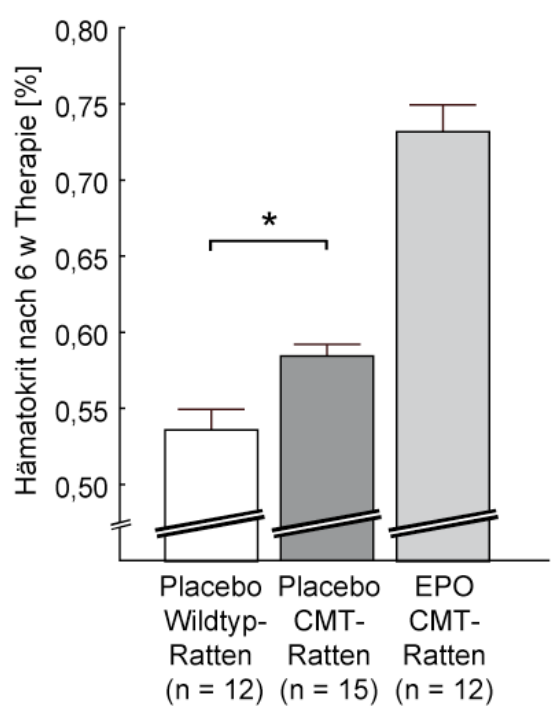

B
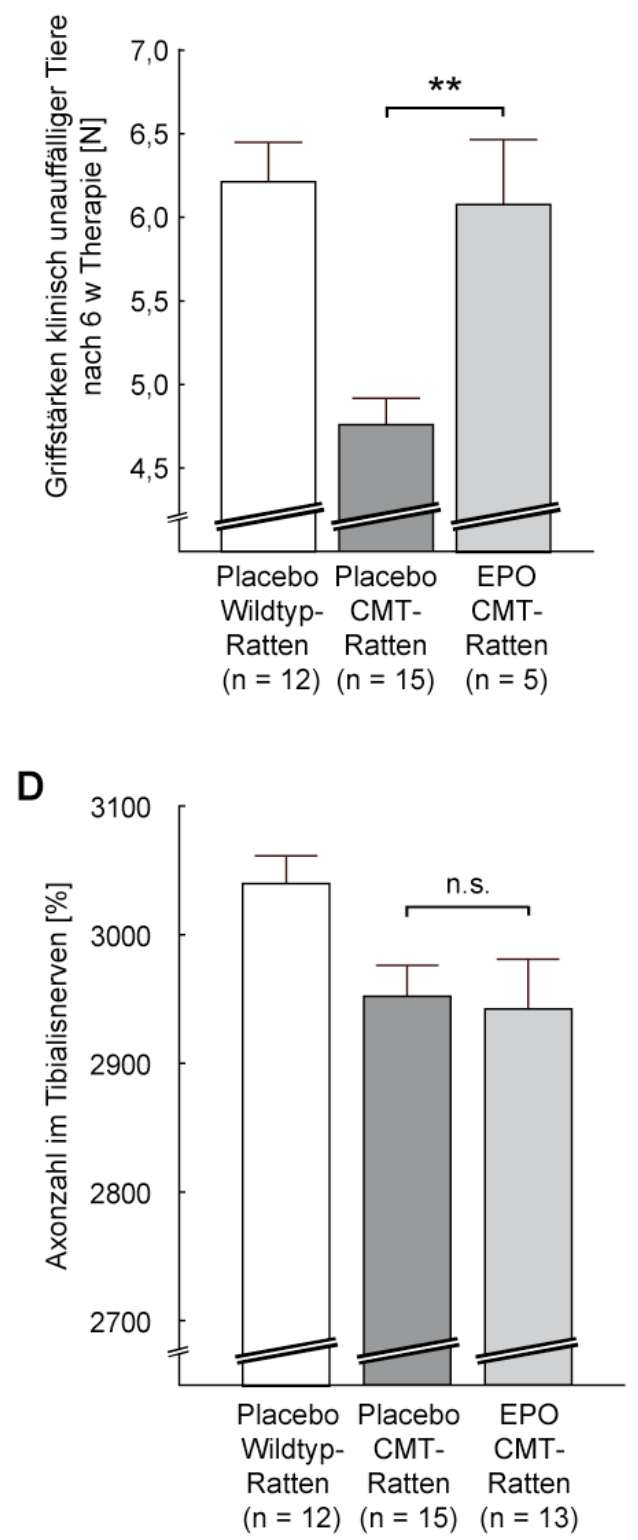

Abbildung 23: Therapie mit Erythropoetin verbesserte bei einigen CMT-Ratten den klinischen Phänotyp, der Axonverlust blieb unverändert

Unter Berücksichtigung aller EPO-behandelter Tiere zeigte sich keine Verbesserung des Phänotyps. Wurden ausschließlich EPO-behandelte Tiere ohne zusätzliche klinische Erkrankungssymptomatik (beschrieben im Text) berücksichtigt, Verbesser- 
te sich die Griffstärke gegenüber den Placebo-behandelten Tieren (A, B). Der Hämatokrit erhöhte sich im Zuge der EPOTherapie signifikant. Signifikant erhöht war der Hk im Vergleich zu Wildtyp-Ratten auch bei Placebo-behandelten transgenen Tieren (C). Auf die Axonanzahl hatte die EPO-Therapie keine Auswirkungen (D). 


\subsection{Auswirkungen der T0901317-Behandlung auf die PMP22- Überexpression}

\subsubsection{Veränderte Expression von Abcal und Pmp22 in Ischiasnerven}

Die Genexpression in Gewebe des Nervus ischiadikus wurden in Zusammenarbeit mit Frau Dr. rer.-nat. Amalia Trousson analysiert. Zielgen von T0901317 ist das Abcal (Repa et al. 2000). Nach oraler Applikation von 5, 20 und $50 \mathrm{mg} / \mathrm{kg} \mathrm{KG} \mathrm{T0} \mathrm{stieg} \mathrm{auch} \mathrm{im} \mathrm{peripheren}$ Nervengewebe die Expression von Abcal signifikant an, Placebo-behandelte Tiere zeigten hingegen nur geringe Expressionslevel. Eine Dosis-Wirkungs-Beziehung war ersichtlich (Abbildung 24 A). Weitere Expressionsanalysen aus Lysaten des Nervus ischiadicus zeigten erwartungsgemäß die signifikante Pmp22-Überexpression in der Gruppe Placebo-behandelter CMT-Ratten. Des Weiteren wurde demonstriert, dass die Applikation von T0 eine signifikante Reduktion dieser Pmp22-Überexpression zur Folge hat. Auch hierbei war eine DosisWirkungs-Beziehung zu erahnen, jedoch nicht in so ausgeprägten Maße wir bei Abcal. Schon in der kleinsten Dosis führte T0 zu einer Reduktion der Pmp22-Expressionslevel auf beinahe wildtyp-Niveau. Höher Dosierungen T0 führten sogar zu einem Unterschreiten des Pmp22Wildtyplevels, jedoch verglichen mit der geringsten Dosis ohne statistische Signifikanz (Abbildung 24 B). 
B

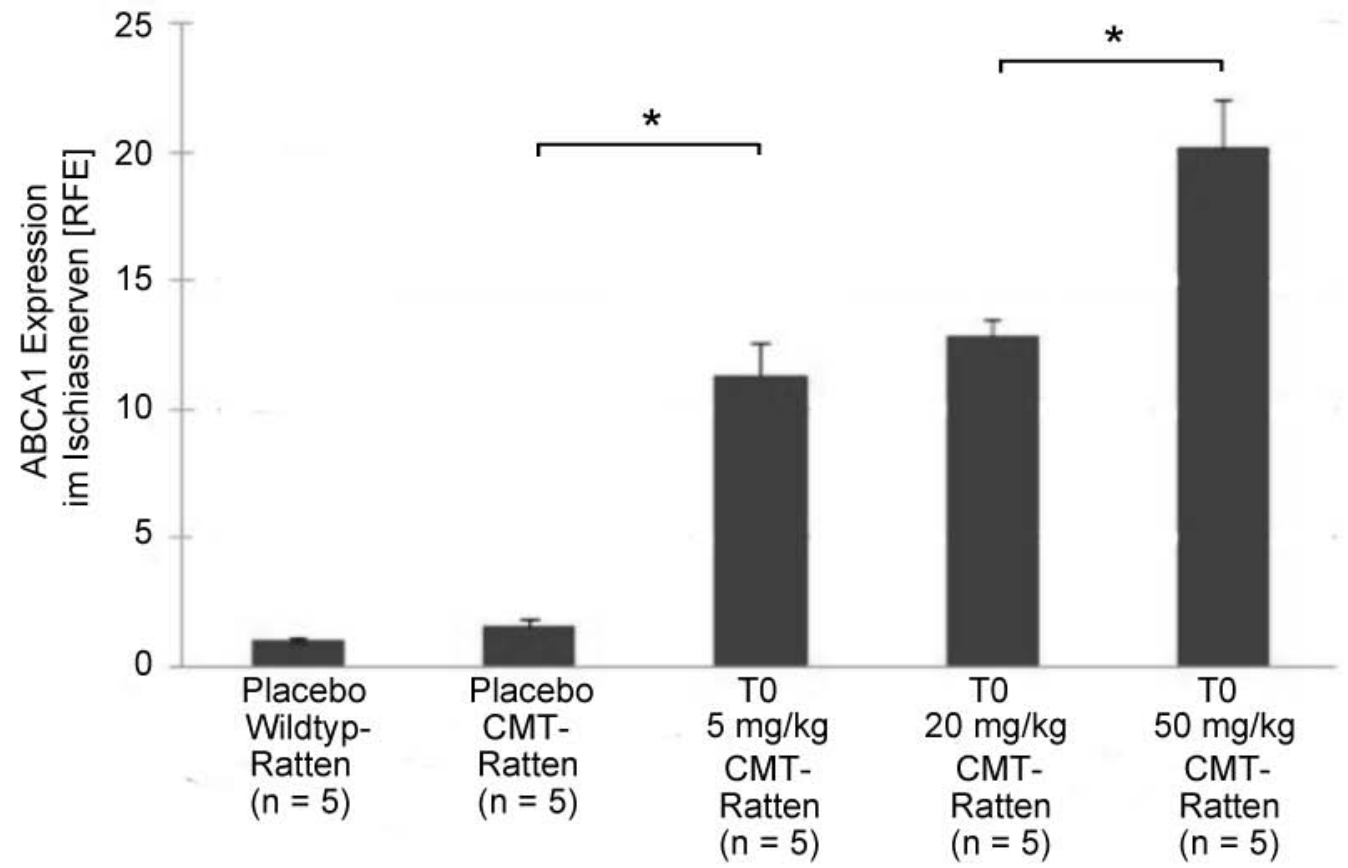

A

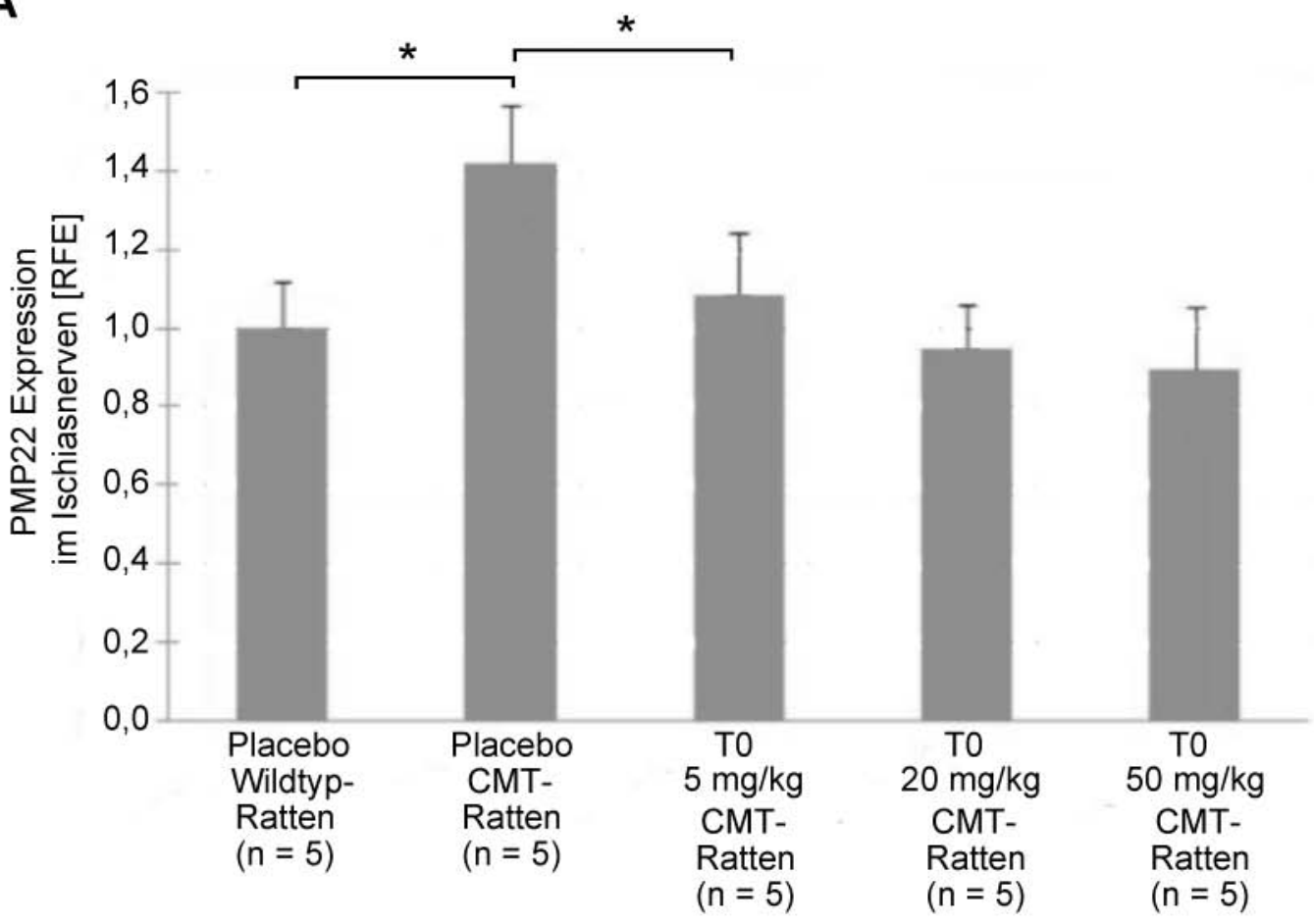

\section{Abbildung 24: Pmp22-Expression reduziert nach Behandlung mit T0901317}

Nach 5 Tagen oraler Behandlung mit T0 zeigte sich eine gesteigerte Expression des Zielgens Abcal. Eine Dosis-WirkungsBeziehung war ersichtlich. Placebo-behandelte Tiere zeigten keine gesteigerte Expression, normalisiert wurde auf den Standard 26S (A). Mit allen drei Dosierungen wurde eine Reduktion der Pmp22-Expression erzielt. Erreicht wurden Level entsprechend der Placebo-behandelten Wildtypgruppe (B). (RFE: relative Fluorezenzeinheiten). 


\subsubsection{Erhöhtes Lebergewicht nach T0-Therapie}

Es ist bekannt, dass T0 zu einer transienten Steatosis von Lebergewebe führt. Zur Dokumentation des Ausmaßes der Leberverfettung wurde am Ende des Pilotexperiments Lebergewebe entnommen und dessen Masse bestimmt. Alle applizierten Dosierungen führten zu einer signifikanten Erhöhung des Lebergewichts. Eine Dosis-Wirkungs-Beziehung war klar ersichtlich. Bei den mit $50 \mathrm{mg} / \mathrm{kg} \mathrm{KG}$ behandelten Tieren verdoppelte sich das Lebergewicht verglichen zu den Placebogruppen (Abbildung 25).

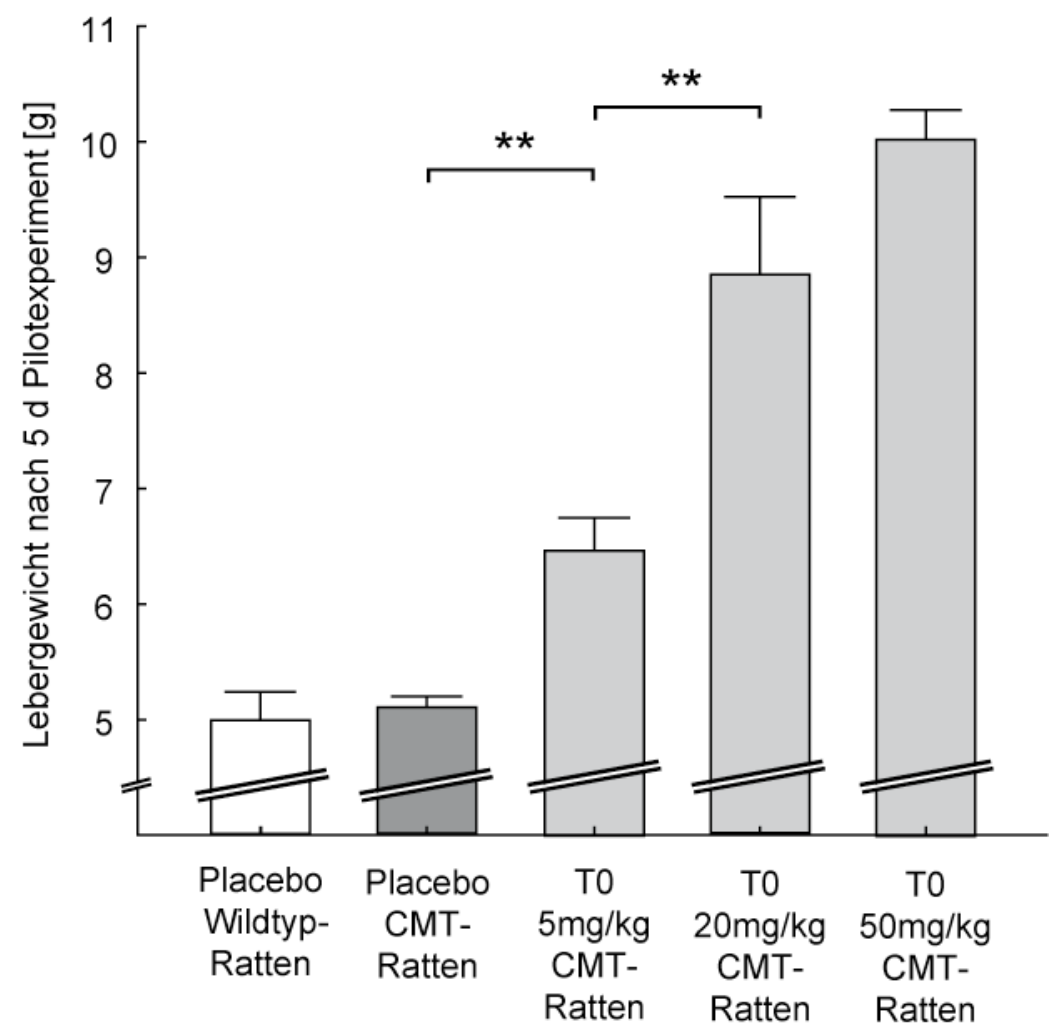

\section{Abbildung 25: Lebergewicht nach fünftägiger T0-Therapie erhöht}

Die am Ende des Pilotexperiments entnommenen Lebern wurden zur Bestimmung des Ausmaßes ihrer Verfettung gewogen. Alle applizierten Dosierungen führten zu einer Erhöhung des Lebergewichtes, eine Dosis-Wirkungs-Beziehung bestand $(\mathrm{n}=$ 5 pro Gruppe). 


\section{Diskussion}

\subsection{Lonaprisan zur Behandlung der CMT1A}

\subsubsection{Verbesserter Phänotyp, Linderung der Axonpathologien und verrin- gerter alpha-Motoneuronverlust bei CMT-Ratten nach Lonaprisan- Behandlung}

In der vorliegenden Arbeit wurde erneut gezeigt, dass ein Progesteronrezeptorantagonist in der Lage ist, die PMP22-Überexpression zu reduzieren. Zudem konnte mittels verschiedener Testverfahren bei zunehmendem Alter und längerer Behandlungsdauer die Verbesserung des klinischen Phänotyps demonstriert werden: Lonaprisan-behandelte CMT-Ratten erreichten beim Stangen- und Griffstärketest sowie bei den elektrophysiologisch gemessenen Muskelsummenaktionspotentialen bessere Ergebnisse als Placebo-behandelte CMT-Ratten; die Testergebnisse bestätigten sich gegenseitig.

Kongruent mit den erhöhten Muskelsummenaktionspotentialen zeigte die histologische Analyse peripherer Nerven einen signifikant verringerten axonalen Verlust nach Lanprisanbehandlung, was in einer Verbesserung des Phänotyps resultierte. Die Gesamtanzahl der Axone lag auf Niveau der Wildtypgruppe. Dennoch stellte sich auch bei Lonaprisan-behandelten CMT-Ratten ein gegenüber der Wildtypsituatiuon reduzierter Phänotyp dar. Diesbezüglich können verschiedene mögliche Gründe herangezogen werden: Zum einen zeigten die Nerven Lonaprisan-behandelter CMT-Ratten stets Axonpathologien der demyelinisierenden Neuropathie. Zwar konnte der Untergang der Axone verhindert bzw. aufgehalten werden, stets ließen sich jedoch noch hypo-, inadäquat hypermyelinisierte und auch unphysiologisch unmyelinisierte Axone quantifizieren. Auch eine gestörte Reizübertragung an den motorischen Endplatten ist als Ursache für den nach Lonaprisan-Therapie nicht der Wildtypsituation entsprechenden Phänotyp denkbar. Der bei dieser Therapiestudie ebenfalls präparierte distal gelegene Musculus tibialis cranialis sollte in elektronenmikroskopischen Analysen auf Pathologien an der neuromuskulären Reizübertragung untersucht werden. Weitere Aufmerksamkeit sollte zudem den nodalen und paranodalen Regionen des Ranvierschen Schnürrings gewidmet werden. Bei PMP22-transgenen Mäusen der Linie C61 wurde kürzlich gezeigt, dass in der paranodalen Region spannungsabhängige Kaliumkanäle abnormal verteilt oder nicht exprimiert 
waren (Kohl et al. 2010a). Da Kaliumkanäle für die Wiederherstellung des Ruhemembranpotentials unabdingbar sind, könnte das Fehlen oder eine Missverteilung in einer Funktionseinschränkung und somit nicht wildtypgleicher Muskelkraft resultieren. Die Hypothese wurde aufgestellt, dass eine reduzierte Muskelkraft direkt mit dieser abnormen Kaliumkanalverteilung zusammenhängt (Kohl et al. 2010a). In Zupffaserpräparaten aus Ischiasnerven sollte in Zukunft auch diese mögliche Veränderung untersucht werden, um die Gründe für die auch nach Lonaprisan-Therapie stets nicht vollständige Behandlung der bei CMT-Ratten reduzierten Muskelkraft zu beleuchten.

Immunhistochemisch wurden in peripheren Nerven von CMT-Ratten vermehrt Makrophagen nachgewiesen. Es ist anzunehmen, dass diese im Zuge der Demyelinisierung sowie des Axonverlusts vermehrt einwandern und die Myelinbruchstücke phagozytieren. Das ist kongruent mit der Beobachtung von signifikant weniger Makrophagen nach Lonaprisan-Therapie, wobei die Makrophagenzahl mit dem Ausmaß des Axonverlusts korrelierte. Als ein sekundärer Effekt der Axonpathologie könnten mehr Makrophagen einwandern und die untergehenden Gewebsstücke phagozytieren. Eine andere Möglichkeit wäre die aktive Beteiligung der Makrophagen am Krankheitsgeschehen der CMT als primärem Effekt. Beschrieben wurde, dass die PMP22-Überexpression zu intrazellulärem Stress der Schwannzelle führt, woraufhin diese MCP-1 exprimiert. MCP-1 würde im folgenden Makrophagen anlocken und aktivieren, es käme zu einem aktiven Prozess der Phagozytose (Kohl et al. 2010a). Unterstützt wurde diese Annahme durch elektronenmikroskopische Aufnahmen, die Makrophagen bei der Phagozytose von scheinbar intaktem, also morphologisch unversehrtem Myelin zeigten (Kobsar et al. 2005). Die Auswirkung der Lonaprisan-Therapie auf die erhöhte Anzahl der Makrophagen ließe sich über beide Ansichten erklären. Ginge man von einem sekundären Effekt aus, würde aufgrund der weniger anfallenden Gewebsbruchstücke eine geringere Zahl an Makrophagen benötigt. Im Falle des primären Effekts, also der aktiven Beteiligung von Makrophagen an der Myelindestruktion, würde die durch Lonaprisan verringerte PMP22Überexpression direkt in die beschriebene Kaskade eingreifen. Die Normalisierung der Überexpression würde den intrazellulären Stress reduzieren, folglich würde weniger MCP-1 ausgeschüttet und weniger Makrophagen angelockt und aktiviert (Abbildung 26).

Differenzierter betrachtet wurden in dieser Arbeit auch die alpha-Motoneurone (MN) der Vorderhörner des Rückenmarks. Veränderungen in diesen sind neben dem axonalen Verlust als Ursache für den klinischen Phänotyp der CMT-Ratten anzusehen. Eine Korrelation von motorischen Defiziten mit der Anzahl erhaltener MN wurde beschrieben (Norreel et al. 2003). Die Quantifizierung der alpha-Motoneurone in CMT-Ratten ergab tatsächlich, dass neben 
dem axonalen Verlust auch ein Verlust von MN vorliegt. Diese Beobachtung ist nicht neu, da bereits in Pmp22-überexprimierenden Mausmodellen (TgN248 und C22-Mauslinie) ein MNVerlust demonstriert wurde, doch waren diese Arbeiten trotz des eindeutigen Ergebnisses kritisch zu hinterfragen. Zur Quantifizierung wurden die MN retrograd markiert, indem vor Präparation ein lipophiler fluoreszenter Tracer an den distalen Stumpf der Ischiasnerven platziert wurde. Der Farbstoff sollte axonal retrograd in Richtung Rückenmark transportiert werden und schließlich eine histologische Quantifizierung der fluoreszent markierten MN ermöglichen (Nattkamper et al. 2009; Norreel et al. 2003). Bei einer Erkrankung mit axonalem Verlust als charakteristischem Merkmal ist eine retrograde Markierung von MN aber sicher nicht die am besten geeignete Methode. Zudem wurde bei CMT-Erkrankungen häufig eine Beeinträchtigung des axonalen Transports diskutiert (de Waegh und Brady 1990; Garcia et al. 2003; Nave et al. 2007). Eine Bestätigung dieser Ergebnisse mit gezielterer Methode, nämlich die Quantifizierung direkt angefärbter $\mathrm{MN}$ in Rückenmarksquerschnitten, war somit notwendig. Auch konnte bestätigt werden, dass es sich bei dem MN-Verlust nicht um ein Artefakt des nicht idealen Tiermodels handelt. Verwandt wurden von Nettkamper et al. 2009 Tiere der Mauslinie TgN248, die mit 16 Kopien des Pmp22-Gens und einer höheren Überexpressionsrate einen weit ausgeprägteren klinischen und histopathologischen Phänotyp zeigen (Magyar et al. 1996). Die dysmyelinisierende anstatt der demyelinisierenden Nervenpathologie spiegelt nicht ideal die Situation der CMT1A-Patienten wieder. Für solche Analysen besser geeignet, also näher dem humanen klinischen und histopathologischen Phänotyp, war somit die CMTRatte (Sereda und Nave 2006). Interessanterweise konnte in dieser Doktorarbeit noch über die Bestätigung der von Nettkamper et al. 2009 erhobenen Ergebnisse hinaus der Einfluss von Lonaprisan auf den MN-Verlust demonstriert werden. Die nach der Therapie signifikant erhöhte Zahl erhaltener MN könnte also neben dem verhinderten Axonverlust eine weitere Ursache für den deutlich verbesserten Phänotyp liefern. Norreel et al. 2003 demonstrierten in der C22-Mauslinie bereits die Korrelation der motorischen Defizite mit der Anzahl erhaltener MN, wohingegen die Anzahl myelinisierter Axone sowie die Dicke der Myelinscheide ( $g$ Ratio) nicht mit dem Phänotyp korrelierten. Es ist somit anzunehmen, dass bei zwar verhindertem Axonverlust aber stets vorhandenen Myelinpathologien auch die Wirkung von Lonaprisan auf Rückenmarksebene die Phänotypverbesserung bedingt. 


\subsubsection{Mögliche Wirkmechanismen des Progesteronantagonisten auf Schwannzell- und neuronaler Ebene}

Auf vielen Ebenen konnte ein Wirken von Lonaprisan gezeigt werden. Der Phänotyp verbesserte sich signifikant, dementsprechend auch das Muskelsummenaktionspotential. Der Axonund MN-Verlust wurde reduziert und als Ausdruck einer milder verlaufenden Axonopathie verringerte sich die Anzahl der endoneuralen Makrophagen.

Wie aber entfaltet der Progesteronrezeptorantagonist seine positive Wirkung auf den Krankheitsverlauf? Auf Schwannzellebene senkt er die PMP22-Überexpression und -durch einen erhaltenen axosupportiven Effekt der Schwannzelle unabhängig ihrer Myelinisierung- den axonalen Verlust (Meyer zu Hörste et al. 2007). Bei Nagetieren und Menschen wurde kürzlich die Expression von PMP22-mRNA und -Protein auch in alpha-Motoneuronen des Rückenmarks gezeigt (Ohsawa et al. 2006; Parmantier et al. 1995). Somit könnte auch in MN die PMP22-Überexpression einen Beitrag zu deren Untergang leisten. Pmp22-Knockout Mäuse zeigen diese Histopathologie der alpha-Motoneuronen nicht, dafür aber Änderungen in ihren Expressionsprofilen. Diese ähnelten denen von Motoneuronen nach Nervenverletzung. Gene, wie Gap43 und Sprrlal, die bei neuronalem Wachstum und Regeneration als differentiell reguliert beschrieben wurden, zeigten sich vermehrt exprimiert. In der Pmp22Überexpressionssituation zeigten sich keine entsprechenden Veränderungen in solchen Expressionsprofilen (Nattkamper et al. 2009). Pmp22-Überexpression spielt folglich eine Rolle beim Untergang von MN in der CMT1A. Der genaue Mechanismus ist jedoch auch hier noch unklar.

Es gilt somit zwei Fragen anzugehen. Zum einen wie es bei der CMT1A-Erkrankung zum Verlust von alpha-Motoneuronen kommt und welche Rolle dabei das PMP22 spielt. Zum anderen, auf welche Weise der Motoneuronenverlust durch eine ProgesteronantagonistenTherapie aufgehalten werden konnte. Gibt es eine direkte neuronale Wirkung der PA, oder handelt es sich bei dem Untergang der MN um das Phänomen des Rücksterbens („DyingBack“--Phänomen) von Axonen zu Neuronen? Dagegen spricht, dass Pmp22-Knockout-Mäuse zwar einen axonalen Verlust demonstrieren, jedoch keinen Motoneuronverlust (Adlkofer et al. 1995; Nattkamper et al. 2009). Um die Wirkung des PA Lonaprisan auf diese Prozesse zu durchleuchten, wird in bereits laufenden Experimenten die vorteilhafte Lage genutzt, Gewebe dreier verschiedener Ausgangssituationen zu vergleichen, nämlich die nach erfolgreicher Therapiestudie präparierten Gewebe von Wildtyp-Ratten sowie von CMT-Ratten mit und ohne Phänotypverbesserung. In einem ersten Schritt werden mit DNA-Mikroarrays von Spinalgan- 
glien (ausschließlich neuronale Perikarya, keine Schwannzellkerne) Expressionsprofile aus diesem rein neuronalen Gewebe erstellt, um anschließend differentiell regulierte Gene auf Real-Time-PCR-Ebene zu validieren. Denkbar sind zum Beispiel sogenannte Regenerationsassoziierte Gene (RAG genes - recovery associated genes) wie das bereits oben genannte Sprrlal. In einem zweiten Schritt sollen diese Gene in durch Laser Capture Microdissection isolierten alpha-Motoneuronen überprüft werden. Und all das stets mit dem im Zuge dieser Doktorarbeit generierten Geweben, vergleichend zwischen Wildtyp und transgenen Tieren, jeweils mit bzw. ohne vorangegangene Lonaprisan-Therapie. Über Datensatz-Analysen können nach Lonaprisan-Therapie regulierte Signalwege ausfindig gemacht werden, welche die neuroprotektive Komponente der Progesteronantagonisten erklären. Mit diesem Wissen könnten neue Targets für ein spezifisches Drug Design definiert werden und im besten Fall eine nebenwirkungsärmere Alternative zum PA liefern. Des Weiteren könnten sich aus neuen Erkenntnissen der PA-Wirkung Therapieansätze für andere neurodegenerative Erkrankungen ableiten lassen, deren Pathogenese nicht auf einem primären Schwannzelldefekt beruht.

\subsubsection{Der diagnostische Biomarker Igfbp5 als Readout einer Lonaprisan- Studie und Möglichkeiten prognostischer Marker bei Therapien der CMT1A}

Das Ziel der Translation präklinisch gewonnener Therapieansätze in erste klinische Studien sollte durch die Bereitstellung von Biomarkern erleichtert werden. Igfbp5 wurde als ein solcher diagnostischer Marker validiert. Seine Expression korreliert signifikant mit dem klinischen Phänotyp sowohl bei Placebo- als auch Lonaprisan-behandelten CMT-Ratten. Mit Igfbp5 wurde somit eine zusätzliche Variable geschaffen, um die Auswirkungen einer Therapie zu monitoren. In einer vom BMBF finanzierten Mulitzenterstudie werden in der CMTRatte definierte Biomarker (Fledrich et al. 2012) bereits an einer ersten Kohorte Duplikationspositiver CMT1A-Patienten validiert. Durch die neu gewonnene Erkenntnis des Ansprechens von Igfbp5 auf die Lonaprisan-Therapie könnte auch im Rahmen einer ersten klinischen Therapiestudie der Verlauf bzw. das Ansprechen mittels Igfbp5 überprüft werden. Man wäre nicht mehr ausschließlich auf den in seiner Änderung sehr trägen CMTNS angewiesen. Sowohl Igfbp5 als auch Igfl konnten in dieser Arbeit als prognostische Marker validiert werden. Ihre Expression zu einem früheren Zeitpunkt korrelierte mit der späteren Erkrankungs- 
schwere. Somit kann mittels dieser prognostischen Marker früh eine Aussage über die zu erwartende Erkrankungsschwere getroffen werden. Bei Patienten würde das Entscheidungen beispielsweise für oder gegen eine nebenwirkungsreiche Therapie erleichtern. Die in dieser Arbeit validierten prognostischen Marker sollen als Exampel dienen, sie entstammen aber nicht der Liste von Fledrich et al. 2012 als hoch signifikant etablierten Biomarker. Sie werden somit nicht als prognostische Marker bei Patienten validiert. Es ist in dieser Arbeit nicht gelungen Signifikanzen bei den etablierten prognostischen Marker zu erzielen. Eine sehr kleine Tierkohorte und der mit 4 Wochen anstatt mit 5 Tagen gewählte Biopsiezeitpunkt liefern dafür eine Erklärung. Der späte Biopsiezeitpunkt schafft eine andere Ausgangssituation. Nach 4 Wochen ist die Erkrankungssymptomatik bereits manifest, das Tier befindet sich in der Adoleszenz, während im Alter von 5 Tagen ein Ausbruch der Erkrankung erst bevorsteht. Bei zukünftigen Studien sollte somit bereits vor Therapiebeginn, in diesem jungen Alter eine Hautbiopsie entnommen werden. Mit diesen Proben ließe sich auch ein weiterer Ansatz überprüfen. Um mittels Biomarker im Vorfeld eine Unterscheidung zwischen Respondern und Non-respondern einer Therapie zu ermöglichen, müssten bei der Analyse prognostischer Marker auch Lonaprisan- (oder eine andere Prüfsubstanz) behandelte Tiere und nicht wie bisher ausschließlich Placebo-behandelte/untherapierte Tiere betrachtet werden. Dazu würden auf Einzeltierebene die Expressionslevel vor und nach einer Therapie verglichen und mit dem Phänotyp korreliert werden. Patienten, bei denen kein Ansprechen zu erwarten ist, könnten somit eine nebenwirkunsreiche aber erfolglose Therapie erspart bleiben.

Für die Durchführungen zukünftiger Studien lassen sich also folgende Verbesserungen zusammenfassen: Um auch prognostische Biomarker zu etablieren sollten Hautbiopsien bereits vor Therapiebeginn im Alter von 5 Tagen entnommen werden. Des Weiteren sollten im Verlauf der Therapie in regelmäßigen Abständen Biopsieentnahmen erfolgen um schließlich longitudinale Markerexpression und Phänotypentwicklung zu analysieren und zu vergleichen.

Mit einem großen Repertoire an validierten Biomarkern wäre eine letzte Verwendung denkbar. Sie könnten als Readout beim Screening nach neuartigen Therapieansätzen dienen, denn nicht bei jedem Therapeutikum wären Auswirkungen auf die PMP22-Expression zu erwarten. Hätte aber ein Biomarker Aussagekraft über Auswirkungen einer Therapie auf die Erkrankung könnten in kürzerer Zeit viele therapeutische Ansätze überprüft werden. 


\subsection{Curcumin zur Behandlung der CMT1A}

\subsubsection{Auswirkungen des Curcumin enthaltenden Prüffutters auf die CMT- Ratte}

Mit Curcumin enthaltendem Prüffutter wurden in dieser Arbeit unter Bedingungen nahe der Patientensituation („Clinical Paradigm“) in ihrer Erkrankungsprogression bereits fortgeschrittene CMT-Ratten für drei Monate behandelt. Eine Besserung des Phänotyps war nicht offensichtlich. Curcumintiere zeigten ein um $12 \%$ geringeres Körpergewicht, erreichten jedoch die gleichen Griffstärkewerte wie Placebotiere. Außerdem erschienen die Tiere einem nicht geblindeten Untersucher kräftiger, auch ihr Gangbild wirkte weniger pathologisch. Die am Ende durchgeführten elektrophysiologischen Befunde entsprachen diesem Eindruck. Verglichen mit der Placebokohorte zeigten Curcumintiere erhöhte Muskelsummenaktionspotentiale und Nervenleitgeschwindigkeiten. Somit stellte sich die Frage, warum der Griffstärketest diese Verbesserung nicht anzeigte. Ursache könnte das geringere Körpergewicht aufgrund einer verzögerten Gewichtszunahme der Curcumintiere sein. Auch mit Curcuminfutter ernährte Wildtyp-Ratten zeigten diese verzögerte Gewichtszunahme, obwohl sie die gleiche Menge Prüffutters zu sich nahmen, wie nicht behandelte Tiere reguläres Futter. Grundlage beider Futtermittel war eine speziell für die Ratten Aufzucht entwickelte Mischung der Firma ssniff Spezialdiäten GmbH. Entsprechend des während dieser Aufzuchtphase erhöhten Nährstoffbedarfs wurden Proteingehalt, Proteinqualität (Aminosäurenzusammensetzung) sowie die Energiedichte angehoben. Die umsetzbare Energie lag mit 13,3 MJ/kg höher als bei Futtermischungen für den Erhaltungsstoffwechsel (Angaben der Firma ssniff Spezialdiäten GmbH). Da das Prüffutter jedoch zu einem Anteil von knapp $17 \%$ die Curcumin-Gewürzmischung enthielt, stellte es weniger Energie bereit als das reguläre Futter. Somit ist nachzuvollziehen, dass die um $17 \%$ geringere Aufnahme dieser sehr energiereichen Futtermischung in einer verzögerten Gewichtszunahme endete. Obendrein wurden bei den mit Curcumin-Prüffutter behandelten Tieren häufiger reduzierte Stuhlkonsistenzen bis hin zu Diarrhöen beobachtet. Auch hierdurch erscheint ein Energieverlust möglich und liefert eine weitere Erklärung für die verzögerte Gewichtszunahme.

Offensichtlich beeinflusste die verzögerte Gewichtszunahme den Griffstärketest negativ, da dieser auch von Größe und Masse der Tiere abhängt. Somit wurden als Konsequenz die Daten des Griffstärketests auf das Körpergewicht normalisiert und der Fehler der verzögerten Ge- 
wichtszunahme rechnerisch ausgeglichen. Die derartig normalisierten Werte offenbarten schließlich einen signifikanten Unterschied zugunsten der Curcumin-behandelten Tiere im Sinne einer subjektiv klinischen Verbesserung, was auch durch elektrophysiologische und histologische Untersuchungen bestätigt wurde. Denn wie nach Erhöhung des Muskelsummenaktionspotentials zu erwarten war wurden signifikant mehr Axone quantifiziert. Um $27 \%$ imponierte diese Verringerung des axonalen Verlusts nach dreimonatiger CurcuminBehandlung. Folglich kann der Schluss gezogen werden, dass die Curcumin-Therapie einen beachtlichen positiven Einfluss auf die CMT1A-Erkrankung hat.

Eine so große Menge des Gewürzextrakts über das Tierfutter zu verabreichen war demzufolge wegen der verzögerten Gewichtszunahme nicht die best geeignete Applikationsform. Einfacher aber mit Mehrkosten verbunden wäre eine Therapie mit der Reinsubstanz Curcumin (Diferuloylmethan), deren Anteil am Gewürzextrakt bei ca. $3 \%$ liegt. So könnten $97 \%$ an Futterzusatz/Prüfsubstanz eingespart werden und der Anteil an Prüfsubstanz läge bei nur noch 0,5\%. Ein äquivalentes Prüffutter hätte nahezu gleiche Energiewerte wie das reguläre Futter. Auch Schlundsondierungen wären denkbar und würden zusätzlich den Vorteil liefern, sich der tatsächlich aufgenommenen Dosis bewusst zu sein. Ein weiterer Vorteil von CurcuminReinsubstanz wäre die Gewissheit, einen therapeutischen/biologischen Effekt ausschließlich durch eben diese Substanz hervorgerufen zu haben. Nicht auszuschließen ist nämlich, dass auch die Kalorienrestriktion einen günstigen Effekt bedingte. Eine Studie an TremblerJMäusen (Punktmutation im Pmp22-Gens als neuropathische Ursache) zeigte eine Verbesserung des Krankheitsverlaufs nach 5-monatiger Diät gemäß dem Modell des intermittierenden Fastens (Madorsky et al. 2009). Dabei wird Futter nicht ad libitum gereicht, sondern jeden zweiten Tag bereitgestellt. Eine absolute Kalorienrestriktion bestand nicht, auch kam es verglichen mit der Kontrollgruppe nicht zu einem Gewichtsunterschied. Fasten durch Kalorienrestriktion mit konsekutiver Gewichtsreduktion wurde in Zusammenhang mit altersassoziierter Neurodegeneration jedoch ebenfalls als neuroprotektiv eingestuft (Martin et al. 2006). Folglich ist der einzige Weg sich der Curcumin-Therapie als alleinige Ursache des Behandlungserfolgs sicher zu sein, eine erneute Studie unter optimierten Bedingungen mit der CurcuminReinsubstanz.

Anders als nach der Therapie mit Lonaprisan zeigte sich nach Curcumin-Behandlung als ein weiterer Parameter auch die Nervenleitgeschwindigkeit signifikant erhöht. Diese Verbesserung schien auf Veränderungen in der Myelinisierng hinzuweisen, was nicht ausreichend durch lichtmikroskopische Auswertung des g-Ratios zu offenbaren war. Stattdessen fanden sich signifikant mehr großkalibrige Axone in den Nerven Curcumin-behandelter Tiere. Diese 
Verschiebung des Axonkalibers könnte die erhöhte NLG erklären, was kongruent wäre mit dem Ergebnis einer Curcumin-Behandlung von TremblerJ-Mäusen, bei denen zwar keine elektrophysiologischen Untersuchungen durchgeführt, auf elektronenmikroskopischer Ebene jedoch ein g-Ratio Unterschied demonstriert wurde (Khajavi et al. 2007). Somit ist zu hinterfragen, ob die lichtmikroskopische Analyse des g-Ratios als Methode geeignet sei. Die elektronenmikroskopische Auswertung sollte folglich in Erwägung gezogen werden. Doch auch weitere Gründe für eine erhöhte Nervenleitgeschwindigkeit kommen in Betracht: Sollte sich das g-Ratio auch elektronenmikroskopisch als unverändert herausstellen sollten immunhistochemisch an Zupffaserpräparaten des Ischiasnerven eine Verlängerung der Internodien, wie auch die Verteilung von Natrium- und Kaliumkanälen am Ranvierschen Schnürring bzw. der paranodalen Region untersucht werden.

\subsubsection{Mögliche Mechanismen der Curcuminwirkung bei der CMT1A}

Vieles deutet darauf hin, dass die neuroprotektiv wirkende Substanz Curcumin auch bei CMT-Ratten zu einer Verbesserung erkrankungscharakteristischer Merkmale führte. Insbesondere imponierte der um 27\% verringerte axonale Verlust. Dabei war der Wirkmechanismus nicht die Milderung der PMP22-Überexpression. Wie aber entfaltete Curcumin seine Wirkung auf die CMT1A? Die genauen Mechanismen, wie die PMP22-Überexpression zur CMT1A-Erkrankung führt sind nicht verstanden. Dennoch werden eine Reihe Mechanismen vorgeschlagen, deren Beteiligung an der Pathogenese wahrscheinlich ist. Einige dieser Hypothesen liefern auch Erklärungen für den Ansatz der Curcuminwirkung:

Beschrieben wurde eine durch den PMP22-Überschuss bedingte Überladung der Proteasomen mit reduziertem Protein-Umsatz und konsekutiver Akkumulation von PMP22 neben weiteren ubiquitinierten Substraten. Assoziation dieser Proteinaggregate mit Autophagosomen und Lysosomen lässt einen zellulären Kompensationsmechanismus vermuten, der aber nicht auszureichen scheint den Erkrankungsausbruch abzuwenden. Die beeinträchtigte Proteasomenaktivität wird als Ursache für eine gestörte intrazelluläre Homöostase gesehen (Abbildung 26 C, c') (Fortun et al. 2006). Unter Curcumin-Behandlung wurde in Zellkulturen eine um 46\% erhöhte Proteasomenaktivität erreicht (Ali und Rattan 2006). Über diesen Mechanismus könnte Curcumin auch seine lindernde Wirkung auf die CMT1A-Erkrankung erzielt haben. Nicht Zwangsläufig müssen bei der CMT-Ratte in gleichem Maße Proteinaggregate vorliegen wie in dem von Fortun et al. 2006 betrachteten PMP22-transgenen Mausmodell 
(C22, sieben Transgenkopien). Eine Beeinträchtigung der Proteasomen wäre auch durch die mildere Überexpression im Falle der CMT-Ratte möglich, denn schon unter physiologischen Bedingungen werden gerade mal $20 \%$ des translatierten PMP22 über den Golgi Apparat in Membranen eingebaut (Pareek et al. 1997). Durch eine Leistungssteigerung könnten die Proteasomen leichter den Proteinüberschuss bewältigen, die negativen Auswirkungen auf die intrazelluläre Homöostase würden somit reduziert. Diese Überlegungen sind im Einklang mit einer Studie an einem Mausmodell für Chorea Huntington bei dem der Proteinüberschuss ebenfalls die Proteasomenfunktion beeinträchtigt. Des Weiteren wurde gezeigt, dass die Proteasomendysfunktion in einer dramatischen Expressionsteigerung des MCP-1 resultiert. In der gleichen Arbeit wurde in Zellkulturen eine Reduktion der MCP-1-Expression durch Curcumin-Behandlung erreicht (Godavarthi et al. 2009).

MCP-1 und die dadurch angelockten und aktivierten Makrophagen wurden auch für die CMT1A als ein kritischer Faktor beschrieben (Kohl et al. 2010a), wobei nicht vollends geklärt ist, ob sie aktiv (primärer Effekt) oder passiv (sekundärer Effekt) am Krankheitsgeschehen beteiligt sind. An beiden Seiten wäre eine Wirkung Curcumins über die nach wie vor noch nicht vollständig geklärte chronisch inflammatorische Komponente der CMT1A denkbar. Nach Curcumin-Behandlung wurde in verschiedenen Zelltypen eine Reduktion der MCP-1Expression demonstriert (Amoli et al. 2006; Panicker und Kartha 2009; Woo et al. 2007). Es ist somit möglich, dass auch auf Schwanzellebene Curcumin eine derartige Wirkung aufweist und der aktive Prozess -Phagozytose scheinbar intaktem Myelins durch von MCP-1 angelockte und aktivierte Makrophagen- verringert wird (Abbildung 26). Kohl et al 2010 hatten MCP1 als ein vielversprechendes Ziel experimenteller Therapieversuche beschrieben. Möglicherweise könnte eine Curcumin-Behandlung diesem Vorschlag gerecht werden. Ginge man von einer passiven Beteiligung der Makropagen am Krankheitsgeschehen aus -erhöhte Makrophagenaktivität durch vermehrtes Vorliegen immunogener Myelinbruchstücke- könnte Curcumin über eine direkte Inhibition der Makrophagenaktivität unabhängig der MCP-1-Expression seine Wirkung erzielen (Abbildung 26). Denn auch eine reduzierte Freisetzung proteolytischer Enzyme wurde über Makrophagen Curcumin-behandelter Ratten beschrieben (Joe und Lokesh 1997, 2000).

Ein weiterer Weg über den Curcumin eine positive Wirkung auf Ebene der Schwannzellen entfalten könnte, wäre durch die Induktion von Hitzeschockproteinen (HSP), die als molekulare Chaperone die Formierung von Proteinaggregaten hemmen. Eine solche Expressionssteigerung durch Curcumin wurde beschrieben (Kato et al. 1998). Auch wäre durch HSPs das Entfalten bereits entstandener Proteinaggregate denkbar, sodass ein Angreifen der als Kom- 
pensationsmechanismus angesehenen autophagischen und lysosomalen Prozesse erleichtert werden würde. Auch bei TremblerJ-Mäusen (Mutation im Pmp22 Gen) wurde eine Rekrutierung von HSPs zu Proteinaggregaten beobachtet (Fortun et al. 2007). Curcumin könnte diesen protektiven Mechanismus potenzieren.

In Abbildung 26 sind die pathomechanistischen Überlegungen zu Wirkungen von Lonaprisan und Curcumin schematisch dargestellt. Es ist anzunehmen, dass Curcumin die intrazelluläre Homöostase der Schwannzellen wieder ins Gleichgewicht bringt, sodass die Schwannzelle wie auch nach der PA-Behandlung ihren axosupportiven Effekt (Meyer zu Hörste et al. 2007) ausüben und somit den axonalen Verlust verringern kann. Auch die direkte Auswirkung von Curcumin auf Makrophagen ist denkbar. Über welchen der beschriebenen Mechanismen Curcumin letztenendes seine Wirkung erzielt oder ob es ein Zusammenspiel verschiedener Wirkungsansätze ist, bleibt offen. Die Vielzahl der bei dieser Therapiestudie gewonnenen biologischen Materialien bietet die Möglichkeit diesen Fragen nachzugehen.

Besonders interessant ist diese Therapieoption, da nicht die Senkung der PMP22Überexpression als Wirkmechanismus anzunehmen ist. Erkenntnisse über die Wirkmechanismen könnten somit auch für andere, höherfrequentierte periphere Neuropathien (z.B. diabetische Neuropathie) von Bedeutung sein und Curcumin sollte als neuroprotektives Therapeutikum auch bei diesen Erkrankungen erwogen werden.

\subsubsection{Der Weg zur Translation der Curcumin-Therapie in die Klinik}

Bei dieser experimentellen Therapie des häufigsten Subtyps der CMT ist es gelungen bei der bereits symptomatischen, also in ihrer Progression vorangeschrittenen Erkrankung, wichtige histopathologische Merkmale wie den Axonverust signifikant zu verringern. Die konsekutive Verbesserung des Phänotyps ist wahrscheinlich, wurde jedoch durch ein reduziertes Körpergewicht als Folge einer nicht idealen Applikationsform überdeckt. Als eine vielversprechende Therapieoption ist Curcumin in besonderem Maße zu werten, da keine unerwünschten $\mathrm{Ne}$ benwirkungen zu erwarten sind. Mit der berechneten humanen Äquivalenzdosis von ca. 5000 mg pro Tag läge man noch weit unter den in klinischen Studien der Phase I sicher applizierten 8000 mg (Cheng et al. 2001). Die Translation in die Klinik wäre somit bedenkenlos möglich. Ein einziger oft angebrachter Schwachpunkt, die zu geringe orale Bioverfügbarkeit, ließe sich durch die Verwendung eines neuen mit Phosphatidylcholine-formulierten Curcumins (Meriva, Indena S.p.A, Mailand, Italien) relativieren. Durch diese Komplexierung konnten fünffach 
höhere Plasmaspiegel erreicht werden (Marczylo et al. 2007). In ersten klinischen Studien (chronisch anteriore Uveitis) erhielten Patienten für mehr als 12 Monate $1200 \mathrm{mg} / \mathrm{d}$ Meriva, Unverträglichkeiten wurden nicht berichtet, Therapieerfolge stellten sich ein (Allegri et al. 2010).

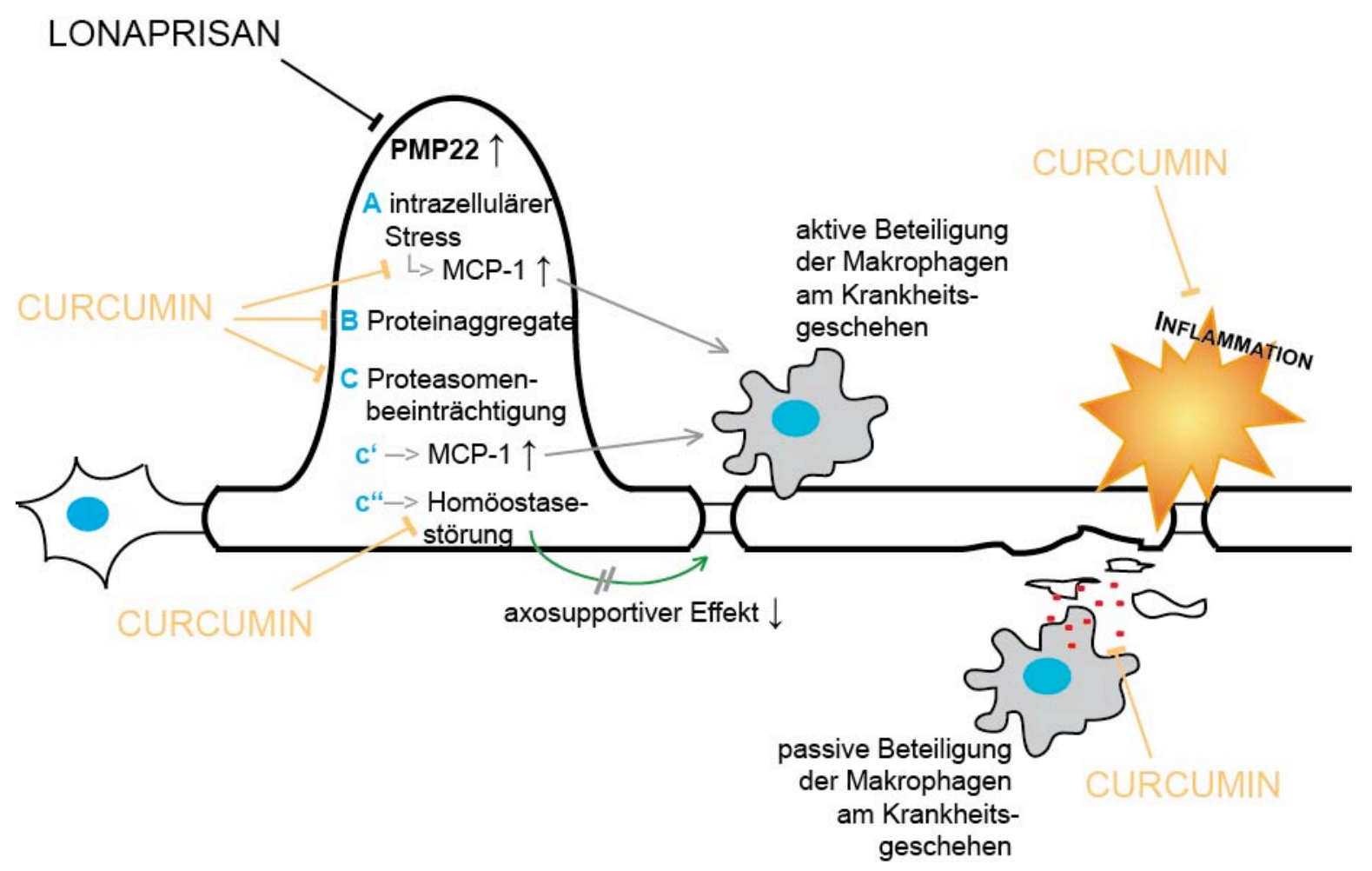

\section{Abbildung 26: Pathomechanistische Überlegungen und mögliche Ansätze der Lonaprisan- und Curcu- min-Behandlung}

Pathomechanistische Überlegungen bezüglich der PMP22-Überexpression sind intrazellulärer Stress der Schwannzelle mit konsekutiver Expression von MCP-1 (A), die Bildung von Proteinaggregaten (B), eine Beeinträchtigung der Proteasomen (C) mit konsekutiver Expression von MCP-1 (c') oder Störung der intrazellulären Homöostase (c')). Der von Meyer zu Hörste et al. 2007 beschriebene axosupportive Effekt der Schwannzellen könnte dadurch beeinträchtigt sein. Makrophagen könnten aktiv (angelockt und aktiviert durch MCP-1) oder passiv (durch das erhöhte Vorkommen immunogener Myelinbruchstücke) am Krankheitsgeschehen der CMT1A beteiligt sein. Es wurde gezeigt, dass Lonaprisan die PMP22-Überexpression verringert und damit eine kausale Therapieoption bietet. Ein Wirken von Curcumin erscheint an vielen Stellen der pathomechanistischen Überlegungen denkbar. Es könnte autophagosomale und lysosomale Kompensationsmechanismen gegen die Bildung von Proteinaggregaten durch die Expression von HSPs und Chaperonen unterstützen oder die Aktivität der Proteasomen steigern und somit die intrazelluläre Homöostase wieder ins Gleichgewicht bringen. Die Schwannzelle könnte wieder dem axosupportiven Effekt nachgehen. Auch könnte Curcumin über eine Verringerung der die MCP-1-Expression wirken oder direkt die Ausschüttung proteolytischer Enzyme der Makrophagen inhibieren. Antiinflammatorische Eigenschaften wie Inhibition und Expressionsreduktion der COX-2, Inhibition der Phospholipase $\mathrm{A}_{2}$ oder die direkte Inhibition zyklischer Endoperoxide wurden beschrieben. 


\subsection{Ausbleibender Therapieerfolg mit Acetylsalicylsäure}

Die Therapie mit Acetylsalicylsäure (ASS) sollte an der bereits angesprochenen möglichen inflammatorischen Komponente der CMT1A ansetzen. Denkbar ist eine Immunzellenstimulierte Demyelinisierung, die gerade in den Anfängen der Erkrankung -lange vor Symptomeintritt sind bei Patienten bereits reduzierte NLGs zu messen- ihren Beitrag zur Pathophysiologie leistet. Das zu einem späteren Zeitpunkt gewonnene konventionelle Nervenbiopsiematerial symptomatisch gewordener Patienten würde diese Pathologie nicht mehr erfassen. Dafür spricht, dass Immunzellen bisher gerade in Nervenbiopsien von Kindern nachgewiesen wurden (Gabreels-Festen et al. 1992). Aber auch später könnte die permanente Präsenz immunogener Myelinbruchstücke zu einer Überreaktivität von Makrophagen führen und somit eine Aggravation der Erkrankung bedingen. Die chronische ASS-Therapie nach dem „Clinical Paradigm“ sollte hier eingreifen. Ein signifikanter Therapieerfolg wurde jedoch nicht erzielt. Lediglich ein geringer Trend in Richtung eines Therapieerfolges war bei Nervenleitgeschwindigkeits-Messungen und der Axonquantifizierung zu erahnen.

\subsubsection{Vergleich der antiinflammatorischen Wirkungen von ASS und Cur- cumin}

Durch das in dieser Arbeit beschriebene Ausbleiben eines ASS-Behandlungserfolgs ist die chronisch inflammatorische Komponente des Pathomechanismus der CMT1A dennoch nicht endgültig auszuschließen. Möglicherweise war die Dosierung zu gering, der gewählte Therapiebeginn zu spät (gerade in Nervenbiopsien von Kindern konnten Immunzellen nachgewiesen werden (Gabreels-Festen et al. 1992)) oder antiinflammatorische Medikamente mit Wirkung auf anderer Ebene hätten einen besseren Erfolg erzielt. Auch über Curcumin wurden antiinflammatorische Eigenschaften berichtet (Abbildung 26). Wie ASS wirkt es durch Inhibition der COX-2, überdies wurde eine verringerte Expression der COX-2 beschrieben (Ramsewak et al. 2000; Surh et al. 2001) und im Gegensatz zu ASS scheint Curcumin als selektiver COX-2-Inhibitor zu wirken. Zusätzlich verringert Curcumin, entsprechend der antiphlogistischen Wirkung von Steroiden, die katalytische Aktivität der Phospholipase $\mathrm{A}_{2}$ und somit die Freisetzung der Arachidonsäure, dem Substrat der Cyclooxygenasen und Lipoxygenasen (Rao et al. 1995). Zuletzt wirkt Curcumin auch auf einige zyklische Endoperoxide (Pro- 
staglandin $E_{2}$, Leukotrien $B_{4}$, Leukotrien $C_{4}$ ) direkt inhibierend (Joe und Lokesh 1997), sodass zusammengefasst ein breiteres antiinflammatorisches Wirkungsspektrum von Curcumin möglich erscheint, als unter ASS zu erreichen war.

Während durch ASS allerhöchstens ein Trend in Richtung einer Verbesserung der Erkrankungsmerkmale erzielt wurde, zeigte die Behandlung mit Curcumin deutliche Therapieerfolge. Ob diese ausschließlich oder nur teilweise durch die antiinflammatorische Wirkung Curcumins erreicht wurden bleibt offen.

\subsection{Erythropoetin als Therapieoption der CMT1A nicht auszu- schließen}

Die Behandlung mit Erythropoetin verringerte den axonalen Verlust bei der CMT1A nicht. Bei einigen Tieren zeigten sich zwar verbesserte Griffstärkewerte, welche jedoch auch einer proanabolischen EPO-Wirkung und nicht einem neuroprotektiven Effekt zuzuschreiben sein könnten. Offensichtlich lag der Fehler in der EPO-Dosierung, der enorm erhöhte Hämatokrit war Ausdruck dafür. Über eine Dosis-Abhängigkeit der neuroprotektive Wirkung von EPO wurde berichtet (Keswani et al. 2004a). Das „therapeutischen Fensters“ wurde somit aller Wahrscheinlichkeit nach verlassen.

Zukünftige Studien sollten Dosierungen sowie Behandlungsschema genauer der Rattensituation anzupassen. Nach einer Therapiedauer von nur 6 Wochen und dem Behandlungsbeginn bei bereits symptomatischen Ratten im ,jungen Erwachsenenalter“ war möglicherweise keine Besserung $\mathrm{zu}$ erwarten. Es ist $\mathrm{zu}$ überdenken, ob nicht ein früherer Therapiebeginn -entsprechend dem „Proof-of-Principle Paradigm“ noch vor Symptomausbruch- eher zu einem neuroprotektiven Therapieerfolg führen könnte. Möglicherweise sollte auch die Therapiedauer verlängert werden. Um die Dosis anzupassen wären Injektionen ein bis maximal zweimal wöchentlich ausreichend. Ein therapeutisches Drug Monitoring des verwendeten rekombinanten EPOs, wie auch Hämatokritmessungen im Therapieverlauf sollten in Erwägung gezogen werden. 


\subsection{LXR-Agonisten als vielversprechende Therapieoption der CMT1A}

In einem Pilotexperiment zeigte sich, dass auch der LXR-Agonist T0901317 in der Lage ist im Nervengewebe die Pmp22-Expression herunterzuregulieren. Somit ist die orale Bioverfügbarkeit bestätigt und eine Blut-Nerven-Schranken Gängigkeit wurde gezeigt. Auch eine Dosis-Wirkungs-Beziehung war ersichtlich. Den Schritt von in vitro zu in vivo ist geglückt.

Es wurde ein neuer Weg aufgezeigt die Erkrankung zu beeinflussen, ohne jedoch die massiven Nebenwirkungen eines endokrin wirksamen Progesteronantagonisten befürchten zu müssen. Problematisch anzusehen sind bei diesem Ansatz jedoch die Auswirkungen auf die Leber. Zwar handelt es sich Erfahrungsberichten anderer Arbeitsgruppen zufolge um eine transiente Steatosis, ein inzwischen neu entwickelter LXR-Agonist GW3965 (GlaxoSmithKline, North Carolina, USA) verspricht jedoch weniger dieser Nebenwirkungen (Miao et al. 2004) und wäre daher vorzuziehen. Weitere experimentelle Therapiestudien sollten in dieser Richtung fortgeführt werden. Dann gilt es zu überprüfen ob auch die mittels eines LXR-Agonisten erzielte Reduktion der Pmp22-Überexpression eine Verbesserung des klinischen Phänotyps und der histopathologischen Merkmale zur Folge hat. 


\section{Zusammenfassung}

\subsection{Deutsch}

Die Charcot-Marie-Tooth-Erkrankung ist die häufigste hereditäre demyelinisierende Neuropathie des peripheren Nervensystems. Eine intrachromosomale Duplikation bedingt den häufigsten Subtyp und führt zu einer toxischen Überexpression des PMP22-Gens (CMT1A). Pmp22 überexprimierende transgene Ratten mimen die Charakteristika der Erkrankung (CMTRatten). Wie bei Menschen führt eine 1,6-fache PMP22-Überexpression zu progressiver Demyelinisierung mit axonalem Verlust und konsekutiver, distal betonter Muskelartrophie und -schwäche.

Vier tierexperimentelle Behandlungsversuche der Charot-Marie-Tooth-Erkrankung 1A und ein Pilotexperiment waren Inhalt dieser Arbeit.

Die Therapie der CMT-Ratten mit Lonaprisan milderte die Pmp22-Überexpression, der Stangen- und der Griffstärketest demonstrierten eine Verbesserung des klinischen Phänotyps, das Muskelsummenaktionspotential war erhöht, in periphere Nerven zeigten sich signifikant mehr Axone sowie weniger Makrophagen und auf Rückenmarksebene fanden sich signifikant mehr alpha-Motoneurone, jeweils bezogen auf die Placebo-Behandlung. Diskutiert wurde neben der Schwannzellkomponennte eine weitere Wirkung des Progesteronantagonisten auf neuronaler Ebene. Um die molekularen Mechanismen der neuroprotektiven ProgesteronantagonistenWirkung zu verstehen lassen sich durch die gewonnenen biologischen Materialien fortführende Experimente auf dieser Arbeit aufbauen. Mit Igfbp5 wurde ein Biomarker (diagnostischer Marker) etabliert, der bei einer klinischen Studie eine weniger träge Variable als der CMTNS liefern könnte. Das Ansprechen auf eine Therapie ließe sich auch darüber monitoren.

Insbesondere Curcumin ist hervorzuheben, da es auch in hohen Dosierungen bei Patienten keinerlei unerwünschte Nebenwirkungen hervorruft. In der experimentellen Therapie der CMT-Ratten imponierte die Reduktion des axonalen Verlusts bei gleichzeitiger Erhöhung von Muskelsummenaktionspotential und Nervenleitgeschwindigkeit. Um auch eine Verbesserung des klinischen Phänotyps zu demonstrieren, die nicht durch eine verzögerte Gewichtszunahme überdeckt wird, und somit der Translation zu einer klinischen Erprobung den Weg zu bereiten, wird eine tierexperimentelle Therapiestudie mit dem erhöht oral bioverfügbaren MerivaCurcumin vorgeschlagen. 
Über die neuroprotektiven Eigenschaften des Erythropoetins und die antiinflammatorische Wirkung der Acetylsalizylsäure war bei CMT-Ratten kein Therapieerfolg zu erzielen. Bei beiden Substanzen sind Dosierungen, Therapieschema und im Falle von ASS auch die Wahl als antiinflammatorisch wirkende Substanz zu überdenken. Vielversprechend und gerade am Anfang der weiteren Erforschung als Therapieoption der CMT1A steht der Leber X Rezeptor (LXR)-Agonist T0901317 denn auch über diesen Mechanismus wurde die Pmp22Überexpression verringert. Eine experimentelle Therapiestudie könnte sich anschließen, zu erwägen wäre jedoch die Wahl des LXR-Agonisten GW3965, der weniger Nebenwirkungen auf die Leber verspricht.

Mit Curcumin und dem Progesteronrezeptorantagonisten Lonaprisan wurden zwei Therapeutika mit eindrucksvoller Wirksamkeit zur Linderung der Charcot-Marie-Tooth-Erkrankung 1A vorgestellt. Die Translation zu einer klinischen Prüfung gilt es jetzt zu bedenken.

\subsection{Englisch}

Charcot-Marie-Tooth Disease is the most common inherited demyelinating neuropathy of the peripheral nervous system. The most frequent subform is caused by an intrachromosomal duplication, leading to toxic overexpression of the PMP22 gene (CMT1A). Transgenic rats overexpressing Pmp22 mimic typical features of the disease ('CMT rats'). Like in humans, a 1.6 fold Pmp22 overexpression leads to progressive demyelination with axonal loss causing distally pronounced muscle atrophy and weakness.

Four experimental therapy trials of the Carcot-Marie-Tooth Disease 1A and one pilot experiment have been carried out.

Treating the CMT rats with Lonaprisan lowered the Pmp22 overexpression and compared to Placebo treated animals the bar- and grip strength test showed an improved motor performance, electrophysiological examinations revealed an increased compound muscle action potential, in peripheral nerves a preserved axonnumber and less macrophages were detected and in spinal cord cross sections a prevention of alpha-motoneuron loss could be observed. This implies neuroprotective properties of the progesterone antagonist in CMT1A. With the collected biological material a full range of ongoing experiments can be built on this study to lighten the underlying molecular mechanisms of this neuroprotection. With Igfbp5 a biomarker (diagnostic marker) was established as an additional readout of a clinical trial next to the CMTNS. This marker could monitor the response to a therapy trial. 
In particular Curcumin has to be accentuated, because also in high dosages no adverse side effects were shown in patients. In the experimental therapy trial the reduced axonal loss impressed, compound muscle action potential and nerve conduction velocity were increased. To show also an improvement of the clinical phenotype that is not covered by a delayed gain of weight and thereby to pave the way for a translation to humans, a new experimental therapy trial with the increased bio-available Meriva Curcumin will be proposed.

The neuroprotective properties of erythropoietin and the anti-inflammatory acting acetylsalicylic acid achieved in the CMT rats no beneficial effect. With both substances the dosages, the treatment scheme and in case of acetylsalicylic acid also the choice of the antiinflammatory substance need to be reconsidered. Promising and at the beginning of further investigation arise the liver $\mathrm{x}$ receptor (LXR) agonist T0901317 since it was able to reduce the Pmp22 overexpression. An experimental therapy trial would be the following step, but GW3965, another LXR agonist would be considered since it exhibited to have less adverse side effects on liver metabolism.

With Lonaprisan and Curcumin new therapeutics sharing a striking effect on CMT1A have been introduced and need to be considered for a translation into humans. 


\section{Abbildungsverzeichnis}

Abbildung 1: CMT1A-Patienten der Göttinger CMT-Ambulanz ......................................... 2

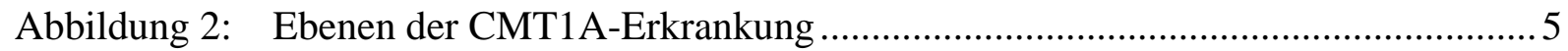

Abbildung 3: Strukturformeln der Curcuminoide ............................................................ 13

Abbildung 4: Synopsis der Lonaprisan-Therapiestudie nach dem „Proof-of-Principle

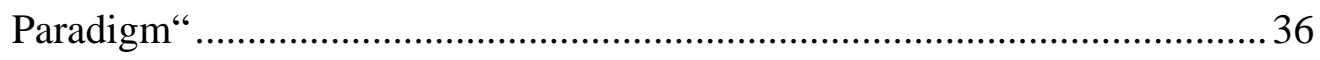

Abbildung 5: Synopsis der Therapiestudie mit Curcumin, Acetylsalicylsäure und Erythropoetin nach dem „Clinical Paradigm“.................................................37

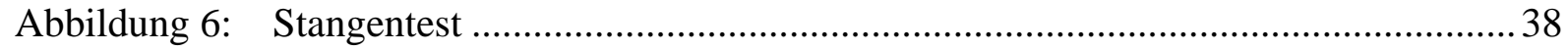

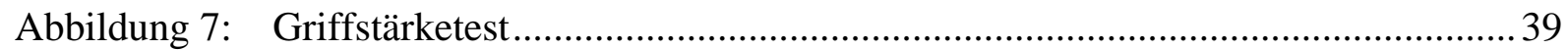

Abbildung 8: Km-Faktoren verschiedener Spezies zur Berechnung der Humanen Äquivalenzdosis

Abbildung 9: Verbesserung des klinischen Phänotyps der CMT-Ratten im Verlauf der

Lonaprisan-Therapie.

Abbildung 10: Elektrophysiologischer Befund einer demyelinisierenden Neuropathie mit axonalem Verlust (reduziertes Muskelsummenaktionspotential und Nervenleitgeschwindigkeit).

Abbildung 11: Nicht degradierte und kontaminierte RNA aus Haut- oder Nervengewebe ... 60

Abbildung 12: Repräsentative grafische Datenerfassung einer semiquantitativen Real-TimePCR 61

Abbildung 13: Reduktion der Pmp22-Überexpression durch den Progesteronantagonisten Lonaprisan ..... 62

Abbildung 14: Lonaprisan erhält die Axone im Nervus ischiadicus 63

Abbildung 15: Veringerung des alpha-Motoneuronverlusts bei CMT-Ratten nach Lonaprisan-Behandlung ..... .65

Abbildung 16: Erhöhte Anzahl an Makrophagen in Nerven von CMT-Ratten. .66

Abbildung 17: Anzahl der Makrophagen korrelierte negativ mit der Anzahl myelinisierter Axone 67

Abbildung 18: Igfbp5 als diagnostischer und prognostische Marker für die LonaprisanTherapie .69

Abbildung 19: Verzögerte Gewichtszunahme und relative Verbesserung des klinischen Phänotyps nach Curcumin-Behandlung .... 
Abbildung 20: Erhöhte Nervenleitgeschwindigkeiten und Muskelsummenaktionspotentiale nach Curcumin-Therapie

Abbildung 21: Verringerter axonaler Verlust und erhöhtes Axonkaliber nach CurcuminTherapie

Abbildung 22: Keine Auswirkungen der Therapie mit Acetylsalicylsäure auf Nervenleitgeschwindigkeit, Muskelsummenaktionspotential und axonalem Verlust 79

Abbildung 23: Therapie mit Erythropoetin verbesserte bei einigen CMT-Ratten den klinischen Phänotyp, der Axonverlust blieb unverändert. .81

Abbildung 24: Pmp22-Expression reduziert nach Behandlung mit T0901317. .84

Abbildung 25: Lebergewicht nach fünftägiger T0-Therapie erhöht. 85

Abbildung 26: Pathomechanistische Überlegungen und mögliche Ansätze der Lonaprisanund Curcumin-Behandlung .97 


\section{Literaturverzeichnis}

Adlkofer K, Martini R, Aguzzi A, Zielasek J, Toyka KV, Suter U (1995): Hypermyelination and demyelinating peripheral neuropathy in Pmp22-deficient mice. Nat Genet 11(3), 274-280.

Afhuppe W, Beekman JM, Otto C, Korr D, Hoffmann J, Fuhrmann U, Moller C (2010): In vitro characterization of ZK 230211--A type III progesterone receptor antagonist with enhanced antiproliferative properties. J Steroid Biochem Mol Biol 119(1-2), 45-55.

Ali RE, Rattan SI (2006): Curcumin's biphasic hormetic response on proteasome activity and heat-shock protein synthesis in human keratinocytes. Ann N Y Acad Sci 1067, 394399.

Allegri P, Mastromarino A, Neri P (2010): Management of chronic anterior uveitis relapses: efficacy of oral phospholipidic curcumin treatment. Long-term follow-up. Clin Ophthalmol 4, 1201-1206.

Amoli MM, Mousavizadeh R, Sorouri R, Rahmani M, Larijani B (2006): Curcumin inhibits in vitro MCP-1 release from mouse pancreatic islets. Transplant Proc $\underline{38}(9), 3035-$ 3038.

Baechner D, Liehr T, Hameister H, Altenberger H, Grehl H, Suter U, Rautenstrauss B (1995): Widespread expression of the peripheral myelin protein-22 gene (PMP22) in neural and non-neural tissues during murine development. J Neurosci Res 42(6), 733-741.

Beato M (1989): Gene regulation by steroid hormones. Cell $\underline{56}(3), 335-344$.

Bence NF, Sampat RM, Kopito RR (2001): Impairment of the ubiquitin-proteasome system by protein aggregation. Science 292(5521), 1552-1555.

Bird SJ, Sladky JT (1991): Corticosteroid-responsive dominantly inherited neuropathy in childhood. Neurology $\underline{41}$ (3), 437-439.

Birouk N, Gouider R, Le Guern E, Gugenheim M, Tardieu S, Maisonobe T, Le Forestier N, Agid Y, Brice A, Bouche P (1997): Charcot-Marie-Tooth disease type 1A with 17 p11.2 duplication. Clinical and electrophysiological phenotype study and factors influencing disease severity in 119 cases. Brain 120 ( Pt 5), 813-823.

Brouk B (1975). Plants consumed by man. London; New York, Academic Press.

Burns J, Ouvrier RA, Yiu EM, Joseph PD, Kornberg AJ, Fahey MC, Ryan MM (2009): Ascorbic acid for Charcot-Marie-Tooth disease type 1A in children: a randomised, double-blind, placebo-controlled, safety and efficacy trial. Lancet Neurol $\underline{8}(6), 537-$ 544.

Cao G, Liang Y, Jiang XC, Eacho PI (2004): Liver X receptors as potential therapeutic targets for multiple diseases. Drug News Perspect 17(1), 35-41.

Cheng AL, Hsu CH, Lin JK, Hsu MM, Ho YF, Shen TS, Ko JY, Lin JT, Lin BR, MingShiang W, et al. (2001): Phase I clinical trial of curcumin, a chemopreventive agent, in patients with high-risk or pre-malignant lesions. Anticancer Res 21(4B), 2895-2900.

Chies R, Nobbio L, Edomi P, Schenone A, Schneider C, Brancolini C (2003): Alterations in the Arf6-regulated plasma membrane endosomal recycling pathway in cells overexpressing the tetraspan protein Gas3/PMP22. J Cell Sci 116(Pt 6), 987-999.

Cole GM, Teter B, Frautschy SA (2007): Neuroprotective effects of curcumin. Adv Exp Med Biol 595, 197-212.

D'Urso D, Ehrhardt P, Muller HW (1999): Peripheral myelin protein 22 and protein zero: a novel association in peripheral nervous system myelin. J Neurosci 19(9), 3396-3403. 
de Waegh S, Brady ST (1990): Altered slow axonal transport and regeneration in a myelindeficient mutant mouse: the trembler as an in vivo model for Schwann cell-axon interactions. J Neurosci 10(6), 1855-1865.

Desarnaud F, Do Thi AN, Brown AM, Lemke G, Suter U, Baulieu EE, Schumacher M (1998): Progesterone stimulates the activity of the promoters of peripheral myelin protein-22 and protein zero genes in Schwann cells. J Neurochem 71(4), 1765-1768.

Dyck PJ, Lambert EH (1968): Lower motor and primary sensory neuron diseases with peroneal muscular atrophy. I. Neurologic, genetic, and electrophysiologic findings in hereditary polyneuropathies. Arch Neurol 18(6), 603-618.

Dyck PJ, Swanson CJ, Low PA, Bartleson JD, Lambert EH (1982): Prednisone-responsive hereditary motor and sensory neuropathy. Mayo Clin Proc 57(4), 239-246.

Dyck PJ, Chance P, Lebo R, Carney JA. Hereditary Motor and Sensory Neuropathy. In: Peripheral Neuropathy. Vol. 2. Dyck PJ und Thomas PK. Saunders. Philadelphia 1993, 1094-1136.

Edwards DP, Altmann M, DeMarzo A, Zhang Y, Weigel NL, Beck CA (1995): Progesterone receptor and the mechanism of action of progesterone antagonists. J Steroid Biochem Mol Biol 53(1-6), 449-458.

Edwards PA, Kast HR, Anisfeld AM (2002): BAREing it all: the adoption of LXR and FXR and their roles in lipid homeostasis. J Lipid Res 43(1), 2-12.

Eldridge CF, Bunge MB, Bunge RP, Wood PM (1987): Differentiation of axon-related Schwann cells in vitro. I. Ascorbic acid regulates basal lamina assembly and myelin formation. J Cell Biol 105(2), 1023-1034.

Fledrich R, Schlotter-Weigel B, Schnizer TJ, Wichert SP, Stassart RM, Meyer zu Hörste G, Klink A, Weiss BG, Haag U, Walter MC, et al. (2012): A rat model of Charcot-MarieTooth disease $1 \mathrm{~A}$ recapitulates disease variability and supplies biomarkers of axonal loss in patients. Brain 135(Pt 1), 72-87.

Folkers K, Simonsen R (1995): Two successful double-blind trials with coenzyme Q10 (vitamin Q10) on muscular dystrophies and neurogenic atrophies. Biochim Biophys Acta 1271(1), 281-286.

Fortun J, Go JC, Li J, Amici SA, Dunn WA, Jr. Notterpek L (2006): Alterations in degradative pathways and protein aggregation in a neuropathy model based on PMP22 overexpression. Neurobiol Dis 22(1), 153-164.

Fortun J, Verrier JD, Go JC, Madorsky I, Dunn WA, Notterpek L (2007): The formation of peripheral myelin protein 22 aggregates is hindered by the enhancement of autophagy and expression of cytoplasmic chaperones. Neurobiol Dis 25(2), 252-265.

Fuhrmann U, Hess-Stumpp H, Cleve A, Neef G, Schwede W, Hoffmann J, Fritzemeier KH, Chwalisz K (2000): Synthesis and biological activity of a novel, highly potent progesterone receptor antagonist. J Med Chem 43(26), 5010-5016.

Gabreels-Festen A, Wetering RV (1999): Human nerve pathology caused by different mutational mechanisms of the PMP22 gene. Ann N Y Acad Sci 883, 336-343.

Gabreels-Festen AA, Joosten EM, Gabreels FJ, Jennekens FG, Janssen-van Kempen TW (1992): Early morphological features in dominantly inherited demyelinating motor and sensory neuropathy (HMSN type I). J Neurol Sci 107(2), 145-154.

Garcia ML, Lobsiger CS, Shah SB, Deerinck TJ, Crum J, Young D, Ward CM, Crawford TO, Gotow T, Uchiyama Y, et al. (2003): NF-M is an essential target for the myelindirected "outside-in" signaling cascade that mediates radial axonal growth. J Cell Biol 163(5), 1011-1020.

Giambonini-Brugnoli G, Buchstaller J, Sommer L, Suter U, Mantei N (2005): Distinct disease mechanisms in peripheral neuropathies due to altered peripheral myelin protein 22 gene dosage or a Pmp22 point mutation. Neurobiol Dis $\underline{18(3), 656-668 .}$ 
Ginsberg L, Malik O, Kenton AR, Sharp D, Muddle JR, Davis MB, Winer JB, Orrell RW, King RH (2004): Coexistent hereditary and inflammatory neuropathy. Brain 127(Pt 1), 193-202.

Godavarthi SK, Narender D, Mishra A, Goswami A, Rao SN, Nukina N, Jana NR (2009): Induction of chemokines, $\mathrm{MCP}-1$, and $\mathrm{KC}$ in the mutant huntingtin expressing neuronal cells because of proteasomal dysfunction. J Neurochem 108(3), 787-795.

Goel A, Kunnumakkara AB, Aggarwal BB (2008): Curcumin as "Curecumin": from kitchen to clinic. Biochem Pharmacol 75(4), 787-809.

Grandis M, Shy ME (2005): Current Therapy for Charcot-Marie-Tooth Disease. Curr Treat Options Neurol 7(1), 23-31.

Guenard V, Montag D, Schachner M, Martini R (1996): Onion bulb cells in mice deficient for myelin genes share molecular properties with immature, differentiated nonmyelinating, and denervated Schwann cells. Glia 18(1), 27-38.

Hagedorn L, Suter U, Sommer L (1999): P0 and PMP22 mark a multipotent neural crestderived cell type that displays community effects in response to TGF-beta family factors. Development 126(17), 3781-3794.

Harding AE, Thomas PK (1980): The clinical features of hereditary motor and sensory neuropathy types I and II. Brain 103(2), 259-280.

Hassan K, Simri W, Rubenchik I, Manelis J, Gross B, Shasha SM, Kristal B (2003): Effect of erythropoietin therapy on polyneuropathy in predialytic patients. J Nephrol $\underline{16}(1), 121$ 125.

Hasse B, Bosse F, Hanenberg H, Muller HW (2004): Peripheral myelin protein $22 \mathrm{kDa}$ and protein zero: domain specific trans-interactions. Mol Cell Neurosci 27(4), 370-378.

Hellemans J, Mortier G, De Paepe A, Speleman F, Vandesompele J (2007): qBase relative quantification framework and software for management and automated analysis of real-time quantitative PCR data. Genome Biol $\underline{8}(2)$, R19.

Huxley C, Passage E, Robertson AM, Youl B, Huston S, Manson A, Saberan-Djoniedi D, Figarella-Branger D, Pellissier JF, Thomas PK, et al. (1998): Correlation between varying levels of PMP22 expression and the degree of demyelination and reduction in nerve conduction velocity in transgenic mice. Hum Mol Genet $\underline{7}(3), 449-458$.

Ionasescu VV (1995): Charcot-Marie-Tooth neuropathies: from clinical description to molecular genetics. Muscle Nerve 18(3), 267-275.

Jang GR, Benet LZ (1997): Antiprogestin pharmacodynamics, pharmacokinetics, and metabolism: implications for their long-term use. J Pharmacokinet Biopharm 25(6), 647-672.

Jelkmann W (2008): Developments in the therapeutic use of erythropoiesis stimulating agents. Br J Haematol 141(3), 287-297.

Joe B, Lokesh BR (1997): Effect of curcumin and capsaicin on arachidonic acid metabolism and lysosomal enzyme secretion by rat peritoneal macrophages. Lipids $\underline{32}(11), 1173-$ 1180.

Joe B, Lokesh BR (2000): Dietary n-3 fatty acids, curcumin and capsaicin lower the release of lysosomal enzymes and eicosanoids in rat peritoneal macrophages. Mol Cell Biochem 203(1-2), 153-161.

Kato K, Ito H, Kamei K, Iwamoto I (1998): Stimulation of the stress-induced expression of stress proteins by curcumin in cultured cells and in rat tissues in vivo. Cell Stress Chaperones $\underline{3}(3), 152-160$.

Keswani SC, Leitz GJ, Hoke A (2004a): Erythropoietin is neuroprotective in models of HIV sensory neuropathy. Neurosci Lett 371(2-3), 102-105.

Keswani SC, Buldanlioglu U, Fischer A, Reed N, Polley M, Liang H, Zhou C, Jack C, Leitz GJ, Hoke A (2004b): A novel endogenous erythropoietin mediated pathway prevents axonal degeneration. Ann Neurol 56 (6), 815-826. 
Khajavi M, Inoue K, Wiszniewski W, Ohyama T, Snipes GJ, Lupski JR (2005): Curcumin treatment abrogates endoplasmic reticulum retention and aggregation-induced apoptosis associated with neuropathy-causing myelin protein zero-truncating mutants. Am J Hum Genet 77(5), 841-850.

Khajavi M, Shiga K, Wiszniewski W, He F, Shaw CA, Yan J, Wensel TG, Snipes GJ, Lupski JR (2007): Oral curcumin mitigates the clinical and neuropathologic phenotype of the Trembler-J mouse: a potential therapy for inherited neuropathy. Am J Hum Genet $\underline{81}(3), 438-453$.

Killian JM, Tiwari PS, Jacobson S, Jackson RD, Lupski JR (1996): Longitudinal studies of the duplication form of Charcot-Marie-Tooth polyneuropathy. Muscle Nerve 19(1), 74-78.

Kobsar I, Hasenpusch-Theil K, Wessig C, Muller HW, Martini R (2005): Evidence for macrophage-mediated myelin disruption in an animal model for Charcot-Marie-Tooth neuropathy type 1 A. J Neurosci Res $\underline{81}$ (6), 857-864.

Kohl B, Fischer S, Groh J, Wessig C, Martini R (2010a): MCP-1/CCL2 modifies axon properties in a PMP22-overexpressing mouse model for Charcot-Marie-tooth 1A neuropathy. Am J Pathol 176(3), 1390-1399.

Kohl B, Groh J, Wessig C, Wiendl H, Kroner A, Martini R (2010b): Lack of evidence for a pathogenic role of T-lymphocytes in an animal model for Charcot-Marie-Tooth disease 1A. Neurobiol Dis $\underline{38}(1), 78-84$.

Koldamova RP, Lefterov IM, Staufenbiel M, Wolfe D, Huang S, Glorioso JC, Walter M, Roth MG, Lazo JS (2005): The liver X receptor ligand T0901317 decreases amyloid beta production in vitro and in a mouse model of Alzheimer's disease. J Biol Chem 280(6), 4079-4088.

Krajewski KM, Lewis RA, Fuerst DR, Turansky C, Hinderer SR, Garbern J, Kamholz J, Shy ME (2000): Neurological dysfunction and axonal degeneration in Charcot-MarieTooth disease type 1A. Brain 123 ( Pt 7), 1516-1527.

Langmade SJ, Gale SE, Frolov A, Mohri I, Suzuki K, Mellon SH, Walkley SU, Covey DF, Schaffer JE, Ory DS (2006): Pregnane X receptor (PXR) activation: a mechanism for neuroprotection in a mouse model of Niemann-Pick C disease. Proc Natl Acad Sci U S A 103(37), 13807-13812.

Lewis RA, Li J, Fuerst DR, Shy ME, Krajewski K (2003): Motor unit number estimate of distal and proximal muscles in Charcot-Marie-Tooth disease. Muscle Nerve 28(2), 161-167.

Luft JH (1961): Improvements in epoxy resin embedding methods. J Biophys Biochem Cytol 9, 409-414.

Lupski JR, Wise CA, Kuwano A, Pentao L, Parke JT, Glaze DG, Ledbetter DH, Greenberg F, Patel PI (1992): Gene dosage is a mechanism for Charcot-Marie-Tooth disease type 1A. Nat Genet 1(1), 29-33.

Lupski JR, de Oca-Luna RM, Slaugenhaupt S, Pentao L, Guzzetta V, Trask BJ, SaucedoCardenas O, Barker DF, Killian JM, Garcia CA, et al. (1991): DNA duplication associated with Charcot-Marie-Tooth disease type 1A. Cell 66(2), 219-232.

Madorsky I, Opalach K, Waber A, Verrier JD, Solmo C, Foster T, Dunn WA, Jr. Notterpek L (2009): Intermittent fasting alleviates the neuropathic phenotype in a mouse model of Charcot-Marie-Tooth disease. Neurobiol Dis 34(1), 146-154.

Magyar JP, Martini R, Ruelicke T, Aguzzi A, Adlkofer K, Dembic Z, Zielasek J, Toyka KV, Suter U (1996): Impaired differentiation of Schwann cells in transgenic mice with increased PMP22 gene dosage. J Neurosci 16(17), 5351-5360.

Marczylo TH, Verschoyle RD, Cooke DN, Morazzoni P, Steward WP, Gescher AJ (2007): Comparison of systemic availability of curcumin with that of curcumin formulated with phosphatidylcholine. Cancer Chemother Pharmacol 60(2), 171-177. 
Martin B, Mattson MP, Maudsley S (2006): Caloric restriction and intermittent fasting: two potential diets for successful brain aging. Ageing Res Rev 5(3), 332-353.

Martini R, Toyka KV (2004): Immune-mediated components of hereditary demyelinating neuropathies: lessons from animal models and patients. Lancet Neurol $\underline{3}(8), 457-465$.

Matsunami N, Smith B, Ballard L, Lensch MW, Robertson M, Albertsen H, Hanemann CO, Muller HW, Bird TD, White R, et al. (1992): Peripheral myelin protein-22 gene maps in the duplication in chromosome 17p11.2 associated with Charcot-Marie-Tooth 1A. Nat Genet 1(3), 176-179.

Mayer P (1891): Ueber das Färben mit Hämatoxylin. Mitt Zool Stat Neapel 10, 170-186.

McKenna NJ, O'Malley BW (2002): Combinatorial control of gene expression by nuclear receptors and coregulators. Cell 108(4), 465-474.

Meade EA, Smith WL, DeWitt DL (1993): Differential inhibition of prostaglandin endoperoxide synthase (cyclooxygenase) isozymes by aspirin and other non-steroidal anti-inflammatory drugs. J Biol Chem 268(9), 6610-6614.

Melcangi RC, Magnaghi V, Cavarretta I, Zucchi I, Bovolin P, D'Urso D, Martini L (1999): Progesterone derivatives are able to influence peripheral myelin protein 22 and P0 gene expression: possible mechanisms of action. J Neurosci Res 56 (4), 349-357.

Meyer zu Hörste G, Nave KA (2006): Animal models of inherited neuropathies. Curr Opin Neurol 19(5), 464-473.

Meyer zu Hörste G, Prukop T, Liebetanz D, Mobius W, Nave KA, Sereda MW (2007): Antiprogesterone therapy uncouples axonal loss from demyelination in a transgenic rat model of CMT1A neuropathy. Ann Neurol 61(1), 61-72.

Miao B, Zondlo S, Gibbs S, Cromley D, Hosagrahara VP, Kirchgessner TG, Billheimer J, Mukherjee R (2004): Raising HDL cholesterol without inducing hepatic steatosis and hypertriglyceridemia by a selective LXR modulator. J Lipid Res 45(8), 1410-1417.

Micallef J, Attarian S, Dubourg O, Gonnaud PM, Hogrel JY, Stojkovic T, Bernard R, Jouve E, Pitel S, Vacherot F, et al. (2009): Effect of ascorbic acid in patients with CharcotMarie-Tooth disease type 1A: a multicentre, randomised, double-blind, placebocontrolled trial. Lancet Neurol $\underline{8}(12), 1103-1110$.

Morales JR, Ballesteros I, Deniz JM, Hurtado O, Vivancos J, Nombela F, Lizasoain I, Castrillo A, Moro MA (2008): Activation of liver X receptors promotes neuroprotection and reduces brain inflammation in experimental stroke. Circulation 118(14), 1450-1459.

Mostacciuolo ML, Micaglio G, Fardin P, Danieli GA (1991): Genetic epidemiology of hereditary motor sensory neuropathies (type I). Am J Med Genet 39(4), 479-481.

Mullis K, Faloona F, Scharf S, Saiki R, Horn G, Erlich H (1986): Specific enzymatic amplification of DNA in vitro: the polymerase chain reaction. Cold Spring Harb Symp Quant Biol 51 Pt 1, 263-273.

Nattkamper H, Halfter H, Khazaei MR, Lohmann T, Gess B, Eisenacher M, Willscher E, Young P (2009): Varying survival of motoneurons and activation of distinct molecular mechanism in response to altered peripheral myelin protein 22 gene dosage. $\mathbf{J}$ Neurochem 110(3), 935-946.

Nave KA, Sereda MW, Ehrenreich H (2007): Mechanisms of disease: inherited demyelinating neuropathies--from basic to clinical research. Nat Clin Pract Neurol $\underline{3}$ (8), 453-464.

Neef G, Beier S, Elger W, Henderson D, Wiechert R (1984): New steroids with antiprogestational and antiglucocorticoid activities. Steroids 44(4), 349-372.

Norreel JC, Vinay L, Fontes M, Clarac F (2003): Close relationship between motor impairments and loss of functional motoneurons in a Charcot-Marie-Tooth type 1A model. Neuroscience 116(3), 695-703.

Notterpek L, Ryan MC, Tobler AR, Shooter EM (1999): PMP22 accumulation in aggresomes: implications for CMT1A pathology. Neurobiol Dis $\underline{6}(5), 450-460$. 
Ohsawa Y, Murakami T, Miyazaki Y, Shirabe T, Sunada Y (2006): Peripheral myelin protein 22 is expressed in human central nervous system. J Neurol Sci 247(1), 11-15.

Palau F, Lofgren A, De Jonghe P, Bort S, Nelis E, Sevilla T, Martin JJ, Vilchez J, Prieto F, Van Broeckhoven C (1993): Origin of the de novo duplication in Charcot-MarieTooth disease type 1A: unequal nonsister chromatid exchange during spermatogenesis. Hum Mol Genet 2(12), 2031-2035.

Panicker SR, Kartha CC (2009): Curcumin attenuates glucose-induced monocyte chemoattractant protein-1 synthesis in aortic endothelial cells by modulating the nuclear factor-kappaB pathway. Pharmacology 85(1), 18-26.

Pareek S, Suter U, Snipes GJ, Welcher AA, Shooter EM, Murphy RA (1993): Detection and processing of peripheral myelin protein PMP22 in cultured Schwann cells. J Biol Chem 268(14), 10372-10379.

Pareek S, Notterpek L, Snipes GJ, Naef R, Sossin W, Laliberte J, Iacampo S, Suter U, Shooter EM, Murphy RA (1997): Neurons promote the translocation of peripheral myelin protein 22 into myelin. J Neurosci 17(20), 7754-7762.

Pareyson D, Reilly MM, Schenone A, Fabrizi GM, Cavallaro T, Santoro L, Vita G, Quattrone A, Padua L, Gemignani F, et al. (2011): Ascorbic acid in Charcot-Marie-Tooth disease type 1A (CMT-TRIAAL and CMT-TRAUK): a double-blind randomised trial. Lancet Neurol 10(4), 320-328.

Parmantier E, Cabon F, Braun C, D'Urso D, Muller HW, Zalc B (1995): Peripheral myelin protein-22 is expressed in rat and mouse brain and spinal cord motoneurons. Eur $\mathrm{J}$ Neurosci 7(5), 1080-1088.

Passage E, Norreel JC, Noack-Fraissignes P, Sanguedolce V, Pizant J, Thirion X, RobagliaSchlupp A, Pellissier JF, Fontes M (2004): Ascorbic acid treatment corrects the phenotype of a mouse model of Charcot-Marie-Tooth disease. Nat Med 10(4), 396401.

Patel PI, Roa BB, Welcher AA, Schoener-Scott R, Trask BJ, Pentao L, Snipes GJ, Garcia CA, Francke U, Shooter EM, et al. (1992): The gene for the peripheral myelin protein PMP-22 is a candidate for Charcot-Marie-Tooth disease type 1A. Nat Genet 1 (3), 159165.

Raeymaekers P, Timmerman V, Nelis E, De Jonghe P, Hoogendijk JE, Baas F, Barker DF, Martin JJ, De Visser M, Bolhuis PA, et al. (1991): Duplication in chromosome 17p11.2 in Charcot-Marie-Tooth neuropathy type 1a (CMT 1a). The HMSN Collaborative Research Group. Neuromuscul Disord 1(2), 93-97.

Ramsewak RS, DeWitt DL, Nair MG (2000): Cytotoxicity, antioxidant and anti-inflammatory activities of curcumins I-III from Curcuma longa. Phytomedicine 7(4), 303-308.

Rao CV, Rivenson A, Simi B, Reddy BS (1995): Chemoprevention of colon carcinogenesis by dietary curcumin, a naturally occurring plant phenolic compound. Cancer Res $\underline{55}(2), 259-266$.

Reagan-Shaw S, Nihal M, Ahmad N (2008): Dose translation from animal to human studies revisited. FASEB J 22(3), 659-661.

Repa JJ, Turley SD, Lobaccaro JA, Medina J, Li L, Lustig K, Shan B, Heyman RA, Dietschy JM, Mangelsdorf DJ (2000): Regulation of absorption and ABC1-mediated efflux of cholesterol by RXR heterodimers. Science 289(5484), 1524-1529.

Richardson KC, Jarett L, Finke EH (1960): Embedding in epoxy resins for ultrathin sectioning in electron microscopy. Stain Technol 35, 313-323.

Robertson AM, Perea J, McGuigan A, King RH, Muddle JR, Gabreels-Festen AA, Thomas PK, Huxley C (2002): Comparison of a new pmp22 transgenic mouse line with other mouse models and human patients with CMT1A. J Anat 200(4), 377-390. 
Robertson JF, Willsher PC, Winterbottom L, Blamey RW, Thorpe S (1999): Onapristone, a progesterone receptor antagonist, as first-line therapy in primary breast cancer. Eur $\mathrm{J}$ Cancer 35(2), 214-218.

Sahenk Z, Nagaraja HN, McCracken BS, King WM, Freimer ML, Cedarbaum JM Mendell JR, (2005): NT-3 promotes nerve regeneration and sensory improvement in CMT1A mouse models and in patients. Neurology 65(5), 681-689.

Saifi GM, Szigeti K, Snipes GJ, Garcia CA, Lupski JR (2003): Molecular mechanisms, diagnosis, and rational approaches to management of and therapy for Charcot-MarieTooth disease and related peripheral neuropathies. J Investig Med 51(5), 261-283.

Sandur SK, Pandey MK, Sung B, Ahn KS, Murakami A, Sethi G, Limtrakul P, Badmaev V, Aggarwal BB (2007): Curcumin, demethoxycurcumin, bisdemethoxycurcumin, tetrahydrocurcumin and turmerones differentially regulate anti-inflammatory and antiproliferative responses through a ROS-independent mechanism. Carcinogenesis $\underline{28}(8)$, 1765-1773.

Schenone A, Nobbio L, Monti Bragadin M, Ursino G, Grandis M (2011): Inherited neuropathies. Curr Treat Options Neurol 13(2), 160-179.

Schmidt RE, Green KG, Feng D, Dorsey DA, Parvin CA, Lee JM, Xiao Q, Brines M (2008): Erythropoietin and its carbamylated derivative prevent the development of experimental diabetic autonomic neuropathy in STZ-induced diabetic NOD-SCID mice. Exp Neurol 209(1), 161-170.

Schultz JR, Tu H, Luk A, Repa JJ, Medina JC, Li L, Schwendner S, Wang S, Thoolen M, Mangelsdorf DJ, et al. (2000): Role of LXRs in control of lipogenesis. Genes Dev 14(22), 2831-2838.

Schultz RL, Karlsson U (1965): Fixation of the Central Nervous System for Electron Microscopy by Aldehyde Perfusion. Ii. Effect of Osmolarity, Ph of Perfusate, and Fixative Concentration. J Ultrastruct Res 12, 187-206.

Sereda M, Griffiths I, Puhlhofer A, Stewart H, Rossner MJ, Zimmerman F, Magyar JP, Schneider A, Hund E, Meinck HM, et al. (1996): A transgenic rat model of CharcotMarie-Tooth disease. Neuron 16(5), 1049-1060.

Sereda MW, Nave KA (2006): Animal models of Charcot-Marie-Tooth disease type 1A. Neuromolecular Med $\underline{8}(1-2), 205-216$.

Sereda MW, Meyer zu Hörste G, Suter U, Uzma N, Nave KA (2003): Therapeutic administration of progesterone antagonist in a model of Charcot-Marie-Tooth disease (CMT-1A). Nat Med 9 (12), 1533-1537.

Shy ME (2004): Charcot-Marie-Tooth disease: an update. Curr Opin Neurol 17(5), 579-585.

Shy ME (2006): Therapeutic strategies for the inherited neuropathies. Neuromolecular Med 8(1-2), 255-278.

Shy ME, Blake J, Krajewski K, Fuerst DR, Laura M, Hahn AF, Li J, Lewis RA, Reilly M (2005): Reliability and validity of the CMT neuropathy score as a measure of disability. Neurology 64(7), 1209-1214.

Sironi L, Mitro N, Cimino M, Gelosa P, Guerrini U, Tremoli E, Saez E (2008): Treatment with LXR agonists after focal cerebral ischemia prevents brain damage. FEBS Lett 582(23-24), 3396-3400.

Skre H (1974): Genetic and clinical aspects of Charcot-Marie-Tooth's disease. Clin Genet 6(2), 98-118.

Smith WL, DeWitt DL, Garavito RM (2000): Cyclooxygenases: structural, cellular, and molecular biology. Annu Rev Biochem 69, 145-182.

Stogbauer F, Young P, Kuhlenbaumer G, De Jonghe P, Timmerman V (2000): Hereditary recurrent focal neuropathies: clinical and molecular features. Neurology 54(3), 546551. 
Surh YJ, Chun KS, Cha HH, Han SS, Keum YS, Park KK, Lee SS (2001): Molecular mechanisms underlying chemopreventive activities of anti-inflammatory phytochemicals: down-regulation of COX-2 and iNOS through suppression of NFkappa B activation. Mutat Res 480-481, 243-268.

Suter U, Scherer SS (2003): Disease mechanisms in inherited neuropathies. Nat Rev Neurosci 4(9), 714-726.

Tayyem RF, Heath DD, Al-Delaimy WK, Rock CL (2006): Curcumin content of turmeric and curry powders. Nutr Cancer 55(2), 126-131.

Timmerman V, Nelis E, Van Hul W, Nieuwenhuijsen BW, Chen KL, Wang S, Ben Othman K, Cullen B, Leach RJ, Hanemann CO, et al. (1992): The peripheral myelin protein gene PMP-22 is contained within the Charcot-Marie-Tooth disease type 1A duplication. Nat Genet 1(3), 171-175.

Valentijn LJ, Bolhuis PA, Zorn I, Hoogendijk JE, van den Bosch N, Hensels GW, Stanton VP, Jr., Housman DE, Fischbeck KH, Ross DA, et al. (1992): The peripheral myelin gene PMP-22/GAS-3 is duplicated in Charcot-Marie-Tooth disease type 1A. Nat Genet 1(3), 166-170.

Vallat JM, Sindou P, Preux PM, Tabaraud F, Milor AM, Couratier P, LeGuern E, Brice A (1996): Ultrastructural PMP22 expression in inherited demyelinating neuropathies. Ann Neurol 39(6), 813-817.

Vandesompele J, De Preter K, Pattyn F, Poppe B, Van Roy N, De Paepe A, Speleman F (2002): Accurate normalization of real-time quantitative RT-PCR data by geometric averaging of multiple internal control genes. Genome Biol 3⑺, RESEARCH0034.

Vane JR (1971): Inhibition of prostaglandin synthesis as a mechanism of action for aspirinlike drugs. Nat New Biol 231(25), 232-235.

Vane JR, Bakhle YS, Botting RM (1998): Cyclooxygenases 1 and 2. Annu Rev Pharmacol Toxicol 38, 97-120.

Verhamme C, de Haan RJ, Vermeulen M, Baas F, de Visser M, van Schaik IN (2009): Oral high dose ascorbic acid treatment for one year in young CMT1A patients: a randomised, double-blind, placebo-controlled phase II trial. BMC Med 7, 70.

Vigo T, Nobbio L, Hummelen PV, Abbruzzese M, Mancardi G, Verpoorten N, Verhoeven K, Sereda MW, Nave KA, Timmerman V, et al. (2005): Experimental Charcot-MarieTooth type 1A: a cDNA microarrays analysis. Mol Cell Neurosci 28(4), 703-714.

Vital A, Vital C, Julien J, Fontan D (1992): Occurrence of active demyelinating lesions in children with hereditary motor and sensory neuropathy (HMSN) type I. Acta Neuropathol 84(4), 433-436.

Vital A, Vital C, Lagueny A, Ferrer X, Ribiere-Bachelier C, Latour P, Petry KG (2003): Inflammatory demyelination in a patient with CMT1A. Muscle Nerve 28(3), 373-376.

Wang L, Schuster GU, Hultenby K, Zhang Q, Andersson S, Gustafsson JA (2002): Liver X receptors in the central nervous system: from lipid homeostasis to neuronal degeneration. Proc Natl Acad Sci U S A 99(21), 13878-13883.

Woo HM, Kang JH, Kawada T, Yoo H, Sung MK, Yu R (2007): Active spice-derived components can inhibit inflammatory responses of adipose tissue in obesity by suppressing inflammatory actions of macrophages and release of monocyte chemoattractant protein-1 from adipocytes. Life Sci 80(10), 926-931.

Wu RC, Smith CL, O'Malley BW (2005): Transcriptional regulation by steroid receptor coactivator phosphorylation. Endocr Rev 26(3), 393-399.

Yoshikawa H, Nishimura T, Nakatsuji Y, Fujimura H, Himoro M, Hayasaka K, Sakoda S, Yanagihara T (1994): Elevated expression of messenger RNA for peripheral myelin protein 22 in biopsied peripheral nerves of patients with Charcot-Marie-Tooth disease type 1A. Ann Neurol 35(4), 445-450. 
Teile dieser Doktorarbeit wurden bereits in wissenschaftlichen Magazinen und auf Konferenzen in Form von Postern, Vorträgen und Abstracts vorgestellt.

\section{Originalarbeiten:}

Fledrich F, Schlotter-Weigel B, Schnizer T, Wichert S, Stassart RM, Meyer zu Hörste G, Weiss BG, Haag U, Walter MC, Rautenstrauss B, Paulus W, Nave KA, Rossner M, Sereda MW. A rat model of Charcot Marie Tooth disease 1A recapitulates disease variability and supplies biomarkers of axonal loss in patients. Brain 2012.

\section{Übersichtsarbeit:}

B.G. Weiss, M. Mannil und M.W. Sereda. Experimentelle Therapiestrategien bei hereditären Neuropathien. Neuro aktuell, 2012.

\section{Poster / Präsentationen / Abstracts:}

B.G. Weiss, R. Fledrich, T. Prukop, K.-A. Nave, M. Sereda. Experimental Therapies in Charcot-Marie-Tooth Disease 1A (CMT1A). Experimentelle PNS-Forschung 2010, Düsseldorf, Germany 2010

M. Sereda, R. Fledrich, B.G. Weiss, T. Nientiedt, T. Prukop, G. Meyer zu Hörste, R.M. Stassart, B.G. Brinkmann, K.-A. Nave. Experimental therapies of demyelinating neuropathies. Welcome Trust Conference Genomic Disorders 2010, Hinxton, UK, 2010

B.G. Weiss, R. Fledrich, T. Prukop, G. Meyer zu Hörste, R. M. Stassart, B.G. Brinkmann, K.A. Nave and M.W. Sereda. Experimental treatment with a new progesterone antagonist (Lonaprisan) in a PMP22 transgenic rat model of Charcot-Marie-Tooth disease 1A (CMT-1A). 3. International CMT Consortium Meeting, Antwerp, Belgium 2009 
R. Fledrich, B.G. Weiss, T. Nientiedt, T. Prukop, G. Meyer zu Hörste, R.M. Stassart, B.G. Brinkmann, K.-A. Nave, Michael Sereda. Experimental therapies of demyelinating neuropathies. DGM, Darmstadt, Germany 2009

M. Sereda, B. Weiss, R. Fledrich, G. Meyer zu Hörste, R. Stassart, B. Brinkmann, K.-A. Nave. Experimentelle Therapien bei hereditären Neuropathien, DGN, Nuernberg, Germany, 2009

R. Fledrich, T. Schnizer, B. Schlotter-Weigel, P. Schneiderat, B.G. Weiss, G. Meyer zu Hörste, R.M. Stassart, B.G. Brinkmann, M.C. Walter, B. Rautenstrauss, W. Paulus, M.J. Rossner, K.A. Nave, M. Sereda. Erkrankungsmarker bei der Charcot-Marie-ToothErkrankung 1A, DGN, Nuernberg, Germany, 2009

R. Fledrich, T. Schnizer, B. Schlotter-Weigel, B. G. Weiss, G. Meyer zu Hörste, R. M. Stassart, M. C. Walter, B. Rautenstrauss, W. Paulus, K.-A. Nave and M. W. Sereda. Identification and Validation of disease markers in Charcot-Marie-Tooth disease type 1A (CMT1A). 3. International CMT Consortium, Antwerp, Belgium 2009 


\section{Danksagung}


9. Lebenslauf 